RODRIGO CÉSAR FRANCESCHINI DE OLIVEIRA

\title{
GERENCIAMENTO DE PROJETOS E A APLICAÇÃO DA ANÁLISE DE VALOR AGREGADO EM GRANDES PROJETOS
}

Dissertação apresentada à Escola Politécnica da Universidade de São Paulo para a obtenção do título de Mestre em Engenharia 
RODRIGO CÉSAR FRANCESCHINI DE OLIVEIRA

\section{GERENCIAMENTO DE PROJETOS E A APLICAÇÃO DA ANÁLISE DE VALOR AGREGADO EM GRANDES PROJETOS}

Dissertação apresentada à Escola Politécnica da Universidade de São Paulo para a obtenção do título de Mestre em Engenharia

Área de Concentração: Eng. Naval e Oceânica

Orientador:

Prof. Dr. Oscar Brito Augusto 
Este exemplar foi revisado e alterado em relação à versão original, sob responsabilidade única do autor e com a anuência de seu orientador.

São Paulo, 30 de outubro de 2003.

Assinatura do autor

Assinatura do orientador

FICHA CATALOGRÁFICA

Oliveira, Rodrigo César Franceschini de

Gerenciamento de projetos e a aplicação da análise de valor agregado em grandes projetos / R.C.F. Oliveira. -- ed.rev. -- São Paulo, 2003.

$128 \mathrm{p}$.

Dissertação (Mestrado) - Escola Politécnica da Universidade de São Paulo. Departamento de Engenharia Naval e Oceânica.

1.Administração de projetos 2.Engenharia e análise do valor I.Universidade de São Paulo. Escola Politécnica. Departamento de Engenharia Naval e Oceânica II.t. 
Aos meus pais

José Roberto e Maria Inez, e à minha irmã Larissa. 


\section{AGRADECIMENTOS}

Ao meu orientador Prof. Dr. Oscar Brito Augusto, pela confiança depositada na minha pessoa e neste trabalho, e pelas ótimas doses de otimismo, incentivo e sabedoria que muito me ajudaram nos momentos de dificuldade.

Ao Eng ${ }^{\circ}$ Eduardo César Basaglia por ter me dado a oportunidade de trabalhar na área de Gestão de Projetos, pelas experiências trocadas, pela confiança em meu trabalho e, sobretudo, pela paciência no meu aprendizado.

Aos meus colegas de faculdade Pablo Rodeiro e Julian Tonioli que, com ótimos trabalhos, se tornaram Mestres em Engenharia e serviram como mais um estímulo para a conclusão desta dissertação.

Ao Prof. Dr. Bernardo L. R. de Andrade pelo incentivo e pelas sugestões dadas ao longo deste trabalho.

À minha família e àqueles que, de um modo ou de outro, sempre me apoiaram e apostaram em meu sucesso. 


\section{SUMÁRIO}

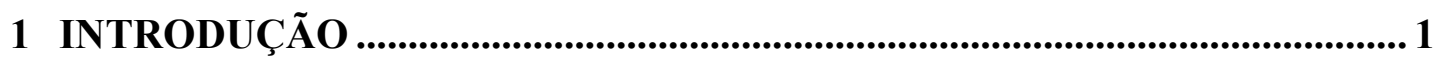

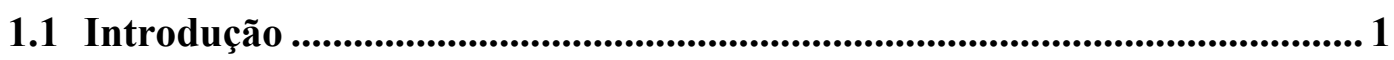

1.2 Objetivos ................................................................................................................. 2

2 TÓPICOS SOBRE O GERENCIAMENTO DE PROJETOS ........................... 4

2.1 Introdução ao Gerenciamento de Projetos ................................................... 4

2.2 Histórico do Gerenciamento de Projetos ....................................................... 7

2.3 As Principais Áreas do Gerenciamento de Projetos............................... 15

2.3.1 Gerenciamento da Integração............................................................ 16

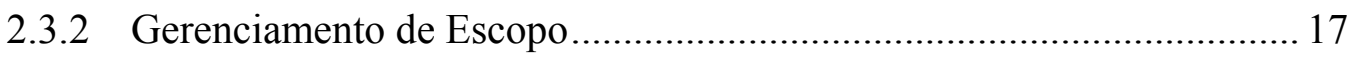

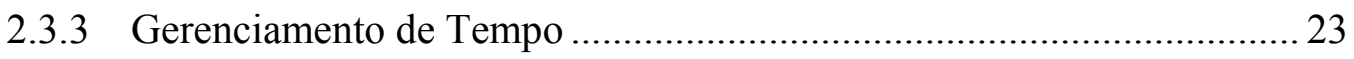

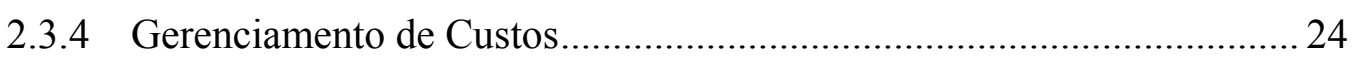

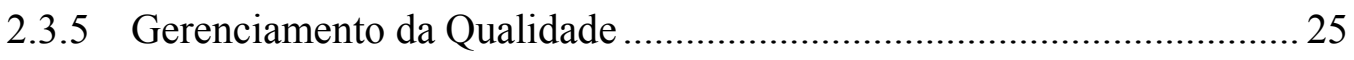

2.3.6 Gerenciamento de Recursos Humanos................................................. 27

2.3.7 Gerenciamento das Comunicações ....................................................... 28

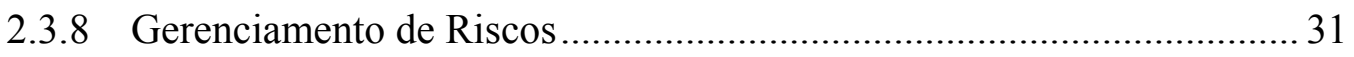

2.3.9 Gerenciamento de Suprimentos e Contratos ........................................ 32

2.4 Perfil do Gerente de Projetos............................................................................... 34

2.5 Necessidades de se Gerenciar por Projetos ................................................39

2.6 O Gerenciamento de Grandes e Complexos Projetos .................................. 43

2.7 Próximos Passos do Gerenciamento de Projetos ........................................ 45

3 TÓPICOS SOBRE A ANÁLISE DE VALOR AGREGADO ......................... 48

3.1 O que é Análise de Valor Agregado? ................................................... 49

3.2 Os Principais Parâmetros da Análise de Valor Agregado .......................... 51

3.3 Projeções Futuras Através da Análise de Valor Agregado ........................55

3.4 Levantamento da Linha Base de Orçamento (baseline) .............................59

3.5 Exemplo Quantitativo da Análise de Valor Agregado ............................. 62 
4 CRITÉRIOS NA APLICAÇÃO DA ANÁLISE DE VALOR AGREGADO 69

4.1 Motivação 69

4.2 Problemas Relatados sobre a Análise de Valor Agregado. 69

4.3 Análise Sobre os Problemas Relatados .................................................. 73

4.4 Algumas Características de Grandes Projetos da Indústria ................... 75

4.5 Medidas para Aplicação da AVA em Projetos Complexos....................... 77

4.6 Aplicação em um Caso Real da Indústria Brasileira ................................8 86

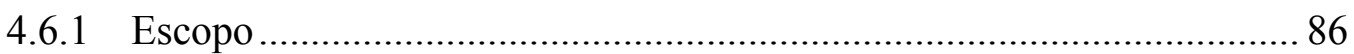

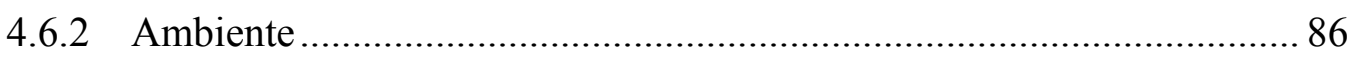

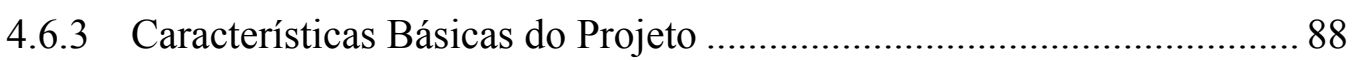

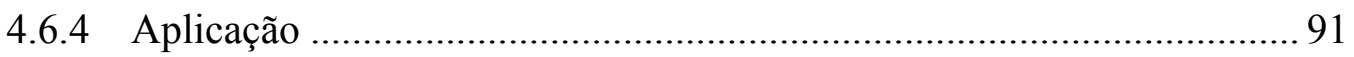

4.6.4.1 Análise do progresso - 20\% de execução .............................................. 96

4.6.4.2 Análise do progresso - 33\% de execução ............................................ 98

4.6.4.3 Análise do progresso - 50\% de execução ......................................... 104

4.6.4.4 Análise do progresso - 70\% de execução ........................................ 110

4.6.4.5 Análise do projeto ao seu término .................................................. 114

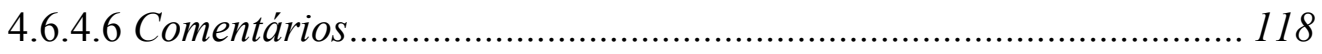

5 CONCLUSÕES E RECOMENDAÇÕES ...................................................... 119

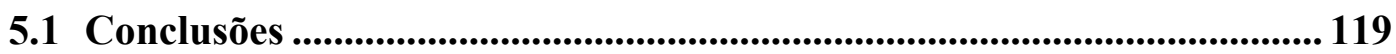

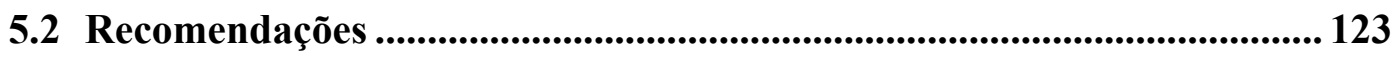

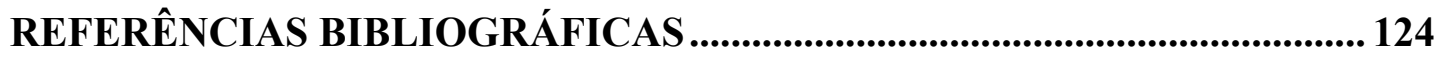




\section{LISTA DE FIGURAS}

Figura 2.1 Esquema típico de ciclo de vida de um projeto (Duncan, 1996) ................ 6

Figura 2.2 Eventos e técnicas que influenciaram a Gestão de Projetos ...................... 9

Figura 2.3 Profissionais que gerenciam projetos (White; Fortune, 2002) ................. 11

Figura 2.4 Projetos abordados na pesquisa (White; Fortune, 2002) ........................ 12

Figura 2.5 Tipos de indústria abordados na pesquisa (White; Fortune, 2002) .......... 13

Figura 2.6 Exemplo de WBS em diagrama de blocos (Cleland; Ireland, 2000)........ 18

Figura 2.7 Exemplo de WBS em formato tabular................................................. 19

Figura 2.8 Exemplo de PBS em formato tabular ....................................................... 20

Figura 2.9 Exemplo de FBS em formato tabular .................................................. 21

Figura 2.10 Inter-relação gráfica entre WBS e OBS.............................................. 22

Figura 2.11 Profissionais requeridos no ciclo de projeto (Vargas, 2000)................. 27

Figura 2.12 Propostas básicas de reuniões (Cleland; Ireland, 2002) ........................ 29

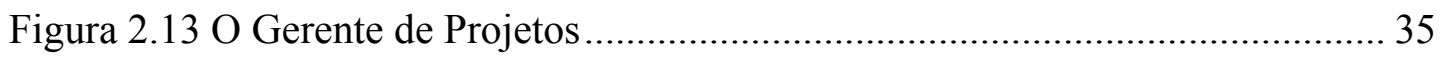

Figura 2.14 Distribuição típica do tempo do gerente de projeto (Keeling, 2002) ..... 36

Figura 2.15 Complexidade e dinâmica dos projetos (Vargas, 2000) ......................... 39

Figura 2.16 Influência dos projetos nos resultados (Cohen; Graham, 2001)............. 41

Figura 2.17 Critério alternativo para sucesso em projetos (Atkinson, 1999)............ 46

Figura 2.18 Processo de evolução da Gestão de Projetos (Kerzner, 2002)................ 47

Figura 2.19 Tempos de mudança na Gestão de Projetos (Kerzner, 2002).................. 47

Figura 3.1 Variáveis intrínsecas da Análise de Valor Agregado .............................. 49

Figura 3.2 Parâmetros básicos para Análise de Valor Agregado.............................. 51

Figura 3.3 Gráfico para Análise de Valor Agregado (Vargas, 2002) ....................... 52

Figura 3.4 Tipos de CPI e SPI para previsões de desempenho (Vargas, 2002)......... 57 
Figura 3.5 Passos para a criação da linha de base (Flemming; Koppelman, 2000)... 61

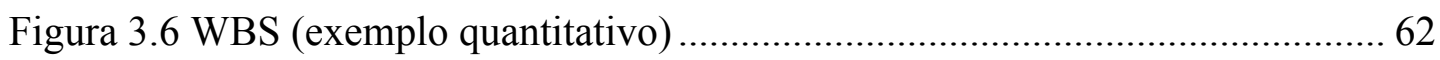

Figura 3.7 Alocação de custos e prazos (exemplo quantitativo)...............................63

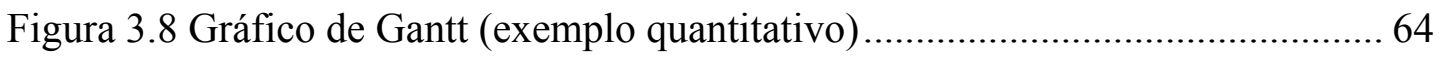

Figura 3.9 Tabela auxiliar para distribuição de custos (exemplo quantitativo) ......... 65

Figura 3.10 Linha base de orçamento - BCWS (exemplo quantitativo) .....................66

Figura 3.11 Dados referentes ao progresso do projeto (exemplo quantitativo) ......... 66

Figura 3.12 Gráfico para Análise de Valor Agregado (exemplo quantitativo).......... 67

Figura 4.1 Limitações das ferramentas de GP (White; Fortune, 2002) .................... 69

Figura 4.2 Popularidade e valor das técnicas de gerenciamento de projetos (Thamhain apud Vargas, 2002) .............................................................. 71

Figura 4.3 Exemplo das fases principais de um projeto na indústria....................... 75

Figura 4.4 Gráficos para acompanhamento simultâneo de cada fase do projeto....... 78

Figura 4.5 Determinação e distribuição de Pacotes de Trabalho ................................ 80

Figura 4.6 Ajuste nos custos devido ao fluxo de caixa (Vargas, 2002) .................... 84

Figura 4.7 Tabela resumo para aplicação da AVA em grandes projetos ................... 85

Figura 4.8 Estrutura organizacional da empresa (Matricial/Composta) ................... 87

Figura 4.9 Relação entre o preço final do contrato e a linha de base para medição de performance (Flemming; Koppelman, 2000) ................................... 89

Figura 4.10 Primeiros níveis do PBS (exemplo de aplicação)................................... 90

Figura 4.11 Caracterização dos custos do projeto conforme orçamento ....................92

Figura 4.12 Linha de Base do Orçamento (baseline - BCWS) geral........................ 93

Figura 4.13 Curva de orçamento geral com eventos físicos ................................... 94

Figura 4.14 Participação dos principais grupos de atividade no orçamento ............... 94 
Figura 4.15 Orçamento geral e de cada grupo principal 95

Figura 4.16 Desempenho geral - 20\% de execução 96

Figura 4.17 Índices de desempenho - 20\% de execução. 96

Figura 4.18 Desempenho geral - 33\% de execução 98

Figura 4.19 Desempenho geral - 33\% de execução (detalhe) 98

Figura 4.20 Índices de desempenho geral - 33\% de execução. 99

Figura 4.21 Desempenho da Engenharia - 33\% de execução 99

Figura 4.22 Índices de desempenho de Engenharia - 33\% de execução. 100

Figura 4.23 Desempenho da Fabricação - 33\% de execução. 100

Figura 4.24 Índices de desempenho de Fabricação - 33\% de execução 100

Figura 4.25 Desempenho da Aquisição de Materiais - 33\% de execução 101

Figura 4.26 Índices de desempenho de Materiais - 33\% de execução 101

Figura 4.27 Desempenho geral - 50\% de execução 104

Figura 4.28 Desempenho geral - 50\% de execução (detalhe) 104

Figura 4.29 Índices de desempenho geral - 50\% de execução. 105

Figura 4.30 Desempenho de Engenharia - 50\% de execução 105

Figura 4.31 Índices de desempenho de Engenharia - 50\% de execução. 105

Figura 4.32 Desempenho de Materiais - 50\% de execução 106

Figura 4.33 Índices de desempenho de Materiais - 50\% de execução 106

Figura 4.34 Desempenho de Subcontratados - 50\% de execução. 107

Figura 4.35 Índices de desempenho de Subcontratados - 50\% de execução 107

Figura 4.36 Desempenho de Fabricação - 50\% de execução 108

Figura 4.37 Índices de desempenho de Fabricação - 50\% de execução 108

Figura 4.38 Desempenho geral - 70\% de execução 110 
Figura 4.39 Índices de desempenho geral - 70\% de execução. 110

Figura 4.40 Desempenho do Comissionamento - 70\% de execução

Figura 4.41 Índices de desempenho do Comissionamento - 70\% de execução

Figura 4.42 Desempenho da Fabricação - 70\% de execução.

Figura 4.43 Índices de desempenho da Fabricação - 70\% de execução

Figura 4.44 Desempenho dos Subcontratados - 70\% de execução

Figura 4.45 Índices de desempenho dos Subcontratados - 70\% de execução

Figura 4.46 Desempenho dos Materiais - 70\% de execução

Figura 4.47 Índices de desempenho dos Materiais - 70\% de execução 112

Figura 4.48 Desempenho geral ao término do projeto 114

Figura 4.49 Caracterização dos custos reais do projeto

Figura 4.50 Curvas dos custos reais do projeto

Figura 4.51 Índices $\mathrm{CPI}_{\mathrm{c}}$ e $\mathrm{SPI}_{\mathrm{c}}$ ao longo do projeto

Figura 4.52 Comportamento dos índices $\mathrm{CPI}_{\mathrm{c}}$ e $\mathrm{SPI}_{\mathrm{c}}$ ao longo do projeto 116

Figura 4.53 Comportamento do índice $\mathrm{CPI}_{\mathrm{c}}$ de cada grupo ao longo do projeto .... 116

Figura 4.54 Comportamento do índice $\mathrm{SPI}_{\mathrm{c}}$ de cada grupo ao longo do projeto..... 117 
LISTA DE ABREVIATURAS E SIGLAS

ACWP

$\mathrm{ACWP}_{\mathrm{c}}$

APMA

AVA

BAC

BCWP

$\mathrm{BCWP}_{\mathrm{c}}$

BCWS

$\mathrm{BCWS}_{\mathrm{c}}$

$\mathrm{CCM}$

CPI

$\mathrm{CPI}_{\mathrm{c}}$

$\mathrm{CPI}_{\mathrm{x}}$

$\mathrm{CPM}$

CRM

$\mathrm{C} / \mathrm{SCSC}$

DAC

DoD

EAC

ERP

ES

ETC

EV

EVA

EVMS

FBS

GF

GP

L \& P
Actual Cost of Work Performed

Actual Cost of Work Performed (cumulated)

Australian Project Management Association

Análise de Valor Agregado

Budget at Completion

Budget Cost of Work Performed

Budget Cost of Work Performed (cumulated)

Budget Cost of Work Scheduled

Budget Cost of Work Scheduled (cumulated)

Critical Chain Management

Cost Performance Index

Cost Performance Index (cumulated)

Cost Performance Index (average of the $x$ last periods)

Critical Path Method

Customer Relationship Management

Cost Schedule Control System Criteria

Delay at Completion

Department of Defense

Estimate at Completion

Enterprise Resource Planning

Engenharia Simultânea

Estimate to Complete

Engenharia de Valor

Earned Value Analysis

Earned Value Management System

Function Breakdown Structure

Gerenciamento Funcional

Gestão de Projetos / Gerenciamento de Projetos

Lucros e Perdas 
MRP

OBI

OBS

PAC

PBS

PERT

PMBoK $^{\circledR}$

$\mathrm{PMI}^{\circledR}$

QFD

SCI

SPI

$\mathrm{SPI}_{\mathrm{c}}$

$\mathrm{SPI}_{\mathrm{x}}$

SV

TAC

TI

TQM

TV

VA

WBS

WP
Material Requirement Planning

Organização Baseada na Informação

Organization Breakdown Structure

Planned at Completion

Product Breakdown Structure

Program Evaluation and Review Technique

Project Management Body of Knowledge

Project Management Institute

Quality Function Deployment

Schedule Cost Index

Schedule Performance Index

Schedule Performance Index (cumulated)

Schedule Performance Index (average of the $x$ last periods)

Schedule Variance

Time at Completion

Tecnologia da Informação

Total Quality Management

Time Variance

Valor Agregado

Work Breakdown Structure

Work Package 


\section{RESUMO}

A crescente complexidade dos projetos modernos, a procura das empresas por um espaço no mercado, a busca pela satisfação dos clientes e a necessidade de se produzir com maior eficiência demandam um tipo de gerenciamento de negócios bastante específico e voltado para estas realidades. O que vem sendo apontado como o que há de mais completo e moderno para suprir esta demanda é o chamado Gerenciamento de Projetos e o seu conjunto de idéias e ferramentas, dentre as quais se destaca a Análise de Valor Agregado. Embora sejam técnicas e conceitos formalmente reconhecidos e aplicados desde meados do século passado, foi a partir da década de 90 que os mesmos alcançaram suas maiores projeções nas empresas. Entretanto, ainda são uma incógnita para muitas pessoas, e alguns de seus usuários ainda encontram muitas dificuldades em suas aplicações. O objetivo deste trabalho é, através de revisão bibliográfica e de observações sobre a rotina de um Gerente de Projetos, levantar as principais características deste tipo de gerenciamento, no intuito de justificar a sua crescente assimilação, bem como evidenciar a sua função estratégica dentro das empresas. Em complemento, este trabalho apresenta um maior aprofundamento sobre a Análise de Valor Agregado, avaliando os problemas relatados por seus usuários e apresentando medidas para a sua melhor aplicação em projetos de grande porte da indústria. Por último, são apresentados os resultados da aplicação de algumas destas medidas em um caso real da indústria brasileira. 


\begin{abstract}
The growing complexity of the modern projects, the search of companies for a place in the market, the client's satisfaction and the need for a more efficient production demand a very specific type of business management, oriented to these points. The so-called Project Management - as well as its concepts and tools, among which we can highlight the Earned Value Analysis - is being pointed as the most modern and complete way of meeting such demands. Although these are formally accepted practices and used since the beginning of last century, they have been adopted by several companies in the last years. These practices, however, are still unclear for many people, and some of the people who adopted them are still facing difficulties in their application. The purpose of this work is to compile the main characteristics and advantages of this type of management, by means of a revision of the literature and day-to-day practical observations of a Project Manager, so as to justify the increasing number of companies adopting these practices and its strategic function inside these companies. In addition to that, this work presents a deeper review on the Earned Value Analysis, evaluating the problems reported by the stakeholders and presenting some measures for its use, aiming at a better project control. To finish, the results of some of these measures applied in a real case in the Brazilian industry are presented.
\end{abstract}




\section{INTRODUÇÃO}

\subsection{Introdução}

A economia mundial vem sofrendo uma série de mudanças ao longo das últimas décadas. A globalização, a crescente complexidade das atividades, a utilização do conhecimento e da informação como novos produtos, e as novas demandas do mercado vêm forçando as empresas cada vez mais a assumirem um posicionamento dinâmico e flexível perante seus clientes, parceiros, concorrentes e até mesmo dentro de suas próprias organizações.

Hoje, qualquer empresa pode gerenciar atividades repetitivas e recorrentes, com base em padrões históricos ou métodos consagrados. Porém o desafio desta nova era, para quem não quer ser apenas mais uma empresa no mercado, está em gerenciar atividades nunca tentadas no passado e que podem jamais vir a se repetir no futuro (Kerzner, 2000).

Alguns pensamentos como o de Stewart apud Kerzner (2002, p.18) se tornam cada vez mais freqüentes no ambiente administrativo: “(...) O trabalho rotineiro não precisa de gerentes; se não pode ser automatizado, pode ser autogerenciado pelos operários (...)". Este tipo de pensamento, ainda que bastante radical, evidencia uma forte intenção em se mudar a maneira como as atividades são tradicionalmente gerenciadas.

Drucker (1987), em artigo publicado na Harvard Business Review, antecipa o surgimento de um novo tipo de organização chamada Organização Baseada na Informação $(\mathrm{OBI})$, onde se procura:

- Menos níveis de gestão (sem níveis intermediários que, muitas vezes, não tomam decisões, servindo unicamente como canais de comunicação, apenas gerando atrasos). 
- Equipes de especialistas autodirigíveis, que normalmente trabalham onde as ações e os problemas se encontram, e não apenas nos escritórios.

- Um Sistema de Informação completo, ágil e de acesso generalizado, integrando e suprindo toda a organização.

Em paralelo ao acima exposto, nota-se nas empresas uma forte tendência em tratar e administrar os seus negócios, principalmente os estratégicos e os que geram maior valor econômico, como se fossem projetos (Cohen; Graham, 2002). Este tratamento tem como objetivo possibilitar uma maior concentração de esforços, viabilizando um gerenciamento específico e mais eficiente nas atividades vitais destas empresas.

Estes pensamentos e uma série de outras vertentes modernas vêm alertando para a necessidade de um novo tipo de gerenciamento e estrutura organizacional. É aí onde se encaixam perfeitamente as características proporcionadas pelas ferramentas e conceitos que integram o chamado Gerenciamento de Projetos.

\subsection{Objetivos}

A presente dissertação tem por finalidade apresentar e discutir os conceitos e ferramentas do Gerenciamento de Projetos, os quais hoje vêm despertando o interesse de muitos, mas também gerando muitas dúvidas e apreensão.

Não é o intuito aqui apresentar detalhamentos e estudos completos sobre o Gerenciamento de Projetos. Serão apresentados os seus pontos principais, suas características práticas e suas qualidades, procurando ressaltar a sua aplicabilidade na indústria e em projetos de Engenharia. 
Será realizada uma pesquisa bibliográfica tendo como base livros, periódicos e artigos publicados em seminários. Serão também adicionadas algumas observações retiradas do dia-a-dia de um Gerente de Projetos em uma indústria de grande porte, líder tecnológica do seu segmento no mundo.

Adicionalmente, será dada atenção especial a uma das principais e mais poderosas ferramentas para controle de projetos: a "Análise de Valor Agregado". Esta ferramenta tem seu mérito vinculado à sua vantagem de proporcionar uma visão completa e dinâmica sobre o projeto, permitindo diagnósticos antecipados sobre eventuais problemas e possibilitando ações corretivas em tempo. Embora os conceitos básicos desta ferramenta sejam bastante simples, o histórico de gestores que tentaram aplicá-la e não obtiveram os resultados esperados ainda é muito grande. Serão analisados alguns problemas encontrados na literatura e no cotidiano dos gestores, procurando se estabelecer medidas para uma aplicação racional desta ferramenta. Estas medidas se dirigirão principalmente aos projetos de grande porte e complexidade da indústria (fonte das maiores reclamações), com posterior exemplo de aplicação em um caso real da indústria brasileira.

Espera-se que este trabalho ajude a divulgar e a elucidar ainda mais os conceitos do Gerenciamento de Projetos e da Análise de Valor Agregado entre estudantes e profissionais de Engenharia, uma vez que nos próximos anos, provavelmente, estes estarão inseridos em um ambiente de trabalho voltado para projetos, independentemente do ramo de atividade. 


\section{TÓPICOS SOBRE O GERENCIAMENTO DE PROJETOS}

\subsection{Introdução ao Gerenciamento de Projetos}

O termo Gerenciamento (ou Gestão) está descrito nos dicionários tradicionais da língua portuguesa como o ato de gerir, administrar, dirigir, regular ou governar algo (Houaiss; Villar, 2003; Ferreira, 2000).

Baguley (1999) interpreta o gerenciamento como a capacidade de organizar pessoas e coisas de modo a gerar resultados requeridos.

Com uma visão mais capitalista e prática, encontra-se também nas empresas a definição de gerenciamento como uma técnica para atingir objetivos internos e externos das mesmas, quais sejam, possibilitar a medição e melhoria dos resultados, compará-los com as metas e com os concorrentes, e satisfazer as expectativas dos investidores, acionistas e clientes.

Estas afirmações, e muitas outras citadas nas mais diversas referências, são verdadeiras, e também bastante genéricas, podendo ser aplicadas em qualquer área ou tipo de atividade.

Dentre os inúmeros tipos de gerenciamento praticados e estudados atualmente, existe um que vem se tornando cada vez mais conhecido e aprovado. Trata-se do Gerenciamento de Projetos (ou Gestão de Projetos), prática esta que vem sendo amplamente adotada, independentemente do ramo de atividade e da dimensão das empresas.

Mas para que se possa entender o Gerenciamento de Projetos, é necessária uma definição sobre o que é um projeto: Juran apud Lewis (1995), um dos mentores do conceito de Qualidade Total (TQM), define projeto como "um problema planejado 
para ser solucionado", onde "problema" é definido como um obstáculo que nos impede de sair de uma situação e ir para outra, a qual desejamos.

Para Vargas (2000), projeto é um empreendimento não repetitivo, caracterizado por uma seqüência lógica e clara de eventos, com início, meio e fim, e que se destina a atingir um objetivo claro e definido. $\mathrm{O}$ autor ressalta também que um projeto é sempre conduzido por pessoas e regulado por parâmetros pré-definidos de tempo, custo, recursos e qualidade.

Knudson; Bitz (1991) definem projeto como um esforço único para introduzir ou produzir um novo produto ou serviço conforme uma certa especificação. Este esforço é balizado por alguns parâmetros que incluem tempo, recursos e orçamentos fixos.

Baguley (1999) considera um projeto como uma seqüência de eventos interligados, que são conduzidos dentro de um período de tempo limitado, cujo objetivo é alcançar um único e bem definido resultado. Baguley (1999) ainda salienta que um projeto pode ser assim classificado independentemente de suas dimensões. Um projeto pode:

- Ser sobre qualquer coisa que se queira e se possa fazer;

- Criar coisas que podem ser tangíveis ou intangíveis;

- Ser pequeno ou grande - ou qualquer dimensão intermediária;

- Durar por décadas - ou ser completado em alguns dias;

- Consumir qualquer quantia de recursos e dinheiro - de dezenas a bilhões;

- Envolver qualquer número de indivíduos - de uma só pessoa até uma nação.

Dadas as definições acima, nota-se que um projeto está intimamente ligado a parâmetros bem definidos de escopo, tempo e custo. Um projeto, portanto, tem começo, meio e fim, e deve consumir uma certa quantidade de recursos para gerar um determinado produto ou serviço. A figura 2.1, a seguir, mostra um ciclo de vida típico de um projeto. Novamente, trata-se de um evento único, não rotineiro e que precisa de um gerenciamento diferenciado face às suas particularidades. 
O Gerenciamento de Projetos é, portanto, a aplicação de conhecimento, habilidades e técnicas específicas para as atividades únicas e limitadas de um projeto, no intuito de alcançar ou superar os objetivos deste, bem como as necessidades e expectativas dos seus envolvidos (Duncan, 1996).

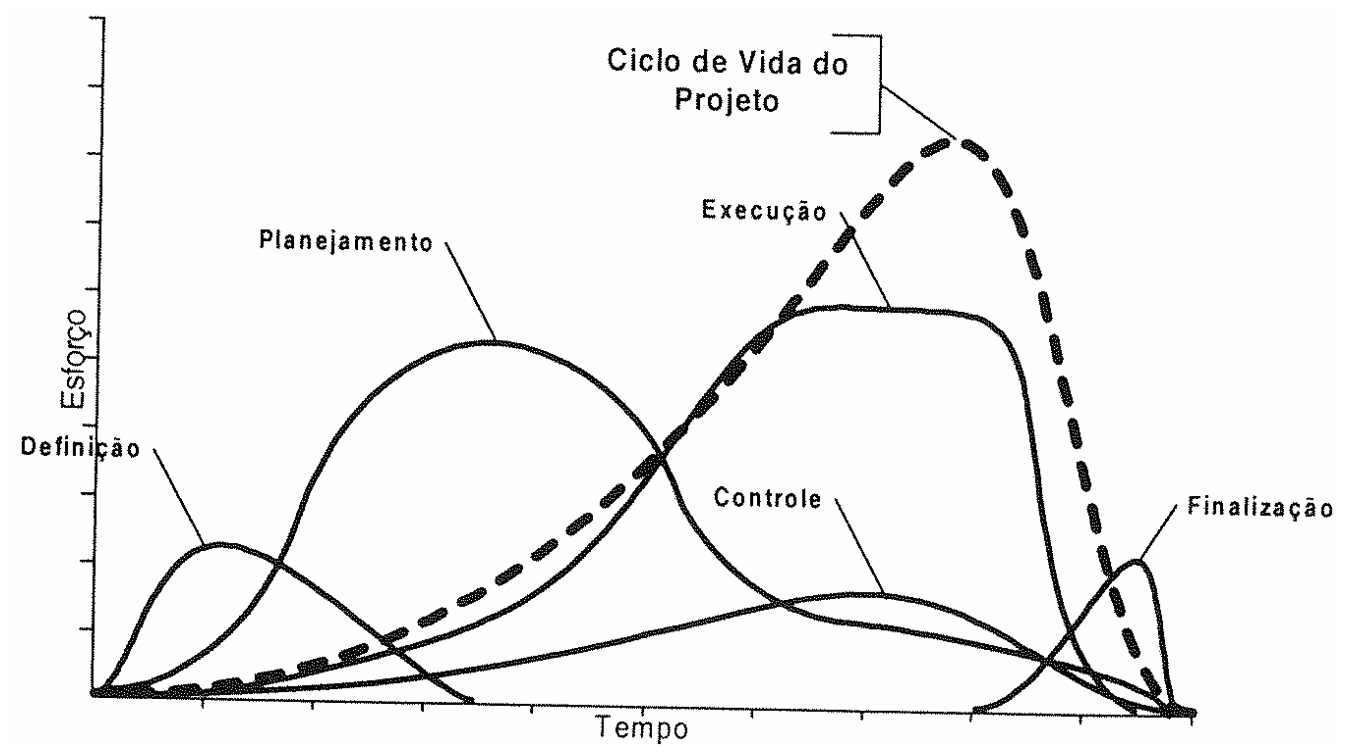

Figura 2.1 Esquema típico de ciclo de vida de um projeto (Duncan, 1996)

O Gerenciamento de Projetos requer uma gama de conhecimentos bastante diversificada e que inclui tanto elementos da ciência como da arte. Elementos da ciência porque utiliza cálculos matemáticos, tabelas, gráficos, e outras ferramentas técnicas. Mas o GP é também influenciado por fatores políticos, organizacionais e humanos. A arte está nas habilidades de comunicação, negociação, criatividade e imaginação necessárias para gerir o projeto adequadamente dentro destes fatores e ambientes (Knudson; Bitz, 1991).

No entanto, o fato mais interessante é que o Gerenciamento de Projetos não traz nenhuma "novidade" científica, mas sim um rearranjo estruturado e lógico dos processos e técnicas já existentes, no intuito de atender com maior eficácia eventos únicos, complexos e dinâmicos (Vargas, 2000).

Nota-se também que sua procura e aplicações mais fortes e freqüentes se dão em atividades de Engenharia, em especial para o desenvolvimento de novos produtos. A Engenharia, por essência, é baseada em projetos e o engenheiro freqüentemente 
apresenta como características pessoais uma visão macro e um raciocínio sistêmico sobre os projetos. A “espiral de projeto”, os conceitos de QFD (Quality Function Deployment), a Engenharia Simultânea e a interatividade dos sistemas existentes em um projeto de Engenharia fazem com que o engenheiro esteja sempre atento e ciente de que qualquer alteração em um dos parâmetros pode impactar fortemente o resultado final. Estas características se encaixam perfeitamente ao perfil que o Gerente de Projetos deve possuir. Em outras palavras, a Gestão de Projetos e a Engenharia possuem naturalmente uma forte relação entre si, principalmente devido às atividades de integração inerentes às mesmas.

\subsection{Histórico do Gerenciamento de Projetos}

O Gerenciamento de Projetos é uma prática nova? Não, certamente não. O homem utiliza determinados conceitos de gerenciamento de projetos desde o princípio da civilização. As grandes obras faraônicas (2000 A.C.), as caravelas e as viagens de circunavegação (1450), o Titanic (1912), o Empire States (1931), a 1 $1^{\text {a }}$ viagem à Lua (1969), a ponte Rio-Niteroi (1974) e demais feitos do homem certamente foram organizados e conduzidos através de algum tipo de gerenciamento especialmente voltado para tais projetos. No entanto, sabe-se que na época destes eventos, principalmente os mais antigos, não existiam metodologias devidamente formalizadas e adaptadas para o uso geral.

Segundo Kerzner (2002), da década de 50, quando as técnicas de gestão de projetos passaram a ser formalmente estudadas, consolidadas e estruturadas, até a década de 90, a gestão de projetos não passava de mais uma teoria, julgada por muitos como incipiente e arriscada, uma vez que não havia experiência na sua aplicação e a mesma era entendida como uma ameaça à estrutura organizacional existente (e conseqüentemente, ao poder). Em meados da década de 90 , devido às recessões econômicas em vários países e ao fenômeno da "globalização" da economia, esta mentalidade começou a mudar. A necessidade de se criar produtos de qualidade, em prazos e preços cada vez menores, aliada à necessidade de se adquirir a confiança e a 
satisfação dos clientes fez com que as empresas procurassem tipos de gerenciamento que proporcionassem algum nível de excelência nestes quesitos.

Há poucas décadas atrás, quem utilizasse cronogramas detalhados como base de trabalho poderia ser considerado como um gestor "sofisticado". Hoje, qualquer empresa pode dispor de softwares para planejamento/gerenciamento e utilizar cronogramas e redes PERT/CPM até nas atividades de menor complexidade ou valor.

Para que possamos avaliar o histórico do GP faz-se necessário olharmos para o início do século $\mathrm{XX}$, quando se iniciaram os primeiros estudos científicos voltados para a administração. Taylor (1916), ao iniciar seus estudos sobre a produção de uma metalúrgica americana, formou um dos primeiros conceitos de gerenciamento moderno: aplicou um raciocínio científico ao trabalho mostrando que este pode ser analisado e melhorado se dividido e focado em suas partes elementares. Iniciam-se, deste modo, os estudos de tempos e movimentos. Por esta teoria, Taylor foi considerado "O Pai da Gestão Científica" (título gravado em seu túmulo, na Filadélfia).

Em paralelo, foi Henry Gantt (sócio de Taylor) que, em seus estudos sobre a construção naval e o suprimento de armamentos durante a $1^{\text {a }}$ Guerra Mundial, introduziu diagramas e gráficos para o controle de atividades. Estes gráficos são hoje conhecidos como Gráficos de Gantt e são utilizados praticamente sem nenhuma alteração em relação aos originais.

Porém, foi a partir da $2^{\mathrm{a}}$ Guerra Mundial que novas e modernas técnicas de administração e gerenciamento passaram a surgir ao redor do mundo. O período pósguerra, marcado por projetos de grande complexidade e prazos de implementação cada vez menores, demandou a criação de uma série de novas ferramentas de gerenciamento, inclusive com a implementação de conceitos de marketing, relações humanas, qualidade e satisfação do cliente. Muitas destas técnicas originaram e integram hoje a gama de ferramentas utilizadas e que dão suporte à Gestão de 
Projetos. A Figura 2.2 mostra o surgimento de algumas destas ferramentas ao longo do tempo e outros acontecimentos intimamente ligados ao crescimento da Gestão de Projetos.

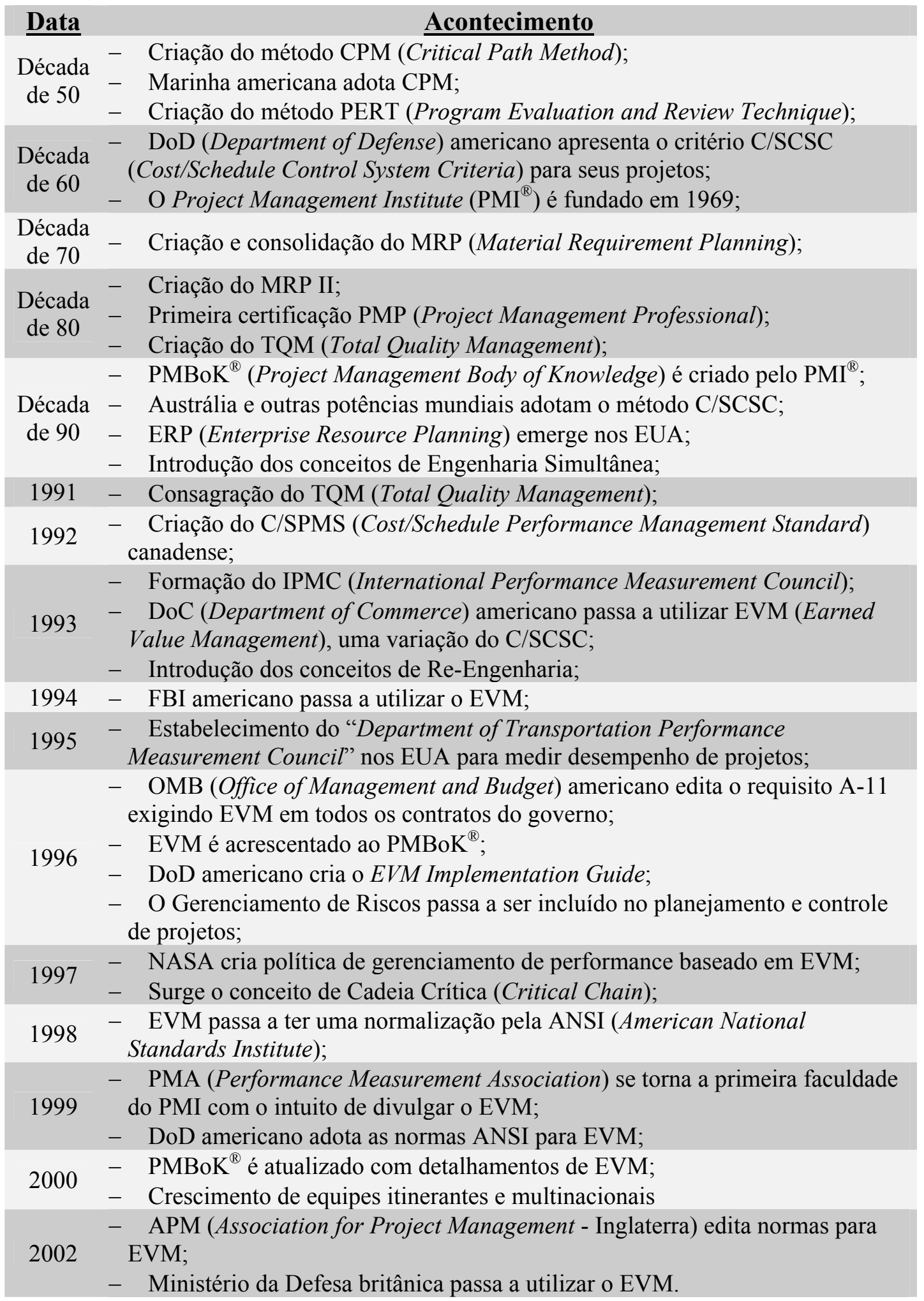

Figura 2.2 Eventos e técnicas que influenciaram a Gestão de Projetos 
Nota-se que, dentre as ferramentas mencionadas neste histórico, existe uma que sempre se manteve em evolução e marcando acontecimentos na Gestão de Projetos: a "Análise de Valor Agregado", inicialmente embutida no critério C/SCSC (Cost/Schedule Control System Criteria) do governo americano e, posteriormente apresentada de uma maneira mais direta através do EVM (Earned Value Management). Conforme já mencionado, esta ferramenta será também abordada com detalhes nesta dissertação.

A elaboração e a adoção de técnicas específicas para o GP tiveram início na década de 50 e, em geral, foram originadas nas forças armadas americanas. Em seguida os conceitos passaram a ser também adotados com maior freqüência pelas indústrias aeroespacial e de construção civil, se concentrando nestas áreas por vários anos. Este histórico e experiência podem justificar o fato de que, embora a GP possa beneficiar qualquer tipo de indústria, a maior parte dos resultados atingidos a partir deste gerenciamento está em indústrias que trabalham com produtos sob encomenda (não seriados) ou de alta tecnologia agregada, onde as interfaces e os processos são bastante complexos e não repetitivos.

$\mathrm{O} \mathrm{PMI}^{\circledR}$ (Project Management Institute - Pennsylvania/EUA), criado em 1969, foi o primeiro órgão que agrupou e consolidou em um só documento todas os conceitos e idéias da gestão por projetos. Idéias estas que certamente já vinham sendo utilizadas por inúmeros profissionais, porém de maneira informal, às vezes inconscientemente e, sobretudo não estruturada. Este documento, mais conhecido como $\mathrm{PMBoK}^{\circledR}$ (Project Management Body of Knowledge), é divulgado pelo $\mathrm{PMI}^{\circledR}$ desde 1987 e é, sem dúvida nenhuma, a referência mais genérica e clássica que se pode encontrar para a gestão de projetos.

Hoje, praticamente toda a publicação que surge a respeito da Gestão de Projetos tem como referência o $\mathrm{PMBoK}^{\circledR}$. Entretanto, a grande maioria destas publicações ainda é muito genérica e introdutória, com pouco aprofundamento em técnicas específicas, e não contemplando analiticamente o dia-a-dia dos Gerentes de Projeto (este último talvez pelo fato de ser muito difícil se estabelecer pontos comuns na rotina destes 
profissionais, uma vez que esta varia muito de empresa para empresa, e de projeto para projeto).

Para se ter uma idéia do panorama atual do Gerenciamento de Projetos, em artigo publicado no International Journal of Project Management, White; Fortune (2002) fornecem um estudo estatístico detalhado onde se pode perceber, entre outras coisas, que muitos profissionais exercem atividades inerentes ao gerenciamento de projetos, porém ainda não se denominam ou não possuem efetivamente o cargo de Gerentes de Projeto. Na referida pesquisa, apenas $47 \%$ dos entrevistados se intitularam como Gerente de Projetos. Os 63\% restantes são outros profissionais funcionais que de uma maneira ou de outra gerenciam projetos dentro da empresa.

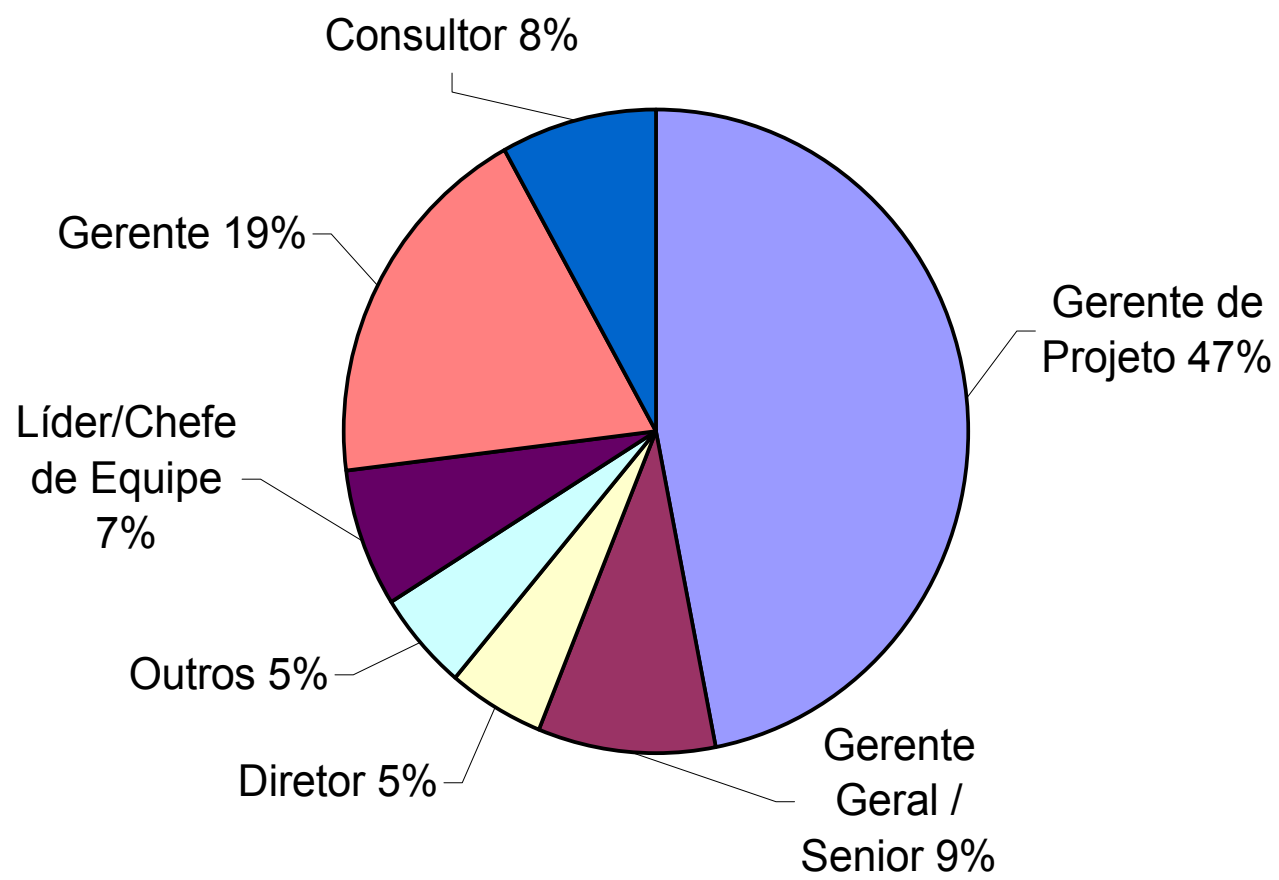

Figura 2.3 Profissionais que gerenciam projetos (White; Fortune, 2002)

Este fenômeno, ilustrado acima, se deve provavelmente a duas razões básicas:

1. O cargo Gerente de Projetos é relativamente novo e, portanto, nem todas as empresas o introduziram em seus organogramas, principalmente aquelas que ainda possuem um organograma não-matricial. Conforme já exposto, a 
introdução de um gerente de projetos no organograma traz, em geral, muitas transformações na estrutura organizacional de uma empresa, e isto nem sempre é visto com bons olhos pelas demais gerências e diretorias, as quais podem se sentir "ameaçadas" por esta transformação. Isto se deve tanto à falta de informação quanto aos interesses pessoais de cada executivo.

2. Os projetos ainda se encontram em um nível relativamente baixo de complexidade e/ou são muito similares e repetitivos, caso este em que as interfaces, custos e prazos já são conhecidos e bem equacionados. Deste modo podem ser "facilmente" controlados, e as funções do Gerenciamento de Projeto podem ser absorvidas por outros profissionais funcionais da empresa.

White; Fortune (2002) classificam também os projetos de acordo com a área e o tipo de indústria. Percebe-se claramente que, de um total de 326 projetos, existe uma maior concentração em projetos relacionados à Tecnologia da Informação e à reorganização interna das empresas.

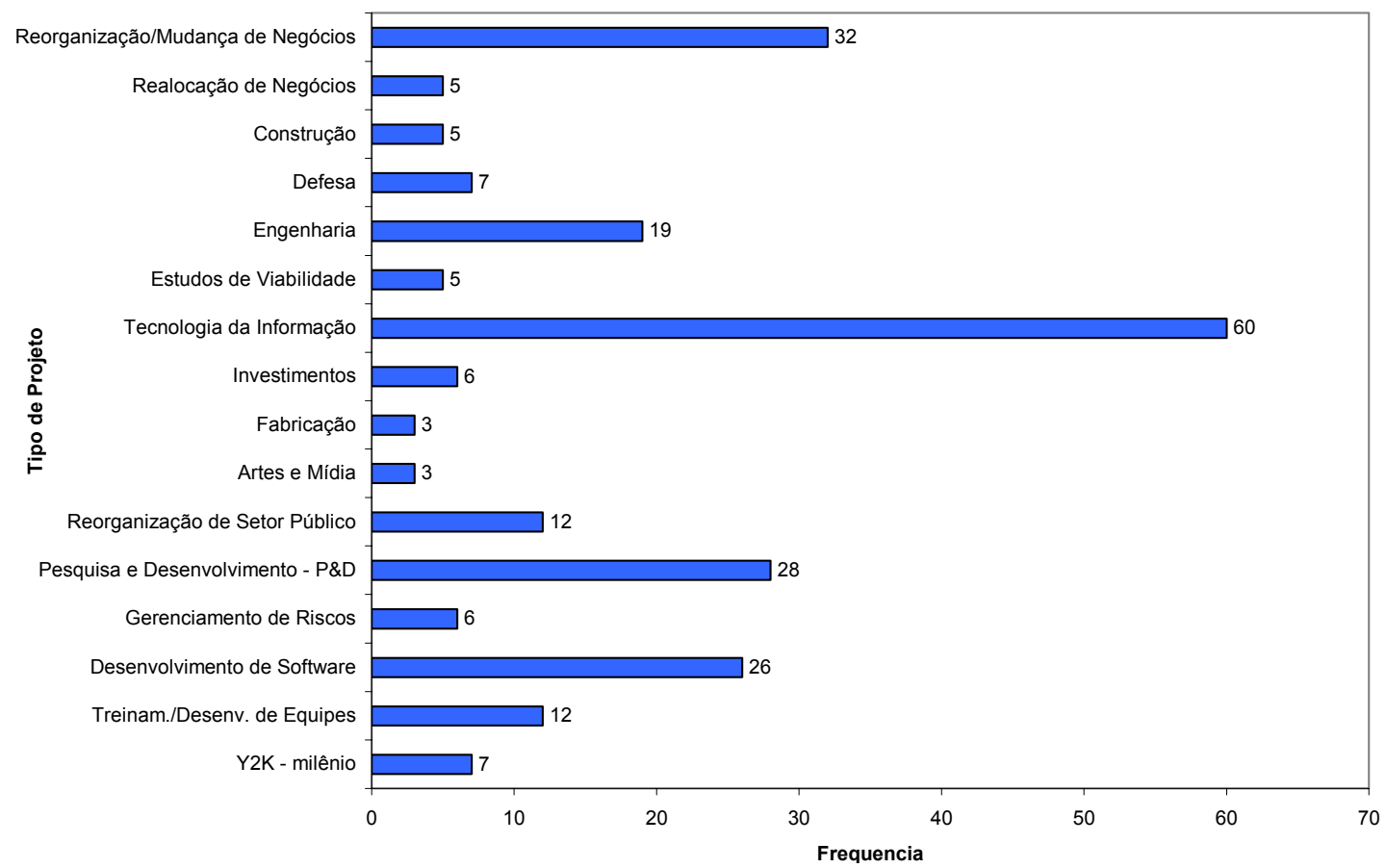

Figura 2.4 Projetos abordados na pesquisa (White; Fortune, 2002) 
Nota-se também, através da Figura 2.5, que são oriundos principalmente dos setores de Tecnologia, Transportes e Comunicação, Financeiro/Bancário e de Administração Pública.

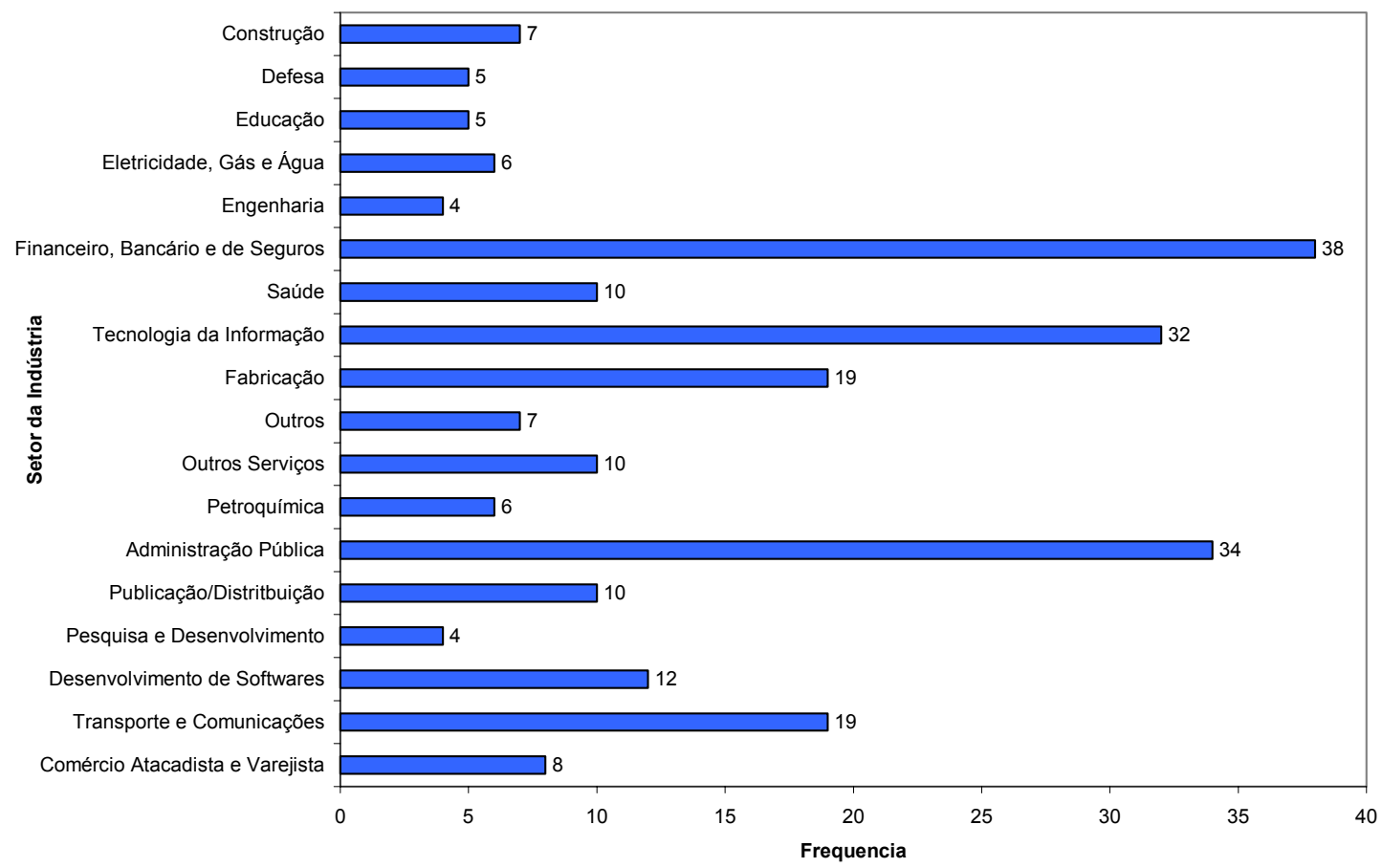

Figura 2.5 Tipos de indústria abordados na pesquisa (White; Fortune, 2002)

Embora esta pesquisa tenha sido realizada na Inglaterra, a concentração do Gerenciamento de Projetos nestas áreas e setores da economia é um fenômeno global. Muito provavelmente devido à natureza das operações nestes setores, as quais exigem profissionais técnicos e administrativos especializados, requerem grande desenvolvimento tecnológico, forte controle de dados e, em geral, se situam em ambientes de alto risco técnico ou gerencial.

No Brasil poucas empresas possuem uma organização totalmente voltada para projetos. De um modo geral, são as empresas de Tecnologia da Informação, Construção Civil, Telecomunicações e Energia que adotam com mais freqüência este tipo de organização. E, muitas vezes, por serem multinacionais estão apenas seguindo os padrões de suas matrizes americanas e européias. 
O que se vê no Brasil, entretanto, é uma forte tendência de divulgação aberta dos conceitos do Gerenciamento de Projetos, seguindo os passos de países como os EUA, a Austrália, a Inglaterra e outros pioneiros nesta área. É importante lembrar que o Brasil foi um dos primeiros lugares, fora dos EUA, a possuir uma entidade afiliada ao PMI. Hoje, a demanda pelo conhecimento e por cursos específicos já fez com que surgissem mais entidades, distribuídas pelas principais capitais brasileiras. 


\subsection{As Principais Áreas do Gerenciamento de Projetos}

No intuito de apresentar o nível de abrangência que o Gerenciamento de Projetos possui, serão apresentadas neste capítulo as principais áreas de conhecimento consideradas e formalizadas pelo PMI ${ }^{\circledR}$ através do guia PMBoK ${ }^{\circledR}$ (Duncan, 1996). São elas:

- Gerenciamento da Integração;

- Gerenciamento do Escopo;

- Gerenciamento do Tempo;

- Gerenciamento de Custos;

- Gerenciamento da Qualidade;

- Gerenciamento de Recursos Humanos;

- Gerenciamento de Comunicação;

- Gerenciamento de Riscos;

- Gerenciamento de Suprimentos.

Cada uma das áreas acima tem as suas próprias particularidades e níveis de complexidade sem, no entanto, deixarem de estar integradas formando um todo único e organizado. Certamente, dependendo do projeto ou da empresa em questão, existem áreas cujas relevâncias poderão ser maiores ou menores, porém, é aconselhável que o gerente de projetos tenha controle sobre todas elas.

Estas nove áreas já possuem vasta literatura e poderiam ser, por si sós, alvos de dissertações específicas. Serão apresentadas, portanto, de maneira macro, buscando mostrar alguns aspectos práticos dentro da indústria. Vale lembrar que dentro do gerenciamento de custos se encontra a Análise de Valor Agregado, uma das ferramentas mais importantes para o controle de projetos e que também será foco de estudo específico nesta dissertação. 


\subsubsection{Gerenciamento da Integração}

Uma das maiores atribuições do Gerente de Projetos é prover a perfeita integração entre as áreas envolvidas em um projeto. $\mathrm{O}$ Gerenciamento da Integração deve garantir que todas as necessidades dos envolvidos sejam atendidas, ou superadas, pelo projeto.

De todas as áreas, esta é talvez a que mais exige uma visão sistêmica e global por parte do gerente de projetos. E também é a que mais exige qualidades diplomáticas e de estrategista, uma vez que para um bom resultado, será necessário angariar a confiança e a cooperação de todos, no ritmo certo, e com o mínimo de conflitos e alterações no status quo. É a integração que faz com que todas as partes distintas do projeto formem um conjunto único e evoluam uniformemente rumo a um objetivo comum. De um modo geral, quanto maior o projeto (mais pessoas envolvidas, muitos sub-projetos, atividades executadas em lugares diferentes, etc.), maior é a necessidade e a importância de uma boa integração.

Para o Gerenciamento de Integração normalmente se confecciona um Plano Global de Gerenciamento do Projeto. Este plano deve detalhar como será a execução e o controle do projeto, deve conter os planos de gerenciamento de todas as outras áreas, e também as informações necessárias (técnicas, administrativas, históricas, políticas e econômicas) para a condução do projeto. Devem também ser explicitadas as restrições do projeto e as estratégias para a melhoria das mesmas.

Em geral este documento é apresentado à alta gerência e, do mesmo modo que o Gerente de Projetos o usa para gerenciar o projeto, ele servirá como critério de avaliação e de acompanhamento pelos seus superiores. Deste modo, fica claro que se trata de um documento de extrema importância e que deve ser atualizado regularmente com o máximo de informações realistas e consistentes. 


\subsubsection{Gerenciamento de Escopo}

Consiste em definir, estruturar e alocar esforços no intuito de assegurar que o produto ou serviço seja obtido em conformidade com as especificações técnicas e funcionais, e que haja o mínimo de alterações durante o ciclo do projeto.

No Gerenciamento do Escopo devem ficar explícitos, a todos os envolvidos, a definição e o detalhamento do escopo, onde:

- Definição do escopo: é a descrição do produto ou serviço a ser fornecido, em geral baseada em contratos e especificações;

- Detalhamento do escopo: através de especificações e normas técnicas, bem como dados históricos, deve ser elaborada uma estrutura analítica do projeto contendo um detalhamento das ações e tarefas que compõem o produto ou serviço final. Esta estrutura analítica, também conhecida por WBS (Work Breakdown Structure), suportará não só o gerenciamento de escopo, mas também os Gerenciamentos de Custos, Tempo, Qualidade, Riscos e Suprimentos.

O WBS deve abranger todo o escopo do projeto e qualquer elemento fora do WBS não pode fazer parte do escopo do projeto (e vice-versa). Esta é a definição que fundamenta a utilização desta ferramenta e a torna imprescindível para um bom controle sobre o projeto (veremos mais tarde o WBS e a sua relação com a Análise de Valor Agregado). O WBS acaba sendo a espinha dorsal do projeto por prover, principalmente, as seguintes funções:

- É a base para a organização e controle do projeto;

- Assegura que todos os assuntos e itens do projeto estão cobertos;

- Ajuda a configurar a responsabilidade de cada envolvido;

- Dá suporte ao gerenciamento de riscos;

- É a base para comunicação e estruturação do sistema de informações. 
O WBS pode se apresentar de diversas maneiras. Na literatura em geral encontram-se estruturas distribuídas graficamente através de diagramas de blocos, conforme exposto na Figura 2.6.

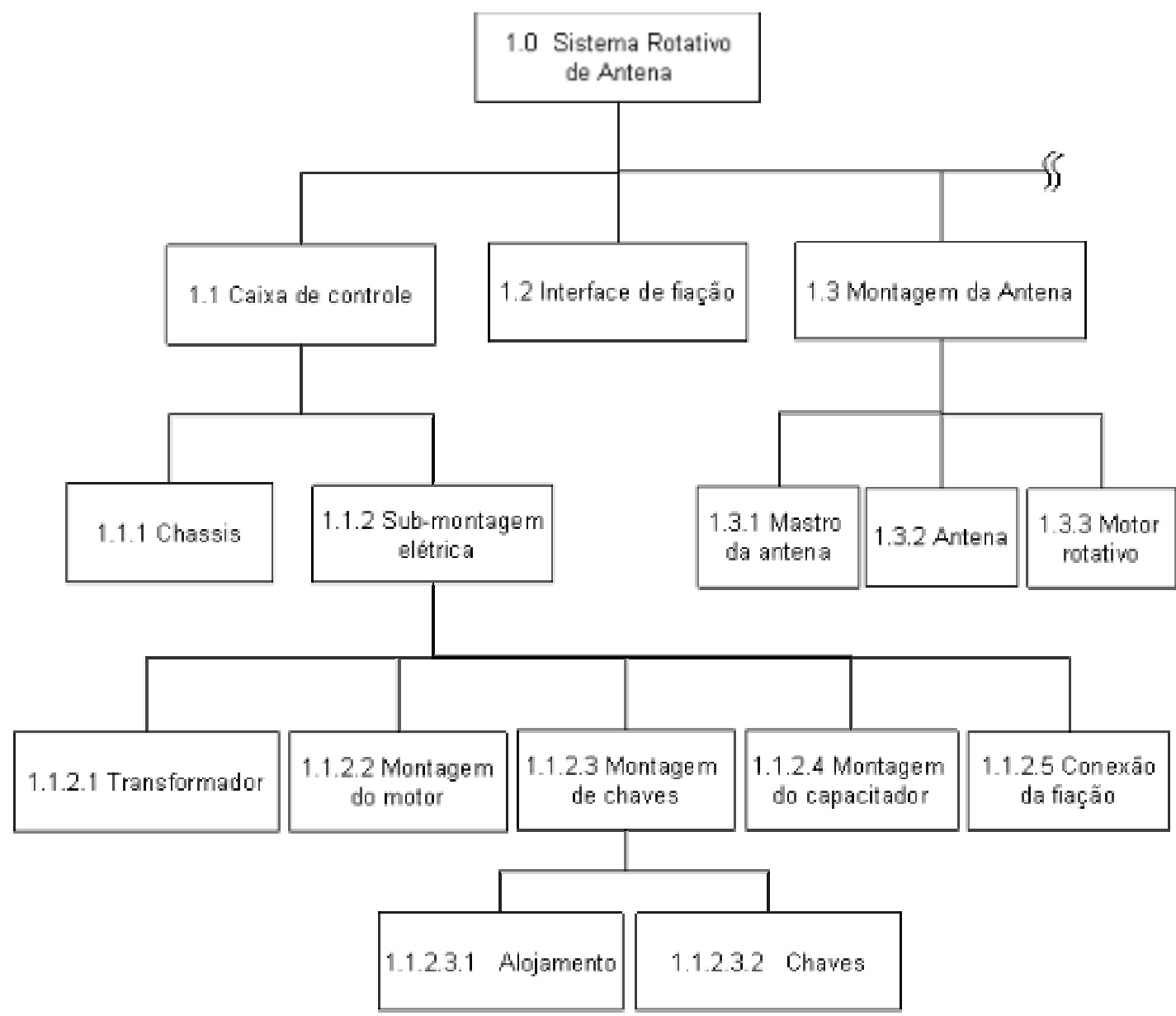

Figura 2.6 Exemplo de WBS em diagrama de blocos (Cleland; Ireland, 2000)

Esta representação é muito útil em termos didáticos e para pequenos projetos, ou ainda quando utilizada apenas para os primeiros níveis do WBS (em geral para reporte ao cliente ou alta direção). Entretanto, para grandes e complexos projetos prefere-se utilizar a forma tabular, pois, embora pareça menos amigável à primeira vista, traz um melhor acondicionamento dos itens e possibilita agregar informações adicionais aos mesmos, sem prejuízos à visualização. 
A Figura 2.7 mostra parte de um WBS típico de Engenharia para um projeto de transporte metropolitano de massa (exemplo real de uma indústria brasileira). Neste caso, além da descrição das tarefas, o WBS básico foi complementado com a nomeação de responsáveis, as fontes de informação. os produtos finais das atividades e os respectivos destinatários.

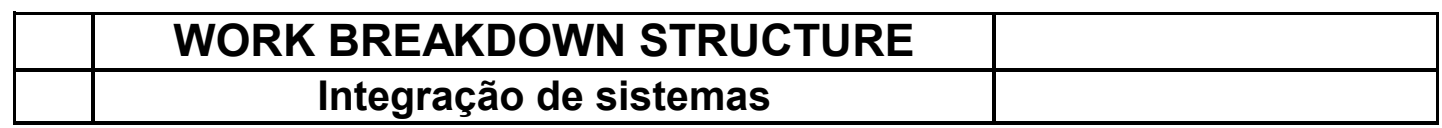

\begin{tabular}{|c|c|c|c|c|c|c|}
\hline Código & Tarefa & Responsável & Entrada & De & Saída & Para \\
\hline 1 & Características do Trem & & & & & \\
\hline 1.1 & Confirmação das Características do Trem & & & & & \\
\hline 1.1.1 & $\begin{array}{l}\text { Elaboração do PBS (Product Breakdown Structure) e do } \\
\text { FBS (Functional Breakdown Structure) }\end{array}$ & José & $\begin{array}{l}\text { Especificação Técnica ("ET") } \\
\text { do Cliente; Modelo padrão de } \\
\text { PBS e FBS }\end{array}$ & Cliente & PBS e FBS & todos \\
\hline 1.1 .2 & Peso e Centro de Gravidade & & & & & \\
\hline 1.1.2.1 & Dados Preliminares do Peso e Centro de Gravidade & João & $\begin{array}{l}\text { Lay-out dos equipamentos no } \\
\text { carro }\end{array}$ & SGR 2 & \begin{tabular}{|l|} 
Relatório de Dados \\
Preliminares do \\
Peso e Centro de \\
Gravidade \\
\end{tabular} & $\begin{array}{l}\text { equipes de tração, } \\
\text { frenagem e } \\
\text { estabilidade }\end{array}$ \\
\hline 1.1.2.2 & Atualização do Peso e Centro de Gravidade & João & $\begin{array}{l}\text { Atualização dos dados de } \\
\text { peso e CG dos equipamentos } \\
\text { instalados }\end{array}$ & $\begin{array}{l}\text { CGR 1; } \\
\text { SGR } 3\end{array}$ & $\begin{array}{l}\text { Relatório Atualizado } \\
\text { de Dados do Peso e } \\
\text { Centro de Gravidade }\end{array}$ & $\begin{array}{l}\text { equipes de tração, } \\
\text { frenagem e } \\
\text { estabilidade }\end{array}$ \\
\hline 1.1 .3 & Dados para elaboração do desempenho tração/freio elétrico & Jonas & $\begin{array}{l}\text { ET do Cliente; Normas } \\
\text { Aplicáveis; Dados da Interface } \\
\text { Tração/Freio }\end{array}$ & Cliente & $\begin{array}{l}\text { Dados para } \\
\text { elaboração do } \\
\text { desempenho } \\
\text { tração/freio elétrico }\end{array}$ & $\begin{array}{l}\text { Cliente e } \\
\text { fornecedores }\end{array}$ \\
\hline 1.1 .4 & Previsão de carga de auxiliares (Inversor estático e bateria) & Carlos & $\begin{array}{l}\text { ET do Cliente; Informações de } \\
\text { Carga dos Fornecedores }\end{array}$ & Cliente & $\begin{array}{l}\text { Previsão de carga de } \\
\text { auxiliares }\end{array}$ & $\begin{array}{l}\text { Cliente e } \\
\text { fornecedores }\end{array}$ \\
\hline 1.2 & RAMS & Alexandre & $\begin{array}{l}\text { Análise de RAMS dos } \\
\text { fornecedores }\end{array}$ & & \begin{tabular}{|l|} 
Status de RAMS do \\
Trem
\end{tabular} & Cliente \\
\hline 1.5 & Elaboração do Projeto Básico Preliminar & Jeferson & $\begin{array}{l}\text { ET do Cliente; Desenhos de } \\
\text { Fornecedores; Desenhos } \\
\text { Preliminares de Instalação }\end{array}$ & Cliente & $\begin{array}{l}\text { Projeto Básico } \\
\text { Preliminar }\end{array}$ & Cliente \\
\hline 2.1 .5 & Sistema de Ventilação & & & & & \\
\hline 2.1 .5 .1 & $\begin{array}{l}\text { Especificação de Fornecimento (EF) do Sistema de } \\
\text { Ventilação }\end{array}$ & José & ET do Cliente & Cliente & \begin{tabular}{|l|} 
EF do Sistema de \\
Ventilação \\
\end{tabular} & $\begin{array}{l}\text { SGR 2.1.5.2; SGR } \\
2.1 .5 .4\end{array}$ \\
\hline 2.1 .5 .2 & |"Design Review" do Sistema de Ventilação & José & $\begin{array}{l}\text { ET do Cliente; EF do Sistema } \\
\text { de Ventilação }\end{array}$ & $\begin{array}{l}\text { Cliente; } \\
\text { SGR } \\
2.1 .5 .1\end{array}$ & \begin{tabular}{|l} 
Análise técnica do \\
Sistema de \\
Ventilação do \\
fornecedor
\end{tabular} & SGR 2.1.5.3 \\
\hline 2.1 .5 .3 & Definição do fornecedor do Ventilação & Eduardo & $\begin{array}{l}\text { Análise técnica do Sistema de } \\
\text { Ventilação do fornecedor }\end{array}$ & \begin{tabular}{|l} 
Cliente; \\
SGR \\
2.1 .5 .2 \\
\end{tabular} & $\begin{array}{l}\text { Definição do } \\
\text { fornecedor }\end{array}$ & SGR 2.1.5.4 \\
\hline 2.1 .8 & Sistema de lluminação (parcial) & & & & & \\
\hline 2.1.8.1 & EF do Sistema de lluminação (parcial) & João & ET do Cliente & Cliente & \begin{tabular}{|l} 
EF do Sistema de \\
lluminação (parcial)
\end{tabular} & $\begin{array}{l}\text { SGR 2.1.8.2; SGR } \\
2.1 .8 .4\end{array}$ \\
\hline 2.1.8.2 & "Design Review" do Sistema de lluminação (parcial) & João & $\begin{array}{l}\text { ET do Cliente; EF do Sistema } \\
\text { de lluminação (parcial) }\end{array}$ & $\begin{array}{l}\text { Cliente; } \\
\text { SGR } \\
2.1 .8 .1\end{array}$ & $\begin{array}{l}\text { Análise técnica do } \\
\text { Sistema de } \\
\text { lluminação (parcial) } \\
\text { do fornecedor }\end{array}$ & SGR 2.1.8.3 \\
\hline 2.1 .8 .3 & Definição do fornecedor do Sistema de lluminação (parcial) & Eduardo & $\begin{array}{l}\text { Análise técnica do Sistema de } \\
\text { lluminação (parcial) do } \\
\text { fornecedor }\end{array}$ & \begin{tabular}{|l} 
Cliente; \\
SGR \\
2.1 .8 .2 \\
\end{tabular} & $\begin{array}{l}\text { Definição do } \\
\text { fornecedor }\end{array}$ & SGR 2.1.8.4 \\
\hline 2.1 .8 .4 & Análise dos desenhos do fornecedor do lluminação (parcial) & Eduardo & $\begin{array}{l}\text { ET do Cliente; EF do Sistema } \\
\text { de lluminação (parcial); } \\
\text { Desenhos do fornecedor }\end{array}$ & $\begin{array}{l}\text { Cliente; } \\
\text { SGR } \\
\text { 2.1.8.3; } \\
\text { SGR } \\
2.1 .8 .1 \\
\end{array}$ & $\begin{array}{l}\text { Status dos desenhos } \\
\text { do fornecedor }\end{array}$ & \\
\hline 2.1 .8 .5 & $\begin{array}{l}\text { Análise dos descritivos do lluminação (parcial) e verificação } \\
\text { de atendimento dos mesmos à ET do cliente }\end{array}$ & Eduardo & $\begin{array}{l}\text { ET do Cliente; EF do Sistema } \\
\text { de lluminação (parcial); } \\
\text { Descritivos do Sistema de } \\
\text { lluminação (parcial) }\end{array}$ & $\begin{array}{l}\text { Cliente; } \\
\text { SGR } \\
\text { 2.1.8.3; } \\
\text { SGR } \\
2.1 .8 .1 \\
\end{array}$ & $\begin{array}{l}\text { Status dos } \\
\text { descritivos do } \\
\text { fornecedor }\end{array}$ & Cliente \\
\hline 2.1 .9 & Sistema de Portas & & & & & \\
\hline 2.1 .9 .1 & EF do Sistema de Portas & Maurício & ET do Cliente & Cliente & $\begin{array}{l}\text { EF do Sistema de } \\
\text { Portas }\end{array}$ & $\begin{array}{l}\text { SGR 2.1.9.2; SGR } \\
2.1 .9 .4\end{array}$ \\
\hline 2.1 .9 .2 & |"DR" do Sistema de Portas & Mauricio & $\begin{array}{l}\text { ET do Cliente; EF do Sistema } \\
\text { de Portas }\end{array}$ & \begin{tabular}{|l} 
Cliente; \\
SGR \\
2.1 .9 .1 \\
\end{tabular} & $\begin{array}{l}\text { Análise técnica do } \\
\text { Sistema de Portas } \\
\text { do fornecedor }\end{array}$ & SGR 2.1.9.3 \\
\hline
\end{tabular}

Figura 2.7 Exemplo de WBS em formato tabular 
Junto ao WBS existem outras estruturas analíticas que podem ajudar a suportar o Gerenciamento de Escopo e de Custos. São eles: o PBS (Product Breakdown Structure), que divide o produto final em vários subprodutos, e o FBS (Function Breakdown Structure) que divide a função do produto final em várias sub-funções. Seguem também exemplos destas duas estruturas.

\begin{tabular}{|c|c|c|c|}
\hline \multicolumn{4}{|c|}{ PBS } \\
\hline \multicolumn{4}{|c|}{ Equipamentos da Cobertura } \\
\hline 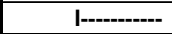 & Unidades Elétricas & & \\
\hline I & I--------- & Módulo de Tração & \\
\hline $\mathbf{I}$ & I & |--------- & Módulo Inversor \\
\hline $\mathrm{I}$ & I & |-------- & Módulo Resistor \\
\hline I & I & |---"--"-- & Módulo Disjuntor Principal \\
\hline $\mathrm{I}$ & $\mathrm{I}$ & |-------- & Ponte Monofásica \\
\hline $\mathrm{I}$ & |--------- & Módulo Auxiliar & \\
\hline $\mathrm{I}$ & I & I-------" & Carregador de Bateria \\
\hline I & |--------- & \multicolumn{2}{|c|}{ Computador de Bordo } \\
\hline $\mathrm{I}$ & I--------- & \multicolumn{2}{|c|}{ Módulo de Baixa Tensão } \\
\hline $\mathrm{I}$ & |--------- & \multicolumn{2}{|c|}{ Caixa de Baterias } \\
\hline |---------" & \multicolumn{3}{|c|}{ Unidade Pneumática } \\
\hline I & I--------- & \multicolumn{2}{|l|}{ Compressor } \\
\hline I & |---------- & \multicolumn{2}{|l|}{ Painel de Freio } \\
\hline I & I--------- & \\
\hline |---------" & Unidade de Ar Con & $\begin{array}{l}\text { Reservatório } \\
\text { ndicionado }\end{array}$ & \\
\hline I & l--------- & \multicolumn{2}{|c|}{ Unidade Evaporadora } \\
\hline I & |---------- & \multicolumn{2}{|c|}{ Unidade Condensadora } \\
\hline $\mathrm{I}$ & |---------" & \multicolumn{2}{|c|}{ Unidade E/C Compacta } \\
\hline |-------" & Indutor & & \\
\hline I & |-------- & \multicolumn{2}{|l|}{ Indutor Auxiliar } \\
\hline $\mathrm{I}$ & |-------- & \\
\hline |---------- & Transformador & \multicolumn{2}{|l|}{ Filtro do Indutor } \\
\hline |--------- & Dispositivos na Cob & \multicolumn{2}{|c|}{ obertura } \\
\hline I & |--------- & \multicolumn{2}{|l|}{ Fusível de Tração } \\
\hline 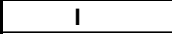 & |---------- & \multicolumn{2}{|l|}{ Disjuntor } \\
\hline $\mathrm{I}$ & |-------. & \multicolumn{2}{|l|}{ Contator } \\
\hline \multicolumn{4}{|c|}{ |------- $\quad$ Pantógrafo } \\
\hline Equipamentos & ob-Estrado & & \\
\hline \begin{tabular}{|c|} 
I------- \\
\end{tabular} & Região de Cabecei & ira Frontal & \\
\hline $\mathrm{I}$ & I--------- & Módulos Elétricos & \\
\hline I & I & I---------- & Traction Case \\
\hline 1 & $\mathrm{I}$ & I & Módulo Inversor \\
\hline I & $\mathrm{I}$ & 1 & I------- $\quad$ Módulo Resistor \\
\hline $\mathbf{I}$ & $\mathrm{I}$ & 1 & |-------- $\quad$ Módulo Disjuntor \\
\hline $\mathrm{I}$ & $\mathbf{I}$ & I & I--------- $\quad$ Ponte Monofásica \\
\hline $\mathrm{I}$ & $\mathbf{I}$ & |---------- & Módulo Auxiliar \\
\hline $\mathbf{I}$ & $\mathrm{I}$ & |--------- & -------Carregador de Bateria \\
\hline $\mathrm{I}$ & I & |-------- & Computador de Bordo \\
\hline 1 & $\mathbf{I}$ & |--------- & Caixa de Baterias \\
\hline I & I & I---------- & Módulo de Baixa Tensão \\
\hline 1 & |---------- & Unidade Pneumátic & \\
\hline 1 & I & |-------- & Compressor \\
\hline I & $\mathbf{I}$ & |--------- & Painel de Freio \\
\hline $\mathrm{I}$ & $\mathrm{I}$ & l------- & Reservatório \\
\hline I & |---------" & Transmissão Mecâ & ânica \\
\hline 1 & I & I---------- & Unidade Hidráulica \\
\hline $\mathbf{I}$ & $\mathrm{I}$ & |--------- & Corrente de Transmissão Mecânica \\
\hline I & I & I & I--a- $\quad$ Eixo Propulsor \\
\hline 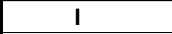 & $\mathrm{I}$ & |---------- & Motor \\
\hline
\end{tabular}

Figura 2.8 Exemplo de PBS em formato tabular 


\begin{tabular}{|c|c|c|c|}
\hline codigo & \multicolumn{3}{|c|}{ FBS } \\
\hline 2. & \multicolumn{3}{|c|}{ Tração e Frenagem Elétrica/Diesel } \\
\hline 2.1 & |----.--. & \multicolumn{2}{|c|}{ Proteção - Corrente Direta } \\
\hline 2.2 & 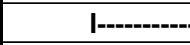 & \multicolumn{2}{|c|}{ Proteção - Corrente Monofásica } \\
\hline 2.3 & 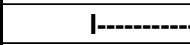 & \multicolumn{2}{|c|}{ Interface Homem-Máquina com Sistema TF } \\
\hline 2.4 & |-----.--.. & \multicolumn{2}{|c|}{ Regulagem Tensão Monofásica } \\
\hline 2.5 & |------.-. & \multicolumn{2}{|c|}{ Conversão de Tensão Direta/Monofásica } \\
\hline 2.6 & |--.---.-.. & \multicolumn{2}{|c|}{ Barramento de Filtragem de Tensão } \\
\hline 2.7 & 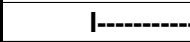 & \multicolumn{2}{|c|}{ Resfriamento da Cadeia de Tração } \\
\hline 2.8 & |-..-........ & \multicolumn{2}{|c|}{ Conversão de Corrente Direta/Trifásica } \\
\hline 2.9 & 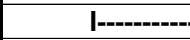 & \multicolumn{2}{|c|}{ Conversão de Energia Elétrica em Mecânica } \\
\hline 2.10 & 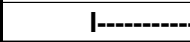 & \multicolumn{2}{|c|}{ Conversão de Energia Elétrica em Térmica } \\
\hline 2.11 & |--------.- & \multicolumn{2}{|c|}{ Checagem/Controle da Cadeia de Tração } \\
\hline 4. & \multicolumn{3}{|c|}{ Transporte de Passageiros } \\
\hline 4.1 & |l------- & \multicolumn{2}{|l|}{ Segurança } \\
\hline 4.1 .1 & I & I--------- & Resistência Estrutural \\
\hline 4.1 .2 & I & |--------. & Dispositivo Anti-Encavalamento \\
\hline 4.2 & |--.-....... & \multicolumn{2}{|c|}{ Habitabilidade / Acessibilidade } \\
\hline 4.2 .1 & I & |--------.- & Interface Veículo / Plataforma \\
\hline 4.2 .5 & I & |---------.- & Requisitos $\mathrm{p} /$ Deficientes \\
\hline 4.3 & 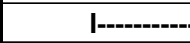 & \multicolumn{2}{|l|}{ Conforto } \\
\hline 4.3 .1 & I & \multicolumn{2}{|c|}{ l------- Conforto Visual / lluminação } \\
\hline 4.3 .2 & I & \multicolumn{2}{|c|}{ |--andorto Acústico } \\
\hline 4.3 .3 & $\mathbf{I}$ & \multicolumn{2}{|c|}{ |------- Conforto Climático } \\
\hline 4.3 .4 & $\mathbf{I}$ & \\
\hline 4.3 .5 & I & \multicolumn{2}{|c|}{$\begin{array}{ll}\text { l------- } & \text { Conforto Postural } \\
\text { l------- } & \text { Arranjos Interiores }\end{array}$} \\
\hline 4.3 .6 & I & \multicolumn{2}{|c|}{ l-------- $\quad$ Estética Exterior } \\
\hline 4.4 & 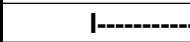 & \multicolumn{2}{|c|}{ Gerenciamento de Informação ao Usuário } \\
\hline 4.4 .1 & I & |---------" & Informação Visual \\
\hline 4.4 .2 & I & |---------" & Informação Sonora \\
\hline
\end{tabular}

Figura 2.9 Exemplo de FBS em formato tabular

Todas estas estruturas (WBS, PBS e FBS), quando devidamente interligadas, tornamse ferramentas poderosíssimas, pois auxiliam na visão total do projeto, evitando enganos, proporcionando uma cadeia fechada de informações e que pode ser usada como um checklist ou roteiro para o projeto.

Existe também uma outra estrutura que representa a organização da empresa e que, em conjunto com o WBS, ajuda a atribuir e visualizar responsabilidades nos projetos. Trata-se do OBS (Organization Breakdown Structure) que tem por característica a discretização das áreas funcionais da empresa. Segue abaixo (Figura 2.10) um exemplo de diagrama contemplando o cruzamento entre o OBS e o WBS, indicando o envolvimento e a responsabilidade de cada equipe ou área da empresa (tanto em termos técnicos como administrativos). 


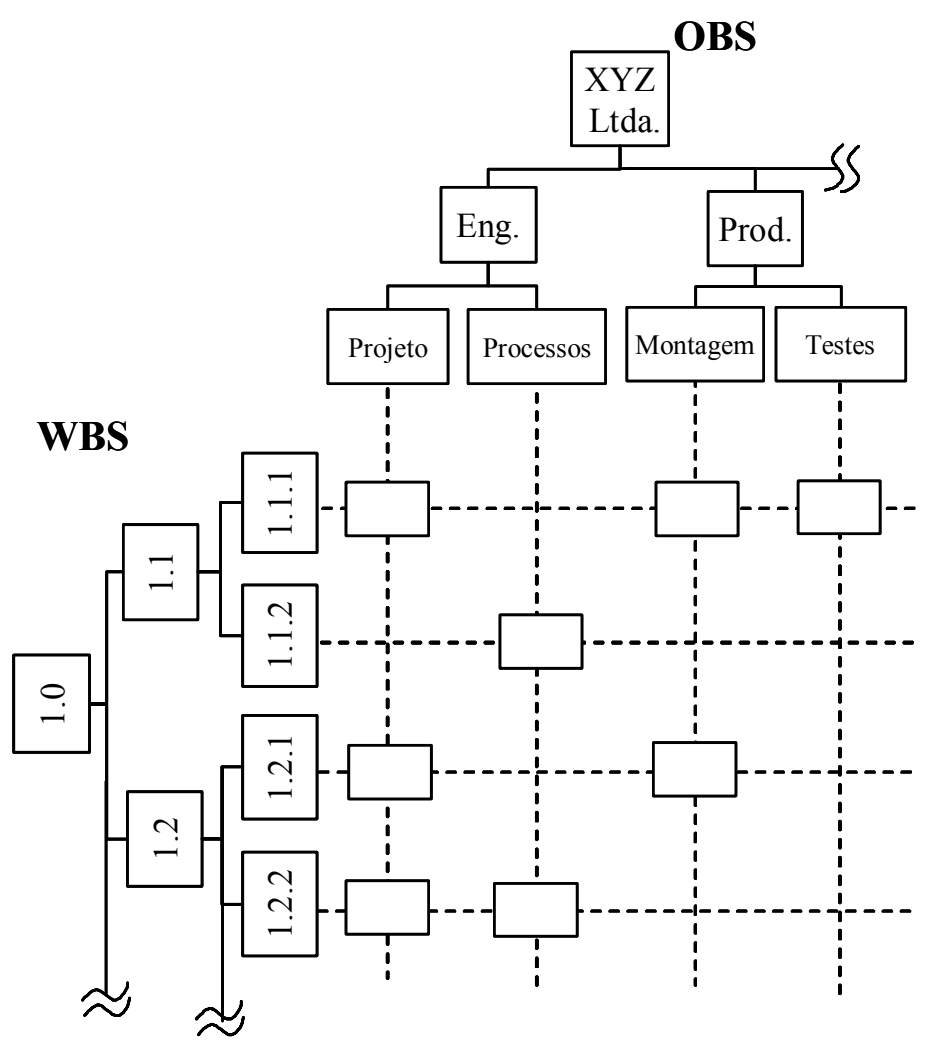

Figura 2.10 Inter-relação gráfica entre WBS e OBS

Novamente, este tipo de representação é bastante útil em níveis macro ou em projetos pouco complexos. Na medida em que aumenta o número de itens do WBS, esta representação se torna praticamente inviável, nos remetendo novamente ao formato tabular e com a inclusão de uma coluna para atribuição de responsabilidades.

Por ser o elemento base e integrador de praticamente todas as áreas do Gerenciamento de Projetos é consenso entre todos os autores que o WBS necessita de atenção especial e racionalização na sua elaboração. Um WBS mal elaborado ou não consistente pode inviabilizar todo o gerenciamento do projeto.

A elaboração de um bom WBS exige bastante conhecimento sobre o produto (ou serviço) e bastante experiência por parte dos envolvidos. Uma referência bastante valiosa é a norma "Practice Standard for WBS" publicada pelo Project Management Institute (2001). 


\subsubsection{Gerenciamento de Tempo}

O Gerenciamento de Tempo tem por função garantir que o projeto seja concluído dentro do prazo determinado. Trata-se do planejamento e monitoramento das ações a serem tomadas ao longo do projeto. Como, em alguns mercados, tempo e prazo de entrega são prioritários sobre qualquer outra característica do projeto, esta é uma área que vem se tornando cada vez mais vital no Gerenciamento de Projetos.

O Gerenciamento de Tempo se inicia junto à confecção do WBS, onde as atividades e entregas a serem efetuadas recebem períodos de duração (estimados).

Para a estimativa de duração de cada atividade do WBS existem vários métodos: dados históricos, estatísticos, simulações e julgamentos especializados. Estas estimativas normalmente são feitas pelos líderes de cada equipe ou pelos gerentes funcionais de cada departamento. Cabe ao Gerente de Projetos analisá-las e, se necessário, contestá-las baseado na sua experiência e em dados históricos.

Por fim as atividades são devidamente concatenadas e interligadas, visando as datas acordadas para início e término do projeto. Para esta programação de datas, é necessária novamente uma consolidação das informações entre todos os envolvidos. Deve-se inclusive avaliá-las junto à alta direção da empresa, uma vez que pode haver outros projetos em andamento, gerando conflito na utilização de recursos e, portanto, alguma prioridade ou estratégia alternativa terá que ser aplicada pela empresa.

Obtém-se então um cronograma completo do empreendimento, possibilitando a geração de gráficos de Gantt, diagramas PERT/CPM, e outras formas de visualização do empreendimento ao longo do tempo.

O cronograma do projeto é a referência para o seu gerenciamento. Vale lembrar, entretanto, que um projeto é um processo dinâmico e que seu planejamento inicial precisará ser ajustado com o passar do tempo. A atualização e a análise regulares do cronograma evitarão possíveis surpresas e possibilitarão ações corretivas em tempo. 


\subsubsection{Gerenciamento de Custos}

O Gerenciamento de Custos deve garantir que todos os recursos necessários para a realização dos trabalhos do projeto estejam dentro do capital disponibilizado para tal.

Esta é considerada por muitos como uma das áreas mais difíceis e essenciais ao Gerenciamento de Projetos. Junto com o Gerenciamento de Tempo, forma a base que originou os conceitos do GP. Embora haja outros parâmetros igualmente importantes no sucesso de um projeto, o bom ou mau desempenho do Gerenciamento de Custos é o primeiro a ser avaliado e o que, em geral, causa maior impacto no resultado final.

Segundo o $\mathrm{PMBoK}^{\circledR}$, o Gerenciamento de Custos pode ser subdividido conforme abaixo:

- Planejamento de Recursos: consiste em determinar quais recursos físicos (materiais, equipamentos e pessoas) e em que quantidades serão utilizados para realizar as atividades do projeto. A melhor maneira de se estimar estes recursos é utilizando as informações de um WBS.

- Estimativa de Custos: consiste em estimar os custos dos recursos do projeto. Também pode ser estimado através de um WBS e necessita do apoio de todas as áreas e departamentos da empresa envolvidos no projeto.

- "Orçamentação": consiste em alocar as estimativas de custo a cada item de trabalho (WBS) de modo a estabelecer uma linha de base de custos para medir a performance do projeto (baseline). O orçamento será a referência para o controle de todo o projeto.

- Controle de Custos: consiste no acompanhamento e avaliação dos fatores que criam mudanças nos custos. Para este controle define-se um Plano de Gerenciamento de Custos, o qual deve conter os procedimentos que serão utilizados para:

- Gerenciar os custos do projeto

- Classificar e identificar mudanças nos custos;

- Atender uma necessidade de investimento não prevista originalmente; 
- $\quad$ Revisar o plano de gerenciamento de custos;

- Definir quem será o responsável pelo controle dos custos.

Atualmente existem várias maneiras de se controlar os custos de um projeto, e uma das mais completas e que melhor conseguem consolidar custos, prazos e performance técnica de um projeto é a Análise de Valor Agregado (ou Earned Value Analysis - EVA), cujos conceitos básicos foram formalizados pelo Departamento de Defesa Americano, na década de 50, sob o nome de C/SCSC. Esta técnica será apresentada com maiores detalhes nos capítulos 3 e 4 desta dissertação.

Na grande maioria dos casos, o orçamento é a maior restrição de um projeto, e a sua manutenção ou melhoria é o maior desafio que um Gerente de Projetos tem pela frente. Por isso, ele deve se cercar das melhores ferramentas, técnicas e profissionais, de modo a assegurar o melhor controle possível dos custos do projeto.

\subsubsection{Gerenciamento da Qualidade}

Esta é a área que deve promover a finalização do projeto dentro dos padrões de qualidade especificados e, por conseguinte, garantir a satisfação do cliente e de todos os envolvidos.

Para tal, é aconselhável que o Gerente de Projetos possua um Plano de Gerenciamento da Qualidade, onde devem constar detalhamentos do Planejamento da Qualidade (identificando os padrões de qualidade exigidos no projeto e de que maneira poderão ser alcançados), bem como a descrição dos processos de Garantia e Controle da Qualidade.

Enquanto o Planejamento da Qualidade é muito particular a cada projeto, a Garantia e o Controle da Qualidade em geral obedecem a padrões corporativos e pré-definidos dentro das empresas. Exceção feita aos requisitos especificados em cada projeto, os 
processos de Garantia e Controle seguem padrões únicos que são desenvolvidos de acordo com as características dos produtos ou serviços da empresa (ex.: uma indústria metalúrgica possui processos de inspeção de solda já pré-definidos e de acordo com normas específicas, inerentes ao produto por ela fabricado).

O Plano de Gerenciamento da Qualidade deve conter, entre outras coisas:

- Como serão gerenciados os requisitos de qualidade;

- Quais as ferramentas a serem utilizadas para o controle e garantia da qualidade (6 Sigma, TQM, QFD...);

- Com que freqüência serão inspecionados os aspectos da qualidade do projeto;

- Como serão tratadas as mudanças na qualidade e as não-conformidades (junto ao cliente e sob qual orçamento interno);

- Quem será o responsável pelo gerenciamento e controle do plano;

Os custos de qualidade (treinamento, controle, testes e auditorias) e principalmente os de não-qualidade (retrabalhos, perdas, reparos e atrasos) devem ser apontados e registrados ao longo do projeto, afim de que se possa corrigi-los durante o processo e de que se tenha um banco de dados, que provavelmente será de grande valia nos projetos futuros.

Vale lembrar que esta área é de fundamental importância para a determinação do sucesso dos projetos (tríade tradicional para o sucesso: custo, prazo, qualidade). Além disso, seus resultados devem ser sempre mantidos em destaque, pois contribuem fortemente para a viabilização e geração de novas vendas, possibilitando a manutenção da imagem e a longevidade da empresa no mercado. 


\subsubsection{Gerenciamento de Recursos Humanos}

No passado, as maiores preocupações dos gestores estavam relacionadas com os aspectos técnicos e financeiros dos projetos. Agora, junto a estes, existem os aspectos humanos sendo levados em consideração, pois a satisfação dos envolvidos passou a ser quesito muito relevante nos projetos.

Hoje também se sabe que o sucesso e o fracasso de um projeto dependem exclusivamente das pessoas envolvidas e de suas ações no decorrer do projeto. Sendo assim, é natural que o Gerenciamento de Recursos Humanos seja mais um item a ser levado em consideração pelo Gerente de Projetos.

Normalmente em grandes projetos, e em empresas não totalmente voltada para projetos, o Gerente de Projetos tem pouco a gerenciar em termos de recursos humanos. Deve, todavia, ter o cuidado de promover a perfeita integração entre os envolvidos, enfatizando o trabalho em equipe e evitando conflitos. Deve também definir as responsabilidades individuais de cada envolvido desde o início do projeto, pois, um profissional só pode desempenhar bem o seu papel se este estiver perfeitamente definido e entendido.

Caso o Gerente de Projetos tenha autonomia para recrutamentos e alocação de recursos humanos, Vargas (2000) sugere na figura abaixo como seria a distribuição típica de profissionais requeridos ao longo do projeto.

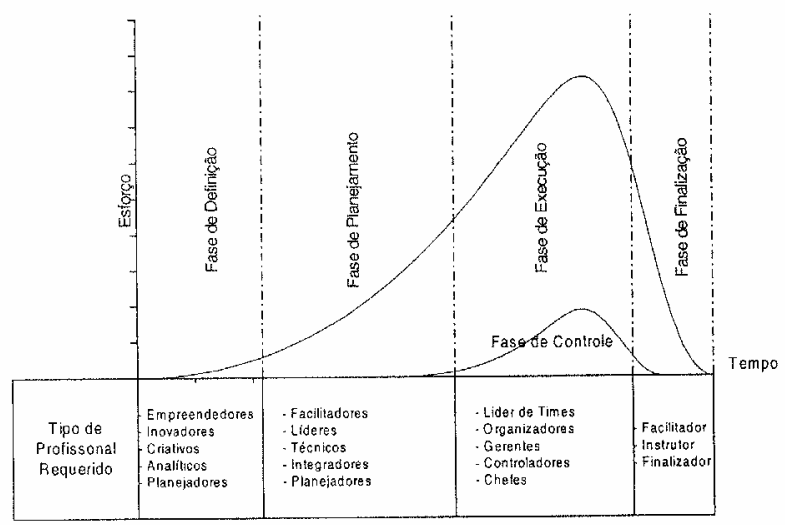

Figura 2.11 Profissionais requeridos no ciclo de projeto (Vargas, 2000) 
Os aspectos comportamentais e as inter-relações pessoais dentro de equipes de projeto foram extensamente explorados por Randolph; Posner (1987), e sem dúvida nenhuma, são também de grande valia para o Gerente de Projetos.

\subsubsection{Gerenciamento das Comunicações}

Para que se tenha uma perfeita integração entre as principais áreas do GP e os demais envolvidos, é fundamental que haja um processo de comunicação ágil, amplo, simples e direto o bastante para não gerar distorções de conteúdo e atrasos nas ações requeridas pelos envolvidos.

É importante lembrar que o Gerente de Projetos não produz diretamente os resultados de um projeto. Para chegar aos resultados, ele utiliza os meios de comunicação para coordenar as suas equipes e para a obtenção das informações necessárias para o controle, monitoramento e tomadas de decisão.

O PMBoK ${ }^{\circledR}$ (Duncan, 1996) subdivide o gerenciamento das comunicações em quatro processos principais:

- Planejamento das Comunicações: onde se determina quando e quais informações serão necessárias para cada envolvido no projeto;

- Distribuição de Informações: onde se determina de que maneira as informações serão disponibilizadas para os envolvidos. Conforme já exposto deve ser um sistema ágil e consistente de modo a não gerar interpretações errôneas e a não introduzir atrasos ou gargalos no sistema.

- Relatórios de Desempenho: trata-se da coleta, compilação e distribuição das informações relativas à performance do projeto.

- Encerramento: processo que formaliza e valida o fechamento do projeto ou de uma de suas fases. Pode também incluir avaliações e ações para as próximas fases ou projetos. 
Um gerente de projetos gasta a maior parte do seu tempo efetuando algum tipo de comunicação: escrevendo, lendo, escutando ou falando, e a maior parte desta comunicação se dá através das reuniões de projeto. A reunião é a maior característica do trabalho em equipe e, portanto, muito freqüente no Gerenciamento de Projetos.

A Figura 2.12 mostra quais são os principais objetivos das reuniões de projetos.

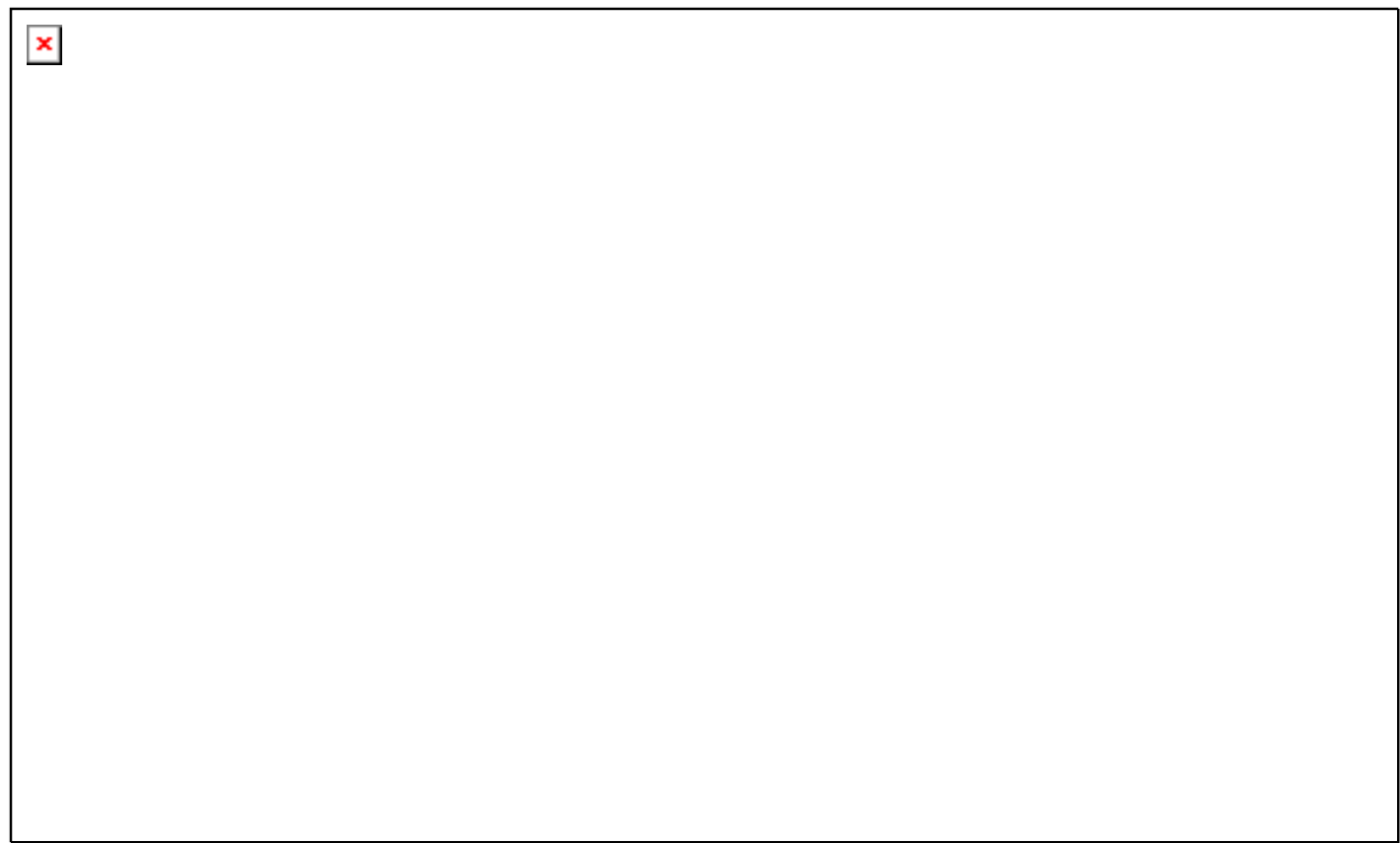

Figura 2.12 Propostas básicas de reuniões (Cleland; Ireland, 2002)

É muito importante que toda a documentação siga padrões pré-estabelecidos durante o projeto (atas, memorandos, relatórios, ordens de serviço), de modo a garantir a segurança, o entendimento e o rastreamento das informações.

Por fim, vale ressaltar que embora a comunicação formal entre os envolvidos no projeto seja muito importante, o Gerente de Projetos deve saber utilizar a comunicação informal, principalmente para o controle do projeto. Quando bem efetuada, a comunicação informal dentro da empresa se torna muito benéfica, e pode apresentar as seguintes vantagens (Knudson; Bitz, 1991): 
- Aprende-se muito mais indo ao local de trabalho dos envolvidos do que permanecendo sentado em sua própria mesa;

- Em seu próprio habitat, as pessoas tendem a estar mais abertas e honestas do que em salas de reunião ou escritórios de chefia;

- Promove a visibilidade do Gerente de Projetos por toda a equipe, e não apenas aos subordinados diretos. Fortalece o espírito de equipe.

- A equipe pode mostrar "in loco" os esforços e os sucessos alcançados, melhorando o relacionamento e incentivando recompensas;

- Os problemas podem ser atacados com antecedência, ao invés de esperá-los aparecer em algum relatório ou reunião;

- Desenvolve-se um "sexto sentido" sobre o que é um desenvolvimento normal para a equipe e, a partir daí, pode-se distinguir problemas potenciais ao longo do projeto.

Há, porém, um cuidado a ser tomado com as comunicações e controles informais: deve-se resistir ao anseio de "micro-gerenciar" as atividades (pulando níveis hierárquicos e organizacionais) e de tomar decisões que são responsabilidades de outros profissionais (normalmente gerentes funcionais). Estes desvios podem tanto gerar conflitos dentro da empresa, como também prejudicar a estrutura que o próprio Gerente de Projetos planejou.

Por fim, vale lembrar que a responsabilidade por assegurar uma comunicação bem sucedida está no comunicador, e não na pessoa a quem a comunicação foi endereçada (Lewis, 95). O Gerente de Projetos deve sempre atentar para este fato, uma vez que ele é o centro de quase toda a comunicação do projeto e sua habilidade em se comunicar clara e objetivamente passa a ser de fundamental importância. 


\subsubsection{Gerenciamento de Riscos}

O Gerenciamento de Riscos é talvez a disciplina mais nova dentro da GP. A necessidade de se gerenciar os riscos de um projeto surgiu devido ao aumento da complexidade, ao aumento dos valores envolvidos, à diminuição dos prazos e à diminuição das margens de lucro dos projetos.

Os riscos também envolvem a imagem da empresa bem como a reputação das equipes e dos patrocinadores do projeto. $\mathrm{O}$ que se precisa é ter conhecimento sobre todos os riscos potenciais do projeto, mapeá-los, e buscar mitigá-los ao máximo.

A metodologia para análise de riscos não é complexa, mas depende muito da experiência dos envolvidos e de conhecimentos técnicos e gerenciais sobre o projeto. O risco é sempre avaliado segundo a sua probabilidade de ocorrência e as suas possíveis conseqüências ao projeto (em geral mensuradas em moeda). Ao se multiplicar estas duas grandezas obtém-se a quantificação do risco, a qual deve ser tabelada para análise dos responsáveis.

Conforme o $\mathrm{PMBoK}^{\circledR}$, o Gerenciamento de Riscos pode ser dividido em 4 processos:

- Identificação dos Riscos: consiste em identificar os riscos que podem afetar o sucesso do projeto e verificar as suas características;

- Quantificação dos Riscos: consiste em medir o impacto dos riscos e classificá-los segundo critérios de prioridade;

- Controle dos Riscos: consiste no desenvolvimento e controle da execução de um Plano de Gerenciamento de Riscos. Neste plano devem estar documentados todos os riscos do projeto, as ações mitigadoras e os seus responsáveis, bem como as contingências e a freqüência para controle dos mesmos;

- Ações para Mitigação dos Riscos: consiste em desenvolver planos de ação para a eliminação, redução ou absorção dos riscos. 


\subsubsection{Gerenciamento de Suprimentos e Contratos}

O Gerenciamento de Suprimentos e de seus respectivos Contratos deve garantir que todo produto e/ou serviço seja fornecido para o projeto, de acordo com as especificações e prazos previamente estipulados.

As estratégias para suprimentos podem variar de empresa para empresa e, de projeto para projeto. Em geral, para grandes empresas e grandes projetos, existe uma área específica (em geral, o departamento de compras) que é a responsável por este acompanhamento. Nestes ambientes o Gerente de Projetos não tem condições e recursos de acompanhar cada fornecimento.

Para que o Gerente de Projetos possa ter controle sobre os suprimentos, estes devem ser classificados em níveis de relevância e complexidade. Como exemplo, podemos citar o projeto de uma embarcação, onde teríamos 3 classes de suprimentos:

- Classe A: Grandes Sistemas como Propulsão (motor/redutor/hélice), Grupo Motor/Gerador, Sistema de Comunicação Interna e Externa, Software de Controle e demais itens de maior complexidade ou maior envolvimento sistêmico.

- Classe B: Suprimento de materiais intermediários como tubulações, janelas, revestimentos, iluminação, etc.

- Classe C: Suprimento de itens de menor valor agregado, complexidade ou risco, como fixadores, piso, mancais, suportes, etc.

O Gerente de Projetos deve ficar atento principalmente aos fornecimentos que se enquadram na Classe $\mathrm{A}$, pois os riscos técnicos e gerenciais envolvidos nestes itens são muito maiores e podem impactar fortemente o resultado final do projeto. Em geral são sistemas vitais, sem equivalentes de mercado, muitas vezes importados e para os quais deve haver um rigoroso processo de compra e acompanhamento. 
Os contratos de fornecimento dos itens "Classe A" devem ser especialmente tratados, buscando sempre impor ao fornecedor os mesmos riscos e penalidades que o projeto possui junto ao cliente final. Como exemplo, é uma prática comum em projetos de alto risco gerencial vincular os pagamentos dos sub-fornecedores aos pagamentos do cliente final. Em outras palavras, só se paga o fornecedor quando se recebe do cliente (trata-se do contrato do tipo pari-passu ou back to back). Deste modo, alguns riscos gerenciais são compartilhados e ainda pode haver benefício no fluxo de caixa.

Para os materiais e serviços da Classe A deve ser também elaborado um Plano de Gerenciamento de Suprimento que deverá conter a metodologia para desenvolvimento e homologação de fornecedores, um planejamento para recebimento destes materiais ou serviços, e padrões para a administração dos contratos, fiscalizando o cumprimento de eventos e garantindo os pagamentos dos fornecedores. 


\subsection{Perfil do Gerente de Projetos}

O gerente de projetos é um "homem de frente", um integrador que trabalha com as diversas áreas internas da empresa, com outras empresas (fornecedores, consorciados, etc.), e também com o cliente final de modo a alcançar um objetivo comum.

Segundo Baguley (1999), o gerente de projetos é a peça chave para o sucesso dos projetos. Ele precisa ter e saber usar uma vasta gama de competências incluindo: habilidade de liderar um time de profissionais variados, de comunicar-se adequadamente com todos os envolvidos, de motivar o time de projetos e saber negociar soluções efetivas para os conflitos que surgem entre as necessidades dos projetos e as de seus envolvidos.

Em adição, o Gerente de Projeto deve tanto liderar, quanto gerenciar um projeto (Cleland; Ireland, 2002). Um líder faz as coisas certas (eficácia), e um gerente faz as coisas da forma certa (eficiência). Para desempenhar tais papéis, exige-se também competência nas seguintes habilidades:

- Possuir compreensão geral sobre a tecnologia envolvida no projeto;

- Ter habilidades interpessoais que promovam um ambiente cultural para os envolvidos, refletindo confiança, lealdade, comprometimento e respeito.

- Compreender os processos gerenciais e suas aplicações ao projeto;

- Ter visão do contexto sistêmico do projeto;

- Ser capaz de tomar e implementar decisões acerca do projeto;

Cohen; Graham (2000) indicam um aspecto muito interessante quanto à visão e à tarefa que este profissional possui. $\mathrm{O}$ gerente de projetos representa, entre outras coisas, os anseios e desejos dos diretores, dos membros da alta cúpula administrativa e dos acionistas das empresas. Por quê? Basta verificar o que basicamente interessa a estas pessoas: retorno sobre o capital investido (a uma certa taxa de risco), e garantia 
de longevidade. O retorno está intimamente associado ao fluxo de caixa (cash-flow) e à margem de lucro (que por sua vez estão ligados ao gerenciamento de custos do projeto), enquanto que a garantia de longevidade está relacionada aos resultados do projeto e principalmente à satisfação do cliente, tanto no quesito qualidade do produto/serviço como no atendimento dos prazos em questão, os quais certamente manterão a empresa em destaque no mercado. Esta visão faz com que o gerente de projetos possua um espírito empreendedor, interpretando o projeto como um empreendimento completo e cujo resultado contribuirá para a sustentação da empresa no mercado.

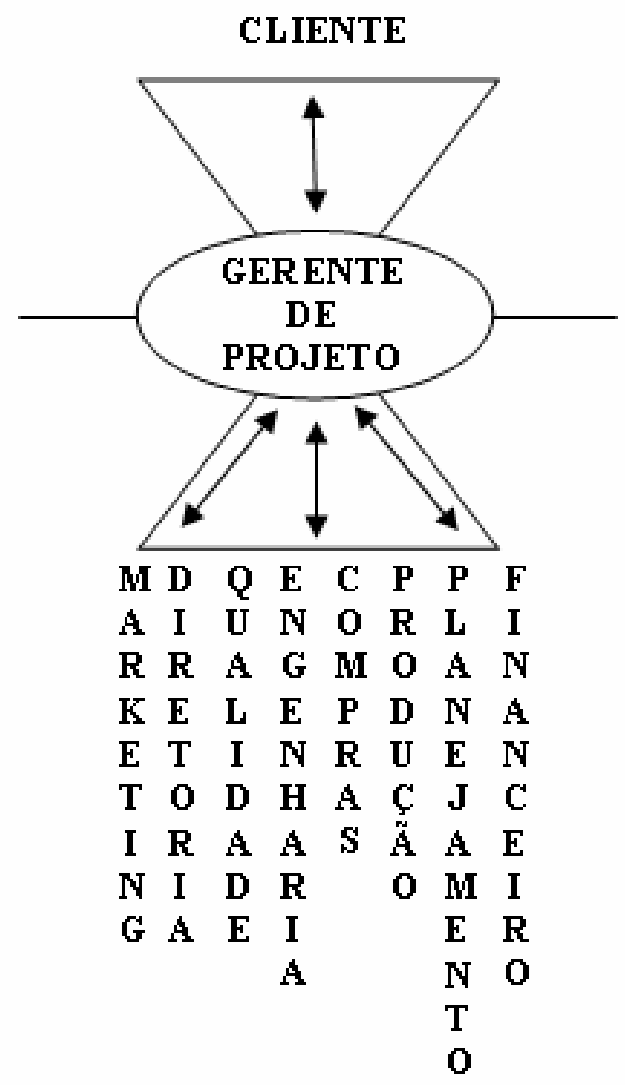

Figura 2.13 O Gerente de Projetos

O Gerente de Projetos também age como filtro e catalisador do empreendimento, ou seja, é ele quem filtra e direciona as informações oriundas das diversas partes. Sendo assim, o Gerente de Projetos é, acima de tudo, um "facilitador" dos processos. É ele 
quem atribui prioridades, nivela as informações entre os envolvidos, mantém o ritmo e abre o caminho para que as equipes possam trilhá-los.

Keeling (2002) acrescenta ainda que o Gerente de Projetos, por ser um "facilitador" dos processos, acaba tendo a maior parte do seu tempo dedicada ao bem-estar e apoio à equipe. É perfeitamente cabível a aplicação da Lei de Pareto nesta observação do dia-a-dia do Gerente de Projetos, o que resultaria na Figura 2.14, abaixo.

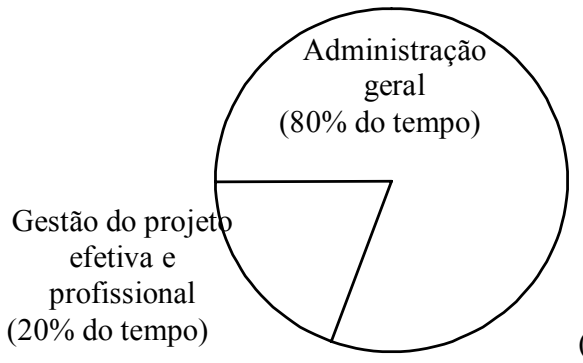

Tempo despendido

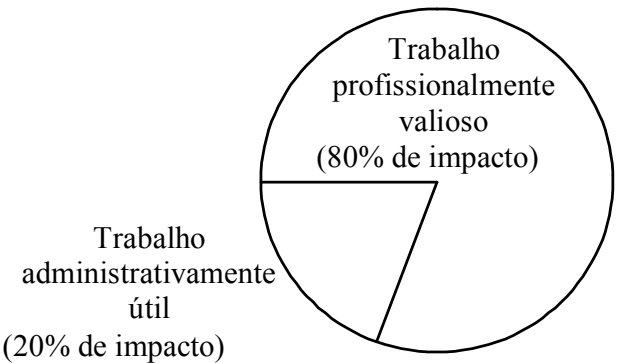

Impacto no resultado

Figura 2.14 Distribuição típica do tempo do gerente de projeto (Keeling, 2002)

Com relação às suas habilidades, o Gerente de Projetos é um profissional administrativo que deve interagir bem com a área técnica (conhecer bem o produto/serviço, saber expô-lo ao cliente, conhecer bem os seus riscos técnicos e os processos envolvidos em seu desenvolvimento) e, ao mesmo tempo, um profissional técnico com conhecimentos gerenciais suficientes para garantir um bom andamento ao projeto, buscar metas e objetivos, bem como reportá-lo de maneira adequada às áreas administrativas e à alta gerência da empresa. Sendo um pouco dos dois ele se torna diferente dos dois, e esta é talvez a principal característica procurada pelas empresas e necessária para a condução dos projetos.

$\mathrm{Na}$ pesquisa realizada por White; Fortune (2002), 43\% dos profissionais que gerenciam projetos afirmam serem os principais tomadores de decisão, 33\% afirmam estarem envolvidos no processo de tomada das principais decisões e $24 \%$ afirmam não terem qualquer influência no processo de tomada destas decisões. Estes dados servem como parâmetro para visualizarmos o grau de responsabilidade que este 
profissional tem em suas mãos. Conseqüentemente, o nível de competência que este deve possuir.

Por outro lado, vale ressaltar que a função de Gerente de Projetos, embora vista por alguns como sendo elitista, não é um "mar de rosas", muito pelo contrário, é uma função que demanda um comprometimento e uma carga de trabalho muito intensa do profissional, haja vista as inúmeras variáveis e situações caóticas que este pode encontrar em seu caminho.

Por serem freqüentes tomadores de decisão, e por estarem fortemente atrelados à integração e ao progresso das atividades, a grande responsabilidade pelo sucesso do projeto recai sempre sobre os ombros dos Gerentes de Projetos. Se o projeto for bem sucedido, não lhe faltarão louros pela vitória, porém se for um fracasso, o primeiro a ser culpado certamente será o gerente de projetos (e, caso não o seja, levará muito tempo para se justificar adequadamente).

De um modo geral, vê-se o Gerente de Projetos com muito mais responsabilidade do que autoridade dentro das empresas, principalmente dentro daquelas que não são orientadas a projetos. Este é um dos fatores que mais geram conflitos internos entre os envolvidos, principalmente com os Gerentes Funcionais, pois envolve alocação de recursos e eficiência técnica. Com organizações orientadas a projetos, a autoridade do Gerente de Projetos é maior e estes conflitos tendem a diminuir.

Outra constante na vida deste profissional é quando, por questões de insegurança e muitas vezes falta de comprometimento, a equipe de projetos e os demais profissionais envolvidos, deixam muitas decisões para que o Gerente de Projetos as tome. Mesmo assuntos banais ou assuntos que este não tem domínio ou mesmo conhecimento.

Existem também situações em que os problemas do projeto, quando ninguém mais consegue resolver, acabam caindo nos braços do gerente de projetos para que este tome uma decisão ou uma atitude a respeito. O Gerente de Projetos acaba se 
tornando um "super-herói", ou "santo", a quem todos recorrem quando não encontram a saída para determinados problemas, ou não se sentem seguros para tomar uma decisão.

O gerente deve estar sempre atento para que isto não se torne um vício dentro de sua equipe e dos demais profissionais envolvidos. O Gerente de Projeto deve incentivar as decisões entre os participantes, dentro de um certo nível e com a devida comunicação a sua pessoa. Caso contrário, o Gerente de Projetos deve sempre exigir que os envolvidos não tragam o problema de uma maneira "crua". Estes devem "mapear" o problema, e oferecer ao Gerente possíveis alternativas para a solução.

E, por fim, uma qualidade que o Gerente de Projetos precisa ter, inclusive para a sua própria saúde, é senso de humor. Haverá uma infinidade de problemas que ele terá que resolver, boa parte do seu planejamento não se concretizará de maneira ideal, a pressão da alta gerência é sempre muito alta, os resultados do projeto oscilam muito, etc. $\mathrm{O}$ número de profissionais que se deixam abater por estes problemas é muito grande. Até hoje, a melhor maneira de se evitar este estresse é utilizando-se do bom humor, fazendo piadas, buscando intervalos nos períodos críticos para dar uma caminhada, se auto renovar e em seguida voltar para procurar uma solução para os problemas. 


\subsection{Necessidades de se Gerenciar por Projetos}

Com o surgimento de atividades e projetos cada vez mais complexos, o crescimento de contratos para fornecimento do tipo "turn-key" (ou "chave na mão", onde o cliente recebe um sistema já totalmente integrado, testado e apto a operar, em geral por um preço pré-fixado), a procura pela satisfação dos clientes e a tendência para a formação de organizações mais flexíveis e dinâmicas, torna-se imprescindível a implantação de um novo formato de gerenciamento, com nova filosofia e novos postos nos organogramas das empresas.

Outras circunstâncias que requerem um gerenciamento diferenciado são aquelas em que se têm altos riscos técnicos ou circunstanciais (econômicos/políticos), ou ainda contratos que prevêem margem de lucro reduzida (em geral provocada pela competitividade do mercado).

Todos estes fatores fazem com que sejam necessários tratamentos e cuidados especiais aos negócios das empresas, o que só pode ser conseguido através de um gerenciamento específico e voltado aos projetos. É aí onde se encaixam o Gerenciamento de Projetos (conceito tradicional e exposto nos capítulos anteriores) e o Gerenciamento por Projetos (conceito mais abrangente para empresas com múltiplos projetos).

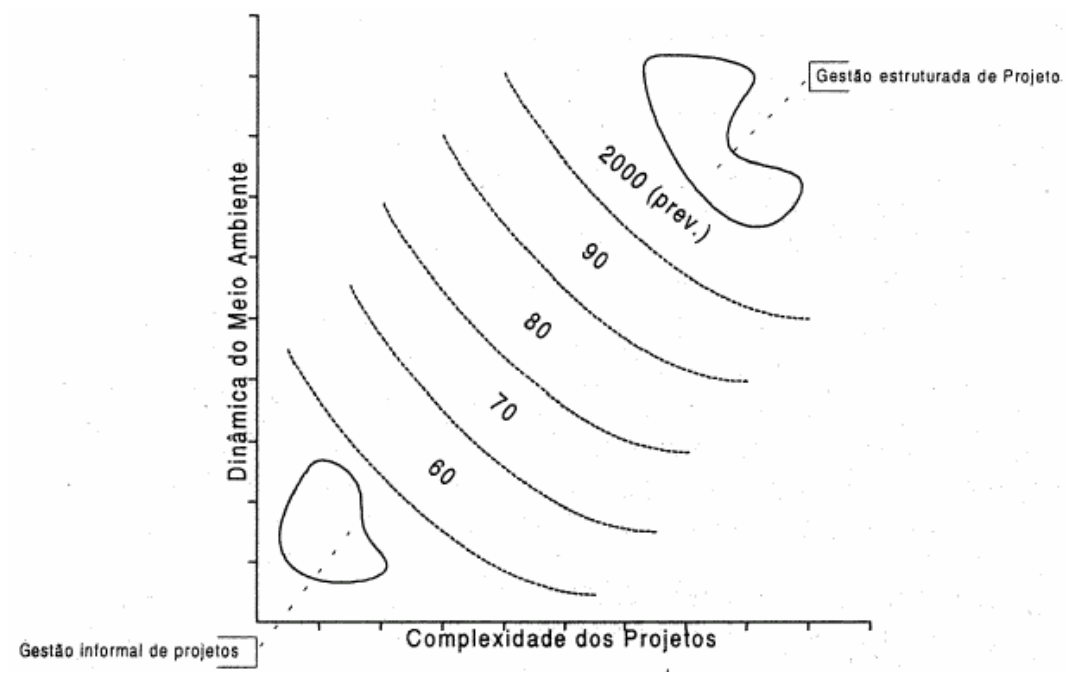

Figura 2.15 Complexidade e dinâmica dos projetos (Vargas, 2000) 
O gerenciamento de projetos influencia e pode muitas vezes transformar radicalmente a organização e a dinâmica interna de uma empresa. Toda a filosofia deve ser renovada de modo a contemplar as particularidades, impactos e benefícios deste tipo de gerenciamento. No entanto, toda esta mudança pode ser rapidamente alcançada se houver uma política adequada para que isto aconteça. Inúmeras empresas nos EUA conseguem se reestruturar em aproximadamente três anos, e algumas delas chegam a alcançar a excelência em gestão de projetos em até cinco anos (Kerzner, 2002).

Kerzner (2002) ressalta também que um dos fatores que fazem com que a Gestão de Projetos seja muito procurada pelas organizações é a sua maior capacidade de evidenciar os verdadeiros responsáveis pelos lucros e perdas (L\&P). Em organizações orientadas a projetos, a responsabilidade pelos lucros e perdas é tangível e bem definida, enquanto que em empresas não orientadas a projetos, esta responsabilidade pode ser uma área indistinta.

Esta característica contribui muito para o crescimento da empresa, uma vez que possibilita uma melhor detecção de problemas e proporciona um melhor retorno de experiência sobre as boas e más práticas adotadas pela empresa, ajudando a indicar os melhores caminhos e alterações necessárias.

Percebe-se também que os projetos, além da sua função original, são pontos estratégicos para uma empresa. Cohen; Graham (2000) explicitam muito bem o papel dos projetos no mecanismo estratégico e financeiro das empresas. A figura a seguir mostra um mapa genérico evidenciando em diversos pontos a influência do gerenciamento de projetos através de suas variáveis financeiras tradicionais (custo, prazo e resultado). Através dos blocos em destaque, obtém-se uma ampla visão das influências diretas e indiretas que o gerenciamento de projetos exerce sobre os pontos vitais de uma organização (contribuição para a estratégia e para a geração de valor econômico). 


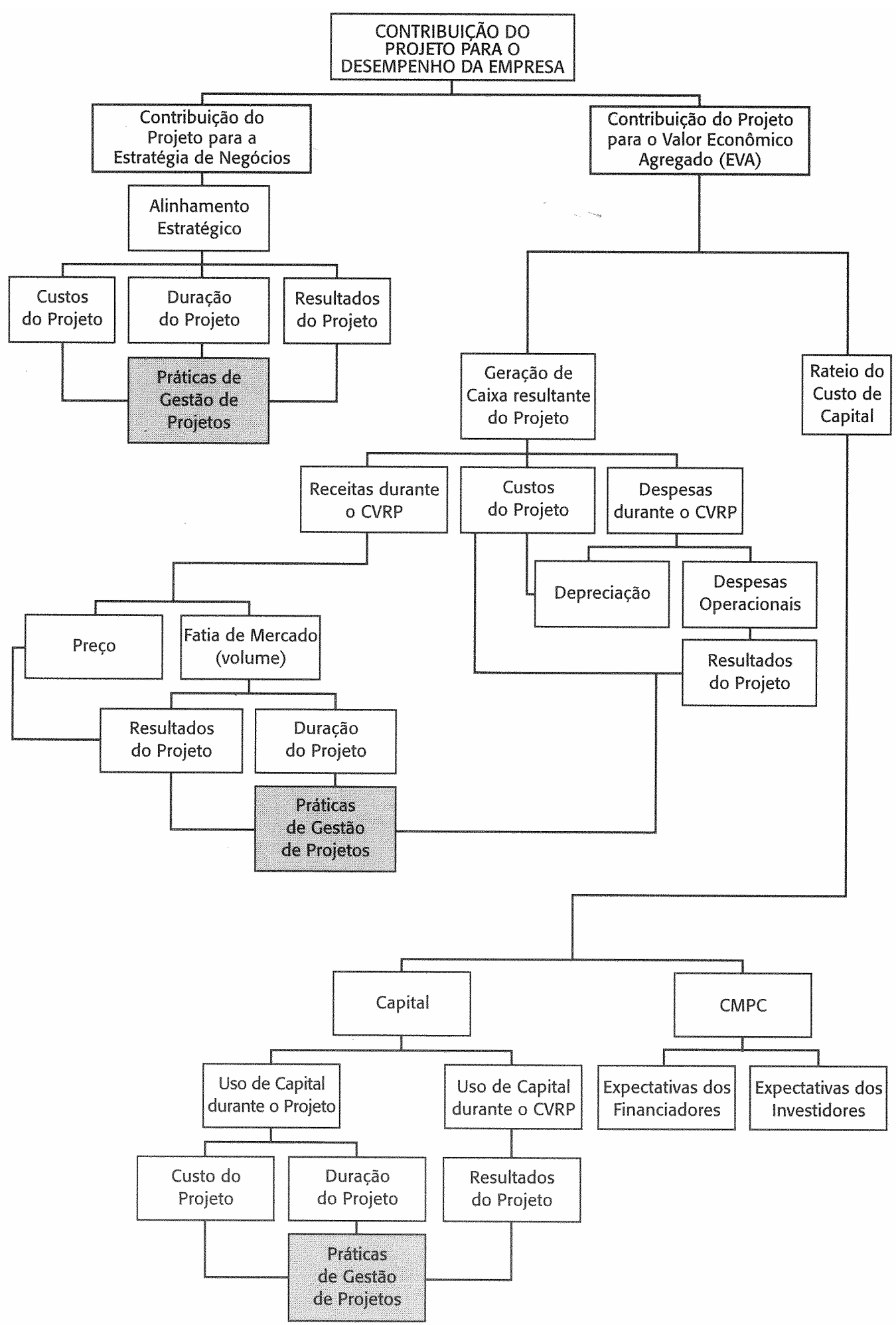

Figura 2.16 Influência dos projetos nos resultados (Cohen; Graham, 2001)

Em termos estratégicos, toda empresa busca vantagens competitivas no mercado para sobreviver. E deseja-se sempre que esta vantagem seja sustentável, ou seja, que 
supere a concorrência hoje, e consiga se manter vitoriosa no futuro. Para que isto aconteça é necessário que a alta gerência da empresa disponha de uma estratégia de sobrevivência, que servirá de guia para a sua atuação dentro do mercado e em relação aos concorrentes.

Esta estratégia deve indicar um conjunto de ações alinhadas e coordenadas que levará a empresa de onde está agora para onde pretende estar no futuro. Um dos resultados mais concretos de um planejamento estratégico é a composição de um portfólio de projetos para se por em prática as intenções da alta gerência. Os projetos serão os motores da mudança que viabilizarão a concretização da estratégia. Eles gerarão novos produtos e serviços, construirão novas fábricas, melhorarão a infraestrutura, desenvolverão novos processos, etc. Sendo assim, fica claro que todas as mudanças significativas a serem implementadas em uma organização, e oriundas de uma estratégia, geralmente assumem a forma de algum tipo de projeto (Cohen; Graham, 2002). E este projeto, para que seja bem sucedido, necessitará de um gerenciamento específico.

Deste modo um projeto não necessariamente tem como resultado um produto ou serviço para um cliente externo. Boa parte dos projetos tem objetivos internos às empresas. Em geral são projetos de reestruturação ou desenvolvimento que seguem uma estratégia e em geral buscam aumentar o valor econômico agregado destas empresas.

Todos estes aspectos reforçam as vantagens do Gerenciamento de Projetos e mostram a responsabilidade que Gerente de Projetos tem em suas costas, bem como o grau de capacitação que deve possuir.

Por fim, em face destas vantagens mencionadas, a maioria das empresas sentirá em breve a necessidade de ter profissionais com habilidades em Gestão de Projetos. Falta hoje, talvez, um amadurecimento maior, um efetivo retorno de experiências e a divulgação adequada dos resultados. 


\subsection{O Gerenciamento de Grandes e Complexos Projetos}

É natural se imaginar que quanto maior o projeto, maior a necessidade de um gerenciamento específico. Mas como se diferencia um projeto grande de um projeto pequeno?

A dimensão de um projeto é um conceito relativo. A expansão de uma refinaria de óleo custando 50 milhões de Reais pode ser um projeto relativamente pequeno em indústrias onde projetos de bilhões de Reais são comuns. Por outro lado, um projeto de desenvolvimento de software de 50 milhões de Reais poderia ser considerado muito grande.

Um fato inegável é que, em geral, empresas pequenas têm projetos pequenos e empresas grandes têm projetos grandes. Isto é intuitivo porque o tamanho e as capacidades da equipe de projeto, bem como os processos existentes nas empresas são apropriados para uma determinada faixa de magnitude de projetos. Quando um projeto é maior do que o nível de conforto em que uma empresa trabalha, conflitos e pressões aparecem e muitas vezes arruínam o andamento deste projeto. Logo, é de se esperar uma proporcionalidade natural entre o projeto e a empresa que o executa.

Existem, entretanto, alguns fatores de complexidade que acabam por multiplicar a magnitude dos projetos. Podem ser citados como fatores deste tipo, a diversidade cultural entre os envolvidos no projeto, o alto nível tecnológico agregado ao projeto, o alto grau de inovação, a composição do projeto por vários sub-projetos, muitas interfaces externas a serem integradas, prazos longos e susceptibilidades às alterações, entre outros.

Portanto, o tamanho de um projeto não deve estar relacionado apenas com seu custo, ou seu período de duração, mas sim com uma série de variáveis do contexto em que ele se encontra e com o esforço que vai requerer do(s) seu(s) gestor(es). Em outras palavras, a magnitude está intimamente ligada com a complexidade do projeto. 
Deste modo, à medida que a magnitude (em termos de custos, escopo e prazos) e a complexidade dos projetos crescem, crescem também os esforços de integração e controle, bem como os cuidados necessários por parte do Gerente de Projeto com relação ao progresso do mesmo. Como é fisicamente impossível para o Gerente de Projeto acompanhar tudo de perto, o seu trabalho como integrador, bem como as suas ferramentas de controle e gestão, passam a ser primordiais para o seu sucesso.

Este é o cenário em que se sobressaem as vantagens do Gerenciamento de Projetos. As técnicas que o compõem estão estruturadas de modo a possibilitar um maior controle e integração dos projetos. É por isso que, embora este tipo de gerenciamento possa ser utilizado em qualquer projeto, os que mais sentirão os seus benefícios são os grandes e complexos projetos, pois nestes, além da aplicabilidade, existe a real necessidade de um gerenciamento específico. 


\subsection{Próximos Passos do Gerenciamento de Projetos}

Assim como as demais técnicas e práticas de gestão, o Gerenciamento de Projetos está em constante transição. O que funcionou no passado pode não funcionar no futuro, principalmente devido às constantes mudanças no mundo dos negócios. Desde a década de 50, os três elementos principais do Gerenciamento de Projetos sempre foram: custo, prazo e qualidade. A inter-relação entre eles era direta e considerada pela grande maioria como critério de sucesso.

Hoje, a GP tem tomado um posicionamento mais comportamental. Procura-se ter uma visão do projeto como um sistema global, enfatizando inclusive os aspectos humanos da mesma maneira que os estruturais. A satisfação dos clientes (CRM) e dos demais envolvidos torna-se bastante relevante e isto leva à adição de mais um elemento na antiga tríade do sucesso: as Pessoas. Deste modo, tem-se que Custo, Prazo, Qualidade e as Pessoas passam a ser os elementos determinantes do sucesso ou fracasso de um projeto (Knudson; Bitz, 1991).

Atkinson (1999) também questiona o uso da tradicional tríade (custo, prazo, qualidade) como critério de sucesso. Este critério pode ser muito simplista e gerar distorções na avaliação de alguns projetos. Há que se levar em conta outros fatores e resultados que sofrem impactos com o desempenho dos projetos. Estes outros itens são de difícil quantificação e alguns deles até bastante subjetivos, mas sem dúvida nenhuma devem ser levados em consideração na avaliação final de um projeto. A Figura 2.17 apresenta uma proposta para critério de avaliação alternativo abrangendo estes novos itens.

Através deste critério alternativo confirma-se a tendência de que a gestão de projetos está adquirindo um enfoque mais global nas empresas e não apenas o de se coordenar um projeto específico e isolado. As ações e decisões tomadas no projeto acabam influenciando e sendo influenciadas por uma gama maior de variáveis, muitas delas sociais e organizacionais. 


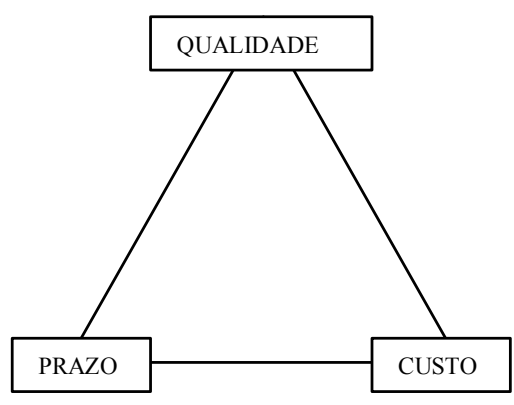

$\underline{\text { Critério Tradicional }}$

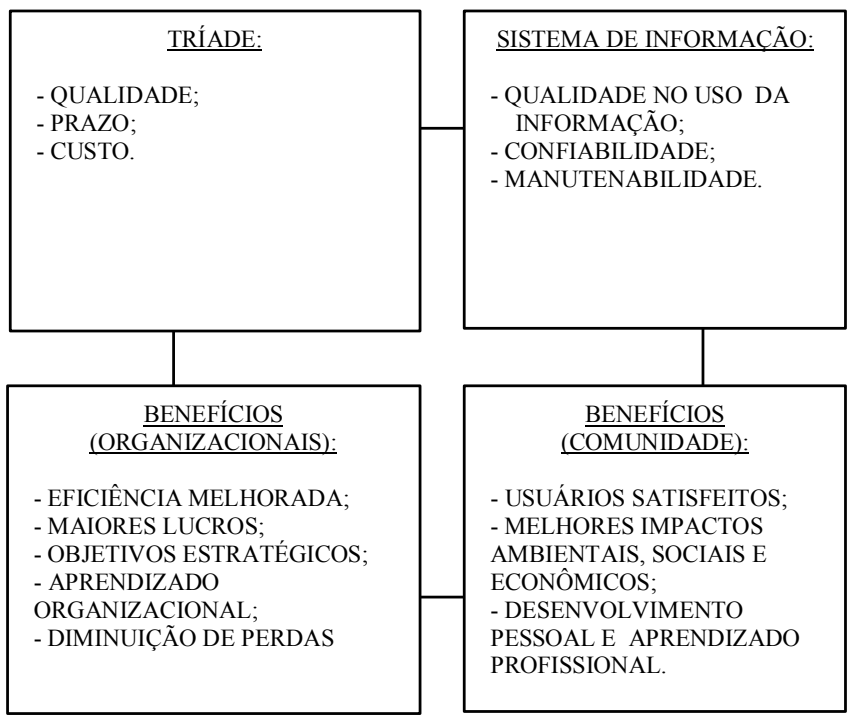

$\underline{\text { Critério Alternativo }}$

Figura 2.17 Critério alternativo para sucesso em projetos (Atkinson, 1999)

Além destas mudanças nos critérios de avaliação, a evolução da Gestão de Projetos também induzirá algumas mudanças no perfil do Gerente de Projetos e nas estruturas das empresas, principalmente devido à sua associação com outras filosofias e conceitos de organização como a Engenharia Simultânea, a Qualidade Total, etc.

Kerzner (2002) aponta a evolução da Gestão de Projetos desde a década de 60 nas duas figuras a seguir, e prevê que, em um breve futuro, o gerente de projetos será um catalisador das mudanças empresariais e dos projetos de melhoria da qualidade. $\mathrm{O}$ gerente de projetos passará a ter maiores contatos com as análises de mercado, avaliações econômicas e terá maior ciência quanto às metas da empresa e o contexto dos projetos nestas metas. Enfim, será um profissional que terá muito a contribuir com o planejamento estratégico das empresas e será peça fundamental à maioria dos fóruns e comitês de direção.

Há ainda quem associe o futuro da Gestão de Projetos ao caminho trilhado pelo movimento da Qualidade nos anos 80, que partiu do controle da qualidade (rejeição de peças fora das especificações), evoluiu para a garantia da qualidade (inspeção dos 
processos ao invés das peças) e finalmente chegou às várias formas de Gestão da Qualidade Total (gerenciamento de todas as partes da organização, visando a melhoria dos resultados). Analogamente, a Gestão de Projetos parte do gerenciamento de projetos isolados, evolui para uma gestão sobre múltiplos projetos e, por fim, atinge uma visão mais holística, originando a gestão empresarial por projetos.

\begin{tabular}{|c|c|c|c|c|}
\hline Período & $\begin{array}{l}\text { Nivel WBS no } \\
\text { qual os geren- } \\
\text { tes de projeto } \\
\text { executam }\end{array}$ & $\begin{array}{l}\text { Experiência } \\
\text { educacional } \\
\text { dos gerentes } \\
\text { de projeto }\end{array}$ & $\begin{array}{l}\text { Estrutura } \\
\text { organizacional }\end{array}$ & $\begin{array}{l}\text { Responsabilidade } \\
\text { final }\end{array}$ \\
\hline $\begin{array}{l}\text { Início dos } \\
\text { anos } 60\end{array}$ & $\begin{array}{c}\text { Níveis técnicos } \\
\text { da WBS }\end{array}$ & Engenharia & Tradicional & $\begin{array}{l}\text { Com os gerentes } \\
\text { de linha }\end{array}$ \\
\hline $\begin{array}{l}\text { Final dos } \\
\text { anos } 60\end{array}$ & $\begin{array}{c}\text { Níveis técnicos } \\
\text { da WBS }\end{array}$ & $\begin{array}{l}\text { A maioria, enge- } \\
\text { nharia; alguns, } \\
\text { negócios }\end{array}$ & Matriz forte & $\begin{array}{l}\text { Com os gerentes } \\
\text { de projetos }\end{array}$ \\
\hline $1970 / 1980$ & $\begin{array}{l}\text { Niveis de gerên- } \\
\text { cia da WBS }\end{array}$ & $\begin{array}{l}\text { A maioria, negó- } \\
\text { cios; alguns, } \\
\text { engenharia }\end{array}$ & Matriz fraca & $\begin{array}{l}\text { Parcialmente } \\
\text { compartilhada }\end{array}$ \\
\hline Década de 90 & $\begin{array}{l}\text { Niveis de gerên- } \\
\text { cia da WBS }\end{array}$ & $\begin{array}{l}\text { A maioria, negó- } \\
\text { cios; alguns, } \\
\text { engenharia }\end{array}$ & $\begin{array}{l}\text { Gestão de pro- } \\
\text { jetos SBU }\end{array}$ & $\begin{array}{l}\text { Totalmente } \\
\text { compartilhada }\end{array}$ \\
\hline
\end{tabular}

Figura 2.18 Processo de evolução da Gestão de Projetos (Kerzner, 2002)

\begin{tabular}{|c|c|c|c|}
\hline Fator & Visão anterior & Visão atual & Visão futura \\
\hline Definição de sucesso & $\begin{array}{l}\text { Exclusivamente em } \\
\text { termos técnicos }\end{array}$ & $\begin{array}{l}\text { Prazos, custos, tec- } \\
\text { nologia e aceitação } \\
\text { pelo cliente }\end{array}$ & $\begin{array}{l}\text { Prazos, custos, tecnolo- } \\
\text { gia e aceitação pelo } \\
\text { cliente; mudanças } \\
\text { mínimas de escopo; } \\
\text { não perturbar o de- } \\
\text { senvolvimento da } \\
\text { atividade empresarial }\end{array}$ \\
\hline $\begin{array}{l}\text { Experiência do } \\
\text { gerente de projetos }\end{array}$ & Técnica & $\begin{array}{l}\text { Técnica ou näo- } \\
\text { técnica }\end{array}$ & $\begin{array}{l}\text { Deverá ter um perfeito } \\
\text { entendimento do } \\
\text { ramo de negócios }\end{array}$ \\
\hline Organização & Equipes exclusivas & $\begin{array}{l}\text { Equipes de exclusi- } \\
\text { vidade parcial }\end{array}$ & Equipes não-exclusivas \\
\hline Autoridade & $\begin{array}{l}\text { O gerente de projetos } \\
\text { tem a máxima } \\
\text { autoridade }\end{array}$ & $\begin{array}{l}\text { Os gerentes de pro- } \\
\text { jeto e de área } \\
\text { compartilham a } \\
\text { autoridade }\end{array}$ & $\begin{array}{l}\text { Autoridade compartilha } \\
\text { da com delegação às } \\
\text { equipes }\end{array}$ \\
\hline Recursos humanos & $\begin{array}{l}\text { Negociar para ter os } \\
\text { melhores quadros }\end{array}$ & $\begin{array}{l}\text { Negociar para ter a } \\
\text { melhor equipe }\end{array}$ & $\begin{array}{l}\text { Negociar para a obten- } \\
\text { ção de resultados }\end{array}$ \\
\hline Montagem da equipe & $\begin{array}{l}\text { Sessões de sensibi- } \\
\text { lização }\end{array}$ & $\begin{array}{l}\text { Curriculo especiali- } \\
\text { zado }\end{array}$ & $\begin{array}{l}\text { Treinamento visando à } \\
\text { certificação e aper- } \\
\text { feiçoamento do } \\
\text { curriculo }\end{array}$ \\
\hline
\end{tabular}

Figura 2.19 Tempos de mudança na Gestão de Projetos (Kerzner, 2002) 


\section{TÓPICOS SOBRE A ANÁLISE DE VALOR AGREGADO}

A Análise de Valor Agregado (ou Earned Value Analysis - EVA) é comumente apontada como uma das mais importantes e poderosas técnicas de controle dentro do Gerenciamento de Projetos.

Existe uma quantidade muito grande de projetos que são finalizados com atrasos e sobre-custos, ou nem são finalizados (em geral, pelos mesmos motivos). E uma alegação freqüente por parte dos gestores é a de que estes só conseguem perceber a real magnitude de tais problemas em estágios já avançados de progresso, onde na maioria das vezes já não se consegue tomar ações corretivas em tempo de evitar desastres ao projeto. A importância e o poder da AVA advém do fato de que ela pode oferecer diagnósticos precisos e completos em qualquer fase do projeto, o que certamente tem ajudado inúmeros gestores a lidar com os problemas acima citados.

Embora esteja enraizada dentro da área de Gerenciamento de Custos, ela sofre ou exerce influência em quase todas as áreas do GP, uma vez que seu princípio se baseia na inter-relação entre custos, prazos e escopo (elementos que figuram em todas as áreas de atuação do Gerente de Projetos).

No início da década de 90, a Análise de Valor Agregado ressurgiu no ambiente administrativo com força total, juntamente com o Gerenciamento de Projetos e, desde então, muitos estudos vem sendo realizados a respeito desta técnica, o que indica que a mesma permanecerá por um bom tempo em voga nos meios acadêmicos e profissionais.

Välimäki (1995), Flemming; Koppelman (2000) e outros autores advogam que a verdadeira Gestão de Projetos obrigatoriamente deve ter em seu âmago os princípios do Valor Agregado, pois este é o meio mais eficiente de se ter controle e visualização sobre o progresso dos projetos. Deste modo, torna-se válida a apresentação desta técnica e das suas principais características. 


\subsection{O que é Análise de Valor Agregado?}

A Análise de Valor Agregado é uma técnica para controle de projetos que integra custos, prazos e progresso físico e que surgiu no "chão de fábrica" dos EUA, no princípio da "Administração Científica" (início do século XX). Seu conceito básico é muito simples: trata-se da avaliação sobre o que foi obtido (valor agregado) em relação ao que foi realmente gasto e ao que se planejava gastar (Vargas, 2002).

Este conceito difere um pouco da prática genérica que se encontra nas empresas. Normalmente, o que se encontra é uma simples comparação entre o que foi gasto e o que se planejava gastar, sem levar em consideração ou sem explicitar o quanto foi efetivamente produzido ou realizado. Esta análise não é completa, mas pode ser suficiente quando, por exemplo, se tem produção em série de um produto, onde os processos já são bem conhecidos e controlados, não há interferências externas ou ainda quando se tem pleno domínio e visão sobre todo o conjunto (projetos pequenos e simples). Entretanto, na medida em que a complexidade do que está sendo controlado aumenta, surge a necessidade de se avaliar também o efetivo valor que foi agregado sobre a produção ou serviço.

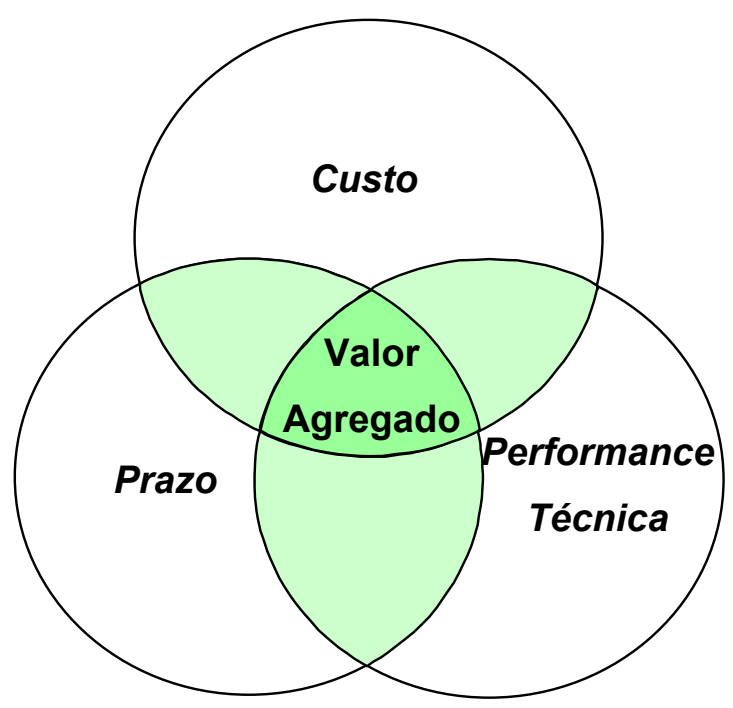

Figura 3.1 Variáveis intrínsecas da Análise de Valor Agregado 
O conceito da Análise de Valor Agregado é bastante simples, porém só passou a ser utilizado de maneira formal, e padronizada, a partir da década de 60 , pela força aérea americana.

Com a constatação de que a análise de Valor Agregado era perfeitamente aplicável a empreendimentos não repetitivos e com duração específica, a mesma passou a integrar o conjunto de técnicas e idéias que formam o Gerenciamento de Projetos e, desde então, o conceito vem sendo adaptado para ser utilizado de uma forma mais simples e imediata nos projetos modernos (Flemming; Koppelman, 2000). 


\subsection{Os Principais Parâmetros da Análise de Valor Agregado}

A Figura 3.2 abaixo mostra os principais parâmetros da Análise de Valor Agregado. Serão preservadas as nomenclaturas originais em inglês por facilitar a associação com outros estudos e com as literaturas existentes.

- BAC - Budget at Completion (Valor Total do Orçamento)

- BCWS - Budgeted Cost of Work Scheduled (Custo Orçado do Trabalho Planejado - também conhecido como Valor Planejado)

- ACWP - Actual Cost of Work Performed (Custo Real do Trabalho Realizado)

- EAC - Estimate at Completion (Valor Total Estimado para os Custos Finais do Projeto)

- BCWP - Budgeted Cost of Work Performed (Custo Orçado do Trabalho Realizado - também conhecido como Valor Agregado)

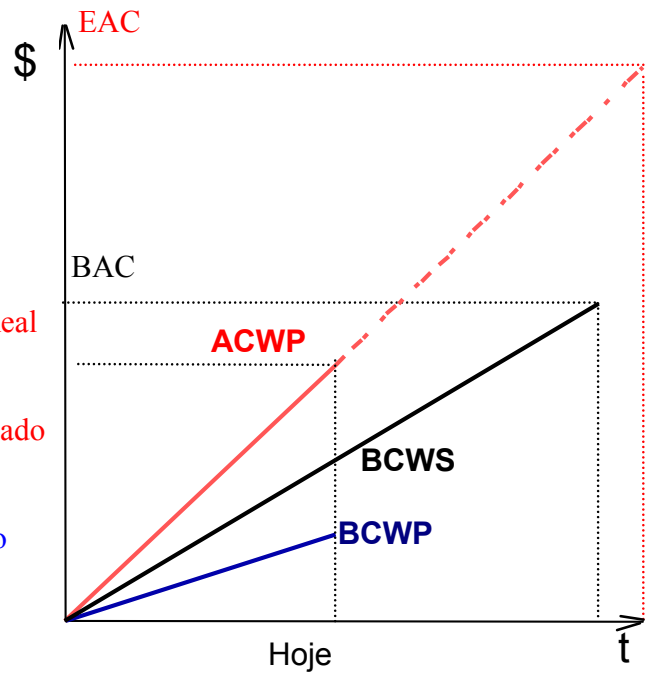

Figura 3.2 Parâmetros básicos para Análise de Valor Agregado

Os parâmetros acima mencionados e que formam os pilares do conceito, têm suas nomenclaturas oriundas de um critério elaborado pelo Departamento de Defesa Americano (DoD - Department of Defense). Este critério chamado de C/SCSC (Cost/Schedule Control Systems Criteria) era formado por um conjunto de 35 regras que incluíam o conceito de valor agregado, balizavam o controle dos projetos e regiam a apresentação dos respectivos relatórios e resultados.

$\mathrm{Na}$ época de sua criação, o $\mathrm{C} / \mathrm{SCSC}$ se tornou obrigatório para todos os contratos e projetos das forças armadas americanas. Isto, por um lado, ajudou a difundir o conceito de valor agregado, mas por outro lado, a sua imposição, aliada à grande burocracia gerada, acabou estigmatizando o seu uso e fazendo com que o critério fosse visto como um mero meio de se reportar ao cliente e não como uma ferramenta realmente útil para o controle dos projetos (Flemming; Koppelman, 2000). 
Com estes parâmetros, e alguns pequenos cálculos, pode-se obter uma série de informações sobre o projeto: a sua situação atual, o seu histórico e também projeções futuras sobre custos e prazos. E uma das melhores maneiras de se interpretar estas informações é através de gráficos conforme exemplificado na figura a seguir.

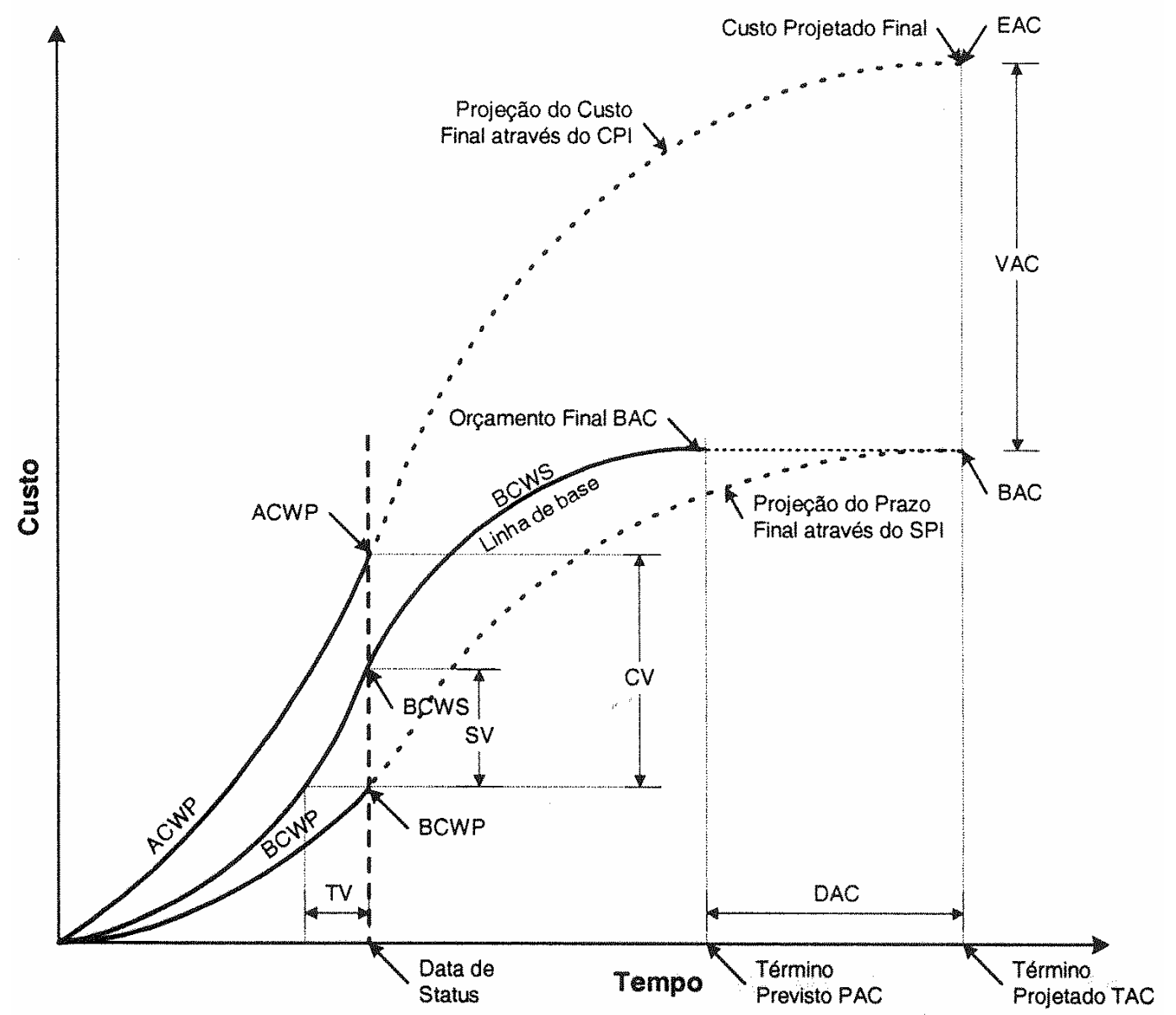

Figura 3.3 Gráfico para Análise de Valor Agregado (Vargas, 2002)

Na figura 3.3 temos a curva referente à linha de base do orçamento (BCWS) que percorre todo o período planejado do projeto, a curva dos custos reais incorridos (ACWP) e a curva do valor que foi agregado até uma determinada data (BCWP). Em um caso ideal, a curva de custos reais (ACWP) e a curva de valor agregado (BCWP) deveriam se sobrepor exatamente à curva do orçamento. Isto representaria um desempenho, de custos e prazos, 100\% igual ao planejado para o projeto. Sabendo, entretanto, que isto é muito difícil de ocorrer na realidade, a idéia é que se considere 
sempre a curva do orçamento (BCWS) como uma referência e um objetivo a ser perseguido, tanto em termos de custos como de prazos.

A análise crítica sobre o progresso e desempenho do projeto é possível através das correlações entre os parâmetros citados, ao longo do período do projeto. As principais correlações, também definidas no critério do DoD (C/SCSC), são apresentadas a seguir:

- CV (cost variance ou variação nos custos): é a diferença entre o valor que foi fisicamente agregado (BCWP) e o custo real do projeto (ACWP), até uma determinada data. Se CV for positiva, a atividade estará com custo abaixo do valor previsto; se for negativa, a atividade terá ultrapassado o orçamento, até a referida data.

$$
\mathrm{CV}=\mathrm{BCWP}-\mathrm{ACWP}
$$

- SV (schedule variance ou variação no cronograma): é a diferença, em termos de custo, entre o Valor Agregado (BCWP) e o valor planejado (BCWS). Se SV for positiva, o projeto está adiantado; se for negativa, o projeto está atrasado.

$$
\mathrm{SV}=\mathrm{BCWP}-\mathrm{BCWS}
$$

- TV (time variance ou variação no tempo): é a diferença, em termos de tempo, entre o Valor Agregado (BCWP) e o valor planejado (BCWS). É encontrado graficamente pela projeção da curva de BCWP, encontrando a data em que o BCWS agrega o mesmo valor de BCWP. A diferença entre a data de referência e a data em que BCWS agrega o mesmo valor que BCWP representa o atraso ou adiantamento do projeto.

- VAC (Variation at Completion ou Variação Final dos Custos): é a diferença entre o custo orçado (BAC - Budget at completion) e o custo projetado final (EAC - Estimated at completion).

$$
\mathrm{VAC}=\mathrm{BAC}-\mathrm{EAC}
$$


- DAC (Delay at Completion ou Variação Final dos Prazos): é a diferença entre o Término Projetado (TAC - Time at Completion) do projeto e o Término Previsto Originalmente (PAC - Planned at Completion).

$$
\mathrm{DAC}=\mathrm{TAC}-\mathrm{PAC}
$$

- SPI (schedule performance index ou índice de performance de cronograma): é a relação entre o Valor Agregado (BCWP) e o valor planejado (BCWS) em uma determinada data. O SPI mostra a taxa de conversão do valor previsto em valor agregado até a referida data.

$$
\mathrm{SPI}=\frac{\mathrm{BCWP}}{\mathrm{BCWS}}
$$

Como exemplo, temos que um SPI $=0,80$ indica que $80 \%$ do tempo previsto no orçamento foi convertido em trabalho. Isto resulta em uma perda de $20 \%$ no tempo disponível.

Resumindo podemos generalizar que um SPI igual a 1 indica que o valor planejado foi integralmente agregado ao projeto. Se o SPI for menor que 1, o projeto está atrasado. Se o SPI é superior a 1, o projeto está adiantado.

- CPI (cost performance index ou índice de performance de custo): é a relação entre o valor agregado (BCWP) e o custo real do projeto (ACWP). O CPI mostra a taxa entre os valores reais consumidos e os valores agregados no mesmo período

$$
\mathrm{CPI}=\frac{\mathrm{BCWP}}{\mathrm{ACWP}}
$$

Como exemplo, temos que um CPI $=0,80$ indica que para $\$ 1$ de capital consumido, apenas $\$ 0,80$ estão sendo convertidos fisicamente em produto. A perda, portanto, é de $\$ 0,20$ por $\$ 1$ gasto.

Analogamente ao SPI, um CPI igual a 1 indica que o valor gasto pelo projeto foi integralmente agregado ao projeto (o projeto está dentro do orçamento previsto). Se o CPI for menor que 1 , o projeto está gastando mais do que o previsto (provavelmente haverá sobre-custo ao final do projeto). Se o CPI é superior a 1, o projeto está custando abaixo do orçamento previsto. 


\subsection{Projeções Futuras Através da Análise de Valor Agregado}

Uma das principais vantagens no uso da Análise de Valor Agregado é poder calcular o desempenho do projeto durante o seu decorrer e, a partir disto, traçar projeções e estimativas quanto aos prazos e custos futuros. Quanto mais fiéis e realistas forem as medições e quanto mais "calibrado" estiver o modelo de controle, melhores serão as projeções e melhores serão as chances do Gerente de Projetos tomar ações com antecedência no intuito de tentar recuperar atrasos ou sobre-custos.

Através dos parâmetros da Análise de Valor Agregado existem várias maneiras e fórmulas de se estimar custos futuros em um projeto. Dentre elas, podemos encontrar na literatura projeções baseadas em regressões (lineares e não-lineares), em heurísticas, e em índices de desempenho (basicamente CPI e SPI). Esta última certamente sendo a mais simples e mais praticada entre os Gerentes de Projeto.

Christensen (1995), no intuito de analisar estes diferentes tipos de estimativas, compilou e analisou 25 trabalhos de pesquisa, elaborados por vários autores e que apresentavam resultados sobre algum tipo de estimativa. Christensen concluiu que com relação às estimativas através de regressões ou heurísticas, a gama de estudos e amostragem existentes ainda é pequena para que se tenha uma análise conclusiva. Por outro lado, em relação às fórmulas baseadas em índices, percebe-se que estas podem ser bastante precisas, porém dependem do tipo de projeto, do seu estágio de progresso e da experiência dos gestores nas suas aplicações.

Em face destes dados, serão apresentadas aqui apenas as fórmulas baseadas em índices de desempenho. Estas fórmulas se utilizam basicamente de dois índices já apresentados no capítulo 3.1, o Índice de Desempenho de Custos (CPI) e o Índice de Desempenho de Cronograma (SPI), os quais podem ser utilizados independentemente ou em conjunto. A premissa utilizada é a de que o desempenho da empresa nas atividades futuras do projeto tende a ser o mesmo daquele conseguido até a presente data (Flemming; Koppelman, 2000). 
De um modo geral a previsão de prazos e custos futuros se dá baseada nas seguintes fórmulas:

- Para estimativa de prazos:

$$
\begin{gathered}
\text { Duração Projetada }=\frac{\text { Duração Prevista Originalmente }}{\text { Índice de desempenho de prazos }} \\
\text { ou } \\
\text { TAC }=\frac{\text { PAC }}{\text { SPI }}
\end{gathered}
$$

Onde:

- PAC (Plan at Completion) = Duração prevista para o projeto

- $\mathrm{TAC}$ (Time at Completion $)=$ Duração projetada para o projeto

- Para estimativa de custos:

$$
\begin{gathered}
\text { Custo estimado final }=\text { Custo incorrido atual }+\frac{(\text { Trabalho restante })}{\text { Indice de desempenho }} \\
\qquad \mathrm{ou} \\
\mathrm{EAC}=\mathrm{ACWP}+\frac{(\mathrm{BAC}-\mathrm{BCWP})}{\mathrm{PI}}
\end{gathered}
$$

Onde PI representa um Índice de Desempenho (Performance Index) e que pode ser substituído pelos seguintes Índices:

1) $\mathrm{CPI}$

2) SPI

3) $\mathrm{SCI}=$ SPI x CPI (SCI $=$ Schedule Cost Index ou Índice Composto de Custo e Prazo)

4) $\mathrm{w}_{1} \times \mathrm{SPI}+\mathrm{w}_{2} \times \mathrm{SPI}$, onde $\mathrm{w}_{1}+\mathrm{w}_{2}=1$ (Índice Balanceado de Custo e Prazo). Os valores para $\mathrm{w}_{1}\left(\mathrm{e}\right.$, por conseguinte $\mathrm{w}_{2}$ ) são definidos pelo Gerente de Projetos (tipicamente $\mathrm{w} 1=0.25,0.50$ ou 0.75$)$.

Resta ao Gerente de Projeto escolher, dentre os índices acima, o que julgar mais adequado ao cálculo que deseja realizar. Os índices CPI e SPI podem ainda ser 
obtidos de diversas formas, variando-se o período de medição e amostragem. A tabela a seguir resume as variantes mais utilizadas.

\begin{tabular}{|c|c|c|}
\hline Tipo de Índice & Descrição & Simbologia / Fórmula \\
\hline $\begin{array}{c}\text { Índice } \\
\text { Acumulado }\end{array}$ & $\begin{array}{c}\text { Utiliza os valores de BCWS, BCWP e ACWP } \\
\text { acumulados até o momento, independentemente dos } \\
\text { valores intermediários }\end{array}$ & $\begin{array}{l}\mathrm{CPI}_{\mathrm{C}}=\frac{\mathrm{BCWP}_{\mathrm{C}}}{\mathrm{ACWP}_{\mathrm{C}}} \\
\mathrm{SPI}_{\mathrm{C}}=\frac{\mathrm{BCWP}_{\mathrm{C}}}{\mathrm{BCWS}_{\mathrm{C}}}\end{array}$ \\
\hline $\begin{array}{c}\text { Índice Mais } \\
\text { Recente }\end{array}$ & $\begin{array}{l}\text { Utiliza os valores de BCWS, BCWP e ACWP do } \\
\text { último período (em geral último mês ou semana), } \\
\text { independentemente dos períodos prévios }\end{array}$ & $\begin{aligned} \mathrm{CPI}_{\mathrm{M}} & =\frac{\mathrm{BCWP}_{\mathrm{M}}}{\mathrm{ACWP}_{\mathrm{M}}} \\
\mathrm{SPI}_{\mathrm{M}} & =\frac{\mathrm{BCWP}_{\mathrm{M}}}{\mathrm{BCWS}_{\mathrm{M}}}\end{aligned}$ \\
\hline Índice Médio A & $\begin{array}{l}\text { Utiliza como base de cálculo a divisão dos somatórios } \\
\text { de BCWS, BCWP e ACWP nos ciclos de medição } \\
\text { (em geral avaliados mensalmente ou semanalmente) }\end{array}$ & $\begin{aligned} \mathrm{CPI}_{\mathrm{x}} & =\frac{\sum \mathrm{BCWP}_{\mathrm{x}}}{\sum \mathrm{ACWP}_{\mathrm{x}}} \\
\mathrm{SPI}_{\mathrm{x}} & =\frac{\sum \mathrm{BCWP}_{\mathrm{x}}}{\sum \mathrm{BCWS}_{\mathrm{x}}}\end{aligned}$ \\
\hline Índice Médio B & $\begin{array}{l}\text { É determinado através do valor médio dos últimos } \\
\text { CPI e SPIs determinados nos últimos ciclos de } \\
\text { medição (em geral avaliados mensalmente ou } \\
\text { semanalmente) }\end{array}$ & $\begin{aligned} \mathrm{CPI}_{\mathrm{X}} & =\frac{\sum \mathrm{CPI}_{\mathrm{M}}}{\mathrm{X}} \\
\mathrm{SPI}_{\mathrm{X}} & =\frac{\sum \mathrm{SPI}_{\mathrm{M}}}{\mathrm{X}}\end{aligned}$ \\
\hline
\end{tabular}

Figura 3.4 Tipos de CPI e SPI para previsões de desempenho (Vargas, 2002)

Com relação ao índice CPI, Christensen (1996) ressalta um fato que é extremamente duro para os Gerentes de Projeto com relação a projeções futuras: o Departamento de Defesa (DoD) americano realizou uma pesquisa com centenas projetos de sua responsabilidade e chegou às seguintes conclusões:

- Após o projeto atingir $20 \%$ de sua execução o seu índice CPI acumulado $\left(\mathrm{CPI}_{\mathrm{c}}\right)$ não variará mais do que $10 \%$ até o fim do projeto, e a grande probabilidade é de que esta variação seja para pior;

- Se o projeto atinge $20 \%$ de execução com um índice CPI acumulado menor do que 0,91 ( $10 \%$ de sobre-custo), a probabilidade de o projeto ultrapassar o seu orçamento final é extremamente alta. 
Estas constatações indicam que existe uma estabilidade do índice CPI a partir de $20 \%$ de execução do projeto. O Departamento de Defesa (DoD) americano é tão confiante quanto ao comportamento e ao uso do CPI como um índice para projeções que, em 1991, incluiu um requisito na política de contratos do governo que impõe a necessidade de justificativas caso algum Gerente de Projetos obtenha qualquer previsão de custos futuros menor do que os custos calculados pela formula do CPI (Flemming; Koppelman, 1999). Em outras palavras, o DoD considera a fórmula do CPI como um patamar mínimo para as estimativas de custos futuros. Qualquer valor menor que este deve ser devidamente justificado.

Christensen (1996) confirma que é uma boa prática considerar o cálculo através do CPI como patamar mínimo para as estimativas. Ele também verificou que a gama de profissionais que não apresenta estimativas precisas é muito grande. Em geral as estimativas estão muito abaixo dos valores encontrados por cálculos utilizando a fórmula de CPI, e o fato de alguns gestores ignorarem os valores calculados através do CPI pode estar relacionado tanto ao excesso de otimismo ou inexperiência em projetos, como também ao receio destes em apresentar resultados adversos, preferindo postergar as "más notícias".

Vargas (2002) compilou estudos de uma série pesquisas que procuravam comparar projeções de custos finais, em projetos americanos, calculadas por meio de diversos índices (apresentados na Figura 3.4). As conclusões foram de que ainda não há um consenso quanto ao melhor índice a ser utilizado, pois existe uma forte relação com o estágio em que o projeto se encontra, e é difícil se correlacionar projetos de diferentes naturezas e que são susceptíveis a ações externas variadas. Cabe novamente ao Gerente de Projetos, através da sua experiência e de uma análise do projeto em questão, escolher o índice mais aplicável. Talvez com o aparecimento de mais pesquisas a respeito, principalmente em contratos não governamentais, possam ser estabelecidos critérios racionais e genéricos para a escolha destes índices. 


\subsection{Levantamento da Linha Base de Orçamento (baseline)}

A confecção da linha base de orçamento é uma das tarefas mais importantes, e mais difíceis, a serem executadas pelo Gerente de Projetos. Basicamente é a distribuição, ao longo do tempo, de todas as atividades do projeto, bem como dos seus respectivos custos e durações.

O Gerente de Projetos deve ter em mente que esta é a curva que servirá de referência para a avaliação e controle do progresso e para estimativas futuras do projeto. Sendo assim, esta curva deve ser muito bem determinada, e representar com a máxima fidelidade o planejamento de todas as atividades do projeto. Sem isto a Análise de Valor Agregado fica muito prejudicada, pois esta depende exclusivamente da comparação entre os progressos físicos e financeiros com a linha de base, ou seja, com o orçamento planejado. Obviamente, uma má correlação entre as informações do planejamento e da AVA causará um enorme transtorno em termos de controle, e possivelmente a perda de todo um esforço despendido para tal.

O pré-requisito para o início da confecção desta curva é possuir um WBS contemplando todas as atividades do projeto e a programação destas ao longo do período do projeto (cronograma).

A partir disto, o Gerente de Projetos deve, com o auxílio dos demais Gerentes Funcionais, estabelecer os recursos necessários para cada atividade e vincular os custos a cada atividade. Para esta "orçamentação" existem várias técnicas à disposição dos envolvidos, dentre as quais destacam-se a utilização de dados históricos e simulações estatísticas (Duncan, 1996). É na “orçamentação" em que ocorre a transformação dos eventos físicos em uma unidade passível de comparação (em geral unidade monetária), a qual possibilitará análises futuras em relação aos custos reais despendidos no projeto.

Só isto já seria suficiente para que se criasse a curva de orçamento (BCWS). No entanto, em geral o WBS possui um nível de detalhamento alto, o que exigiria um 
esforço gerencial muito grande para controle do projeto. O que se faz, portanto, é criar células de controle (CAP - Control Account Plans) que agregam uma série de atividades correlatas e que serão controladas como um todo, proporcionando praticidade e economia de esforços. Cada CAP deve conter um escopo do trabalho, prazo para sua realização, suas interdependências com outros CAPs, recursos alocados e orçamento e, por fim, um responsável pelo seu monitoramento.

A quantidade ideal de células de controle (CAPs) e a quantidade de atividades que cada uma conterá farão parte de um compromisso entre viabilidade/capacidade de controle e precisão dos resultados. Quanto mais células e atividades definidas, maiores os esforços necessários para controle e administração destes, por outro lado, maior será a precisão dos resultados, e vice versa. Cabe ao Gerente de Projetos definir uma proporção adequada, levando em consideração a sua experiência, o orçamento disponível para gerenciar o projeto e os níveis de complexidade e risco envolvidos.

Nesta fase define-se também a métrica que será utilizada para avaliar o progresso de cada atividade, a qual também é muito importante para o sucesso da técnica (Flemming; Koppelman, 2000):

Uma vez definidas as células de controle (CAPs), os seus respectivos orçamentos e suas alocações no cronograma geral do projeto, resta apenas dispô-los graficamente, ou seja, levantar a Linha Base de Orçamento (ou BCWS).

A curva BCWS reflete o valor acumulado planejado dos esforços e recursos ao longo do projeto. Isto permite também a visualização do quão homogêneo é este planejamento, se há picos de alocação e em que fases estão os maiores gradientes de custos e uso destes recursos. 
Segue abaixo (Figura 3.5) um resumo dos passos necessários para a confecção da Curva de Orçamento (BCWS).

1) Definição do escopo do projeto - WBS;

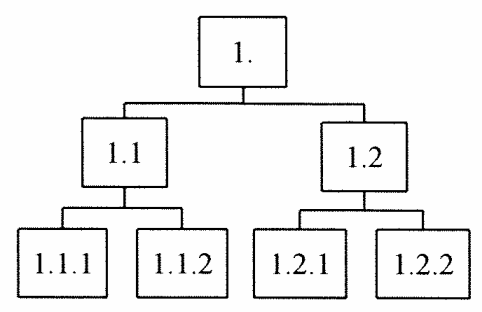

2) Planejamento e programação das atividades (cronograma/ gráfico GANTT/ diagrama PERT);

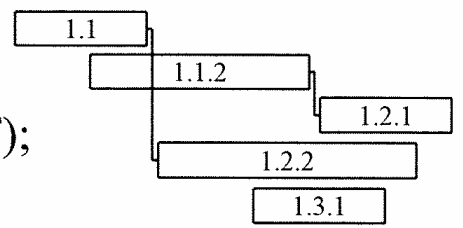

3) Alocação de recursos e definição das células de controle;

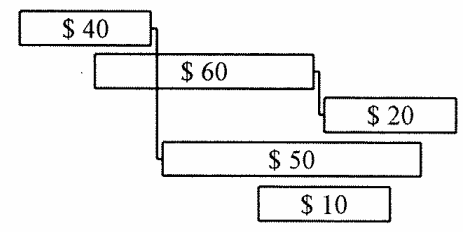

4) Confecção da linha de base do projeto baseline (BCWS).

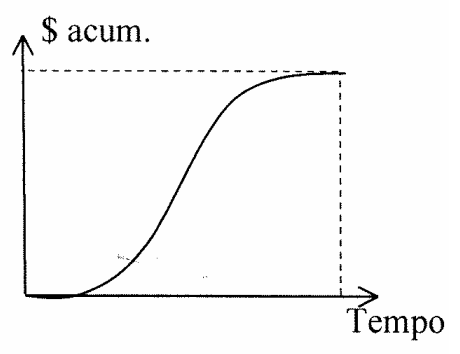

Figura 3.5 Passos para a criação da linha de base (Flemming; Koppelman, 2000)

A confecção da linha de base é uma das atividades mais demoradas e custosas da AVA, mas, por ser uma das mais importantes, não deve ser alvo de "economias" por parte do Gerente de Projetos. Os benefícios de uma boa referência para o controle do projeto certamente compensarão estes esforços e custos iniciais. Isso sem falar na integração proporcionada aos envolvidos, uma vez que estes precisarão interagir entre si para poder fornecer as informações necessárias à sua confecção. 


\subsection{Exemplo Quantitativo da Análise de Valor Agregado}

Para melhor ilustração sobre o funcionamento da Análise de Valor Agregado, será apresentado aqui um exemplo de aplicação desde o início do projeto, ou seja, desde a confecção do WBS. Obviamente este exemplo tem cunho apenas didático e visa ilustrar os conceitos ora apresentados, de uma maneira quantitativa.

- Projeto: Construção de um muro de contenção de concreto

- Características básicas:

- Comprimento: $20 \mathrm{~m}$

- Altura: $5 \mathrm{~m}$

- Espessura: 0,4 m

- Orçamento disponível (BAC): $\$ 25.000$

- Prazo para construção (PAC): 21 dias

A equipe de projeto então define um WBS para o projeto conforme abaixo:

\begin{tabular}{|c|c|}
\hline WBS & \\
\hline 1.0 Muro completo & \\
\hline |------ 1.1 Adequação do & terreno \\
\hline & ----1.1.Retirada de entulho; \\
\hline & 1.1.2.Terraplanagem/Nivelamento; \\
\hline |------ 1.2. Execução do I & Projeto \\
\hline & 1.2.1.Execução dos cálculos estruturais; \\
\hline & -----2.2.Cálculo da quantidade de concreto e aço necessários; \\
\hline & 1.2.3.Desenhos e documentações de projeto executivo; \\
\hline |------- 1.3. Aprovisionam & nento \\
\hline & --- 1.3.1.Compra dos materiais de suporte (aço e madeira); \\
\hline & ---1.3.2.Contratação do caminhão concreteiro; \\
\hline |----- 1.4. Execução da & Obra \\
\hline & 1.4.1.Montagem dos suportes; \\
\hline 1 & |---o- 1.4.1.1.Corte do aço e das madeiras; \\
\hline 1 & |--------- 1.4.1.2.Soldagem e rebitagem dos suportes; \\
\hline & 1.4.2.Descarregamento do concreto; \\
\hline & -------- 1.4.3.Prazo para cura; \\
\hline & 1.4.4.Desmontagem dos suportes; \\
\hline & ------- 1.4.5.Acabamento. \\
\hline
\end{tabular}

Figura 3.6 WBS (exemplo quantitativo) 
Depois de definido o WBS, a equipe estima o custo de cada atividade e a sua duração, através de dados históricos.

\begin{tabular}{|c|c|c|}
\hline WBS & Custo (\$) & Duração \\
\hline \multicolumn{3}{|l|}{ 1.0 Muro completo } \\
\hline \multicolumn{3}{|l|}{ |--------- 1.1 Adequação do terreno } \\
\hline |-------- 1.1.1.Retirada de entulho; & 2400 & 5 dias \\
\hline (1.2.Terraplanagem/Nivelamento; & 1000 & 3 dias \\
\hline \multicolumn{3}{|l|}{ |-1.2. Execução do Projeto } \\
\hline |-osecução dos cálculos estruturais; & 3200 & 5 dias \\
\hline 1.2.2.Cálculo da quantidade de concreto e aço necessários; & 1200 & 2 dias \\
\hline 1.2.3.Desenhos e documentações de projeto executivo; & 2500 & 5 dias \\
\hline \multicolumn{3}{|l|}{ |---о-о 1.3. Aprovisionamento } \\
\hline |--ora 1.3.1.Compra dos materiais de suporte (aço e madeira); & 4000 & 2 dias \\
\hline |-1.3.2.Contratação do caminhão concreteiro; & 4000 & 2 dias \\
\hline \multicolumn{3}{|l|}{ |------- 1.4. Execução da Obra } \\
\hline |---1.4.1.Montagem dos suportes; & & \\
\hline | & 2400 & 2 dias \\
\hline | $\quad$ |----- 1.4.1.2.Soldagem e rebitagem dos suportes; & 1900 & 4 dias \\
\hline 1.4.2.Descarregamento do concreto; & 660 & 1 dia \\
\hline |-Prazo para cura; & 300 & 1 dia \\
\hline |-1.4.4.Desmontagem dos suportes; & 960 & 2 dia \\
\hline |--o-s-o- 1.4.5.Acabamento. & 480 & 2 dias \\
\hline TOTAL & 25000 & \\
\hline
\end{tabular}

Figura 3.7 Alocação de custos e prazos (exemplo quantitativo)

O próximo passo é programar as atividades no tempo, levando em conta o prazo de entrega e as precedências entre as atividades. O gráfico de Gantt é uma das melhores representações que se pode ter para tal programação (ver Figura 3.8). Observa-se que as barras em vermelho indicam as atividades de menor folga e que definem a duração total do projeto ou seja, as atividades que compõem o "Caminho Crítico" do projeto.

Para a determinação da linha base do orçamento, faz-se agora necessário distribuir os custos nas respectivas atividades. Por facilidade, estes custos foram distribuídos uniformemente ao longo da duração de cada atividade. Ou seja, se a atividade tem custo de $\$ 2500$ e duração de 5 dias, estipulou-se que diariamente serão despendidos $\$ 500(\$ 2500 / 5)$.

Isto feito, somam-se os custos individuais de cada período (no caso, dia) e os custos acumulados até o fim do projeto (Figura 3.9) para a confecção do gráfico, o qual servirá de base para as análises futuras (Figura 3.10). 


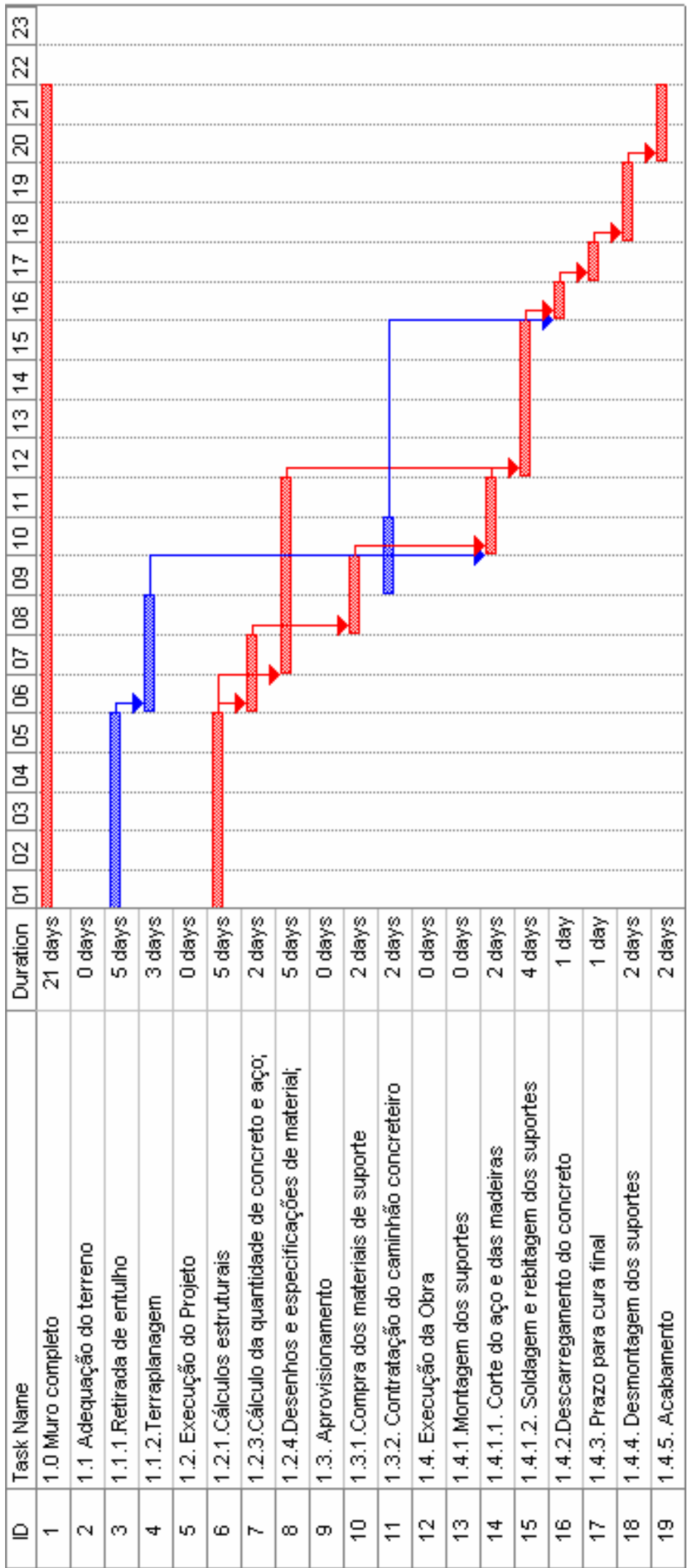

Figura 3.8 Gráfico de Gantt (exemplo quantitativo) 


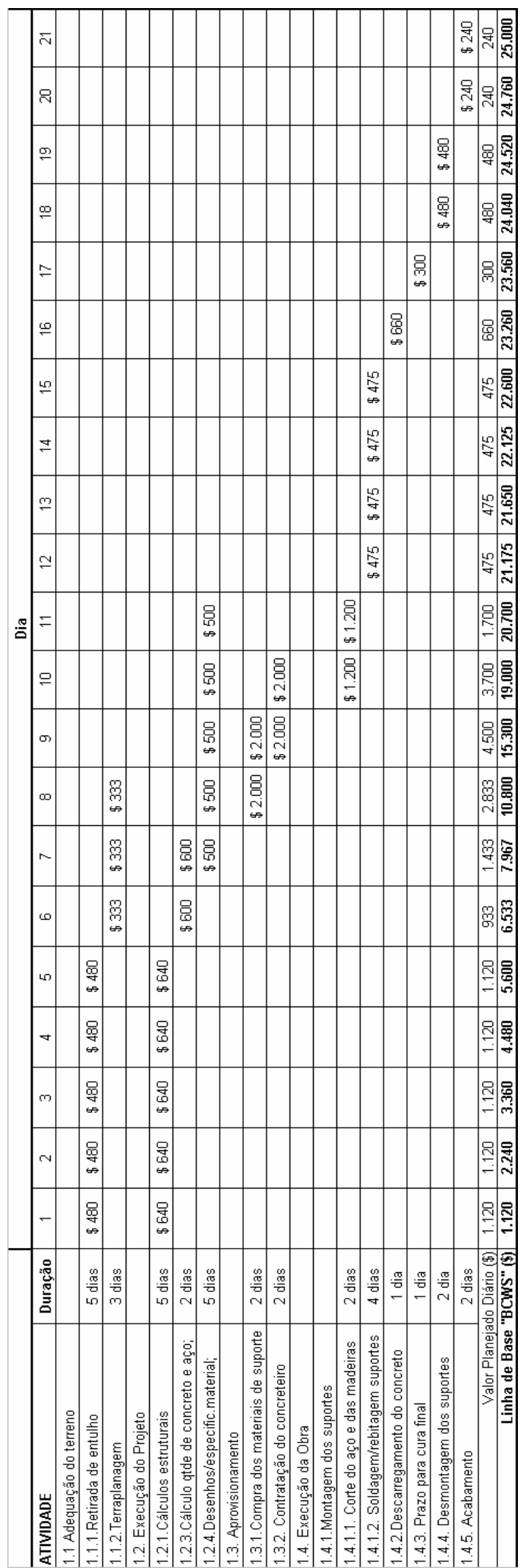

Figura 3.9 Tabela auxiliar para distribuição de custos (exemplo quantitativo) 


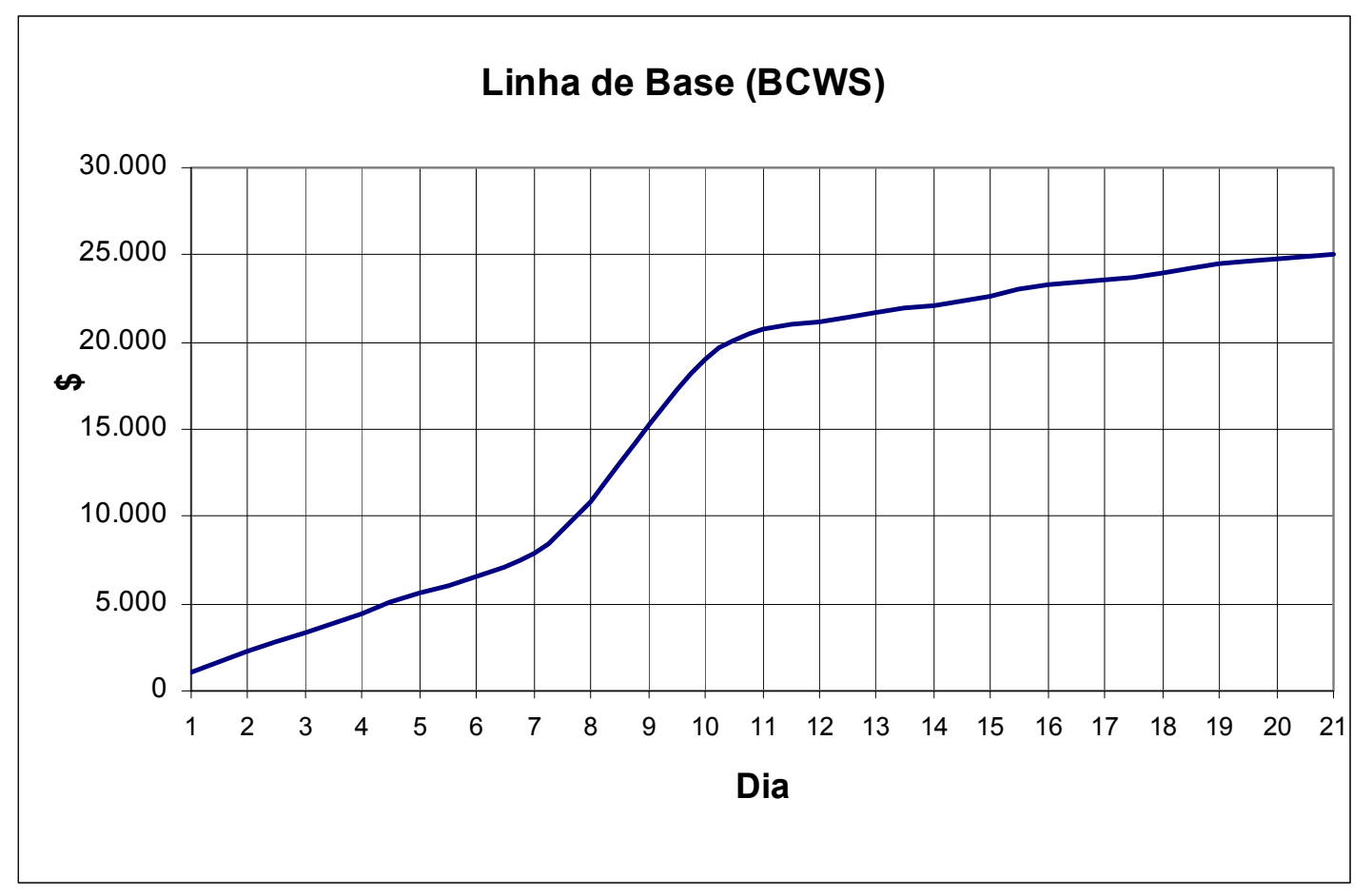

Figura 3.10 Linha base de orçamento - BCWS (exemplo quantitativo)

Basta agora acompanhar o progresso do projeto e avaliar o seu desempenho. Para tal, o Gerente de Projetos teve o cuidado de apontar os custos e medir o progresso diariamente e, ao término do $6^{\circ}$ dia, resolveu analisar o projeto como um todo. Com os custos incorridos (retirados de seu caderno contábil) e o progresso físico medido através de observações em campo e estimativas junto aos seus engenheiros, o Gerente de Projetos pôde levantar as curvas de ACWP e BCWP conforme demonstrado a seguir.

\begin{tabular}{|r|r|r|r|r|r|r|r|}
\hline & \multicolumn{7}{|c|}{ Dia } \\
\cline { 2 - 8 } & $\mathbf{1}$ & $\mathbf{2}$ & $\mathbf{3}$ & $\mathbf{4}$ & $\mathbf{5}$ & $\mathbf{6}$ & $\mathbf{7}$ \\
\hline Valor Planejado Diário & 1.120 & 1.120 & 1.120 & 1.120 & 1.120 & 933 & 1.433 \\
\hline Valor Planejado Acum. (BCWS) & $\mathbf{1 . 1 2 0}$ & $\mathbf{2 . 2 4 0}$ & $\mathbf{3 . 3 6 0}$ & $\mathbf{4 . 4 8 0}$ & $\mathbf{5 . 6 0 0}$ & $\mathbf{6 . 5 3 3}$ & $\mathbf{7 . 9 6 7}$ \\
\hline Custo Real Diário & 1.050 & 1.000 & 1.000 & 1.000 & 1.000 & 1.100 & \\
\hline Custo Real Acum. (ACWP) & 1.050 & 2.050 & 3.050 & 4.050 & 5.050 & 6.150 & \\
\hline Valor Agregado Diário & 800 & 900 & 900 & 900 & 1.000 & 1.000 & \\
\hline Valor Agregado Acum. (BCWP) & 800 & 1.700 & 2.600 & 3.500 & 4.500 & 5.500 & \\
\hline
\end{tabular}

Figura 3.11 Dados referentes ao progresso do projeto (exemplo quantitativo) 
Observa-se que o Gerente havia planejado gastar um total de $\$ 6.533$ até o $6^{\circ}$ dia de projeto. Porém foram gastos apenas $\$ 6.150$ e só se agregou um valor correspondente à $\$ 5.500$.

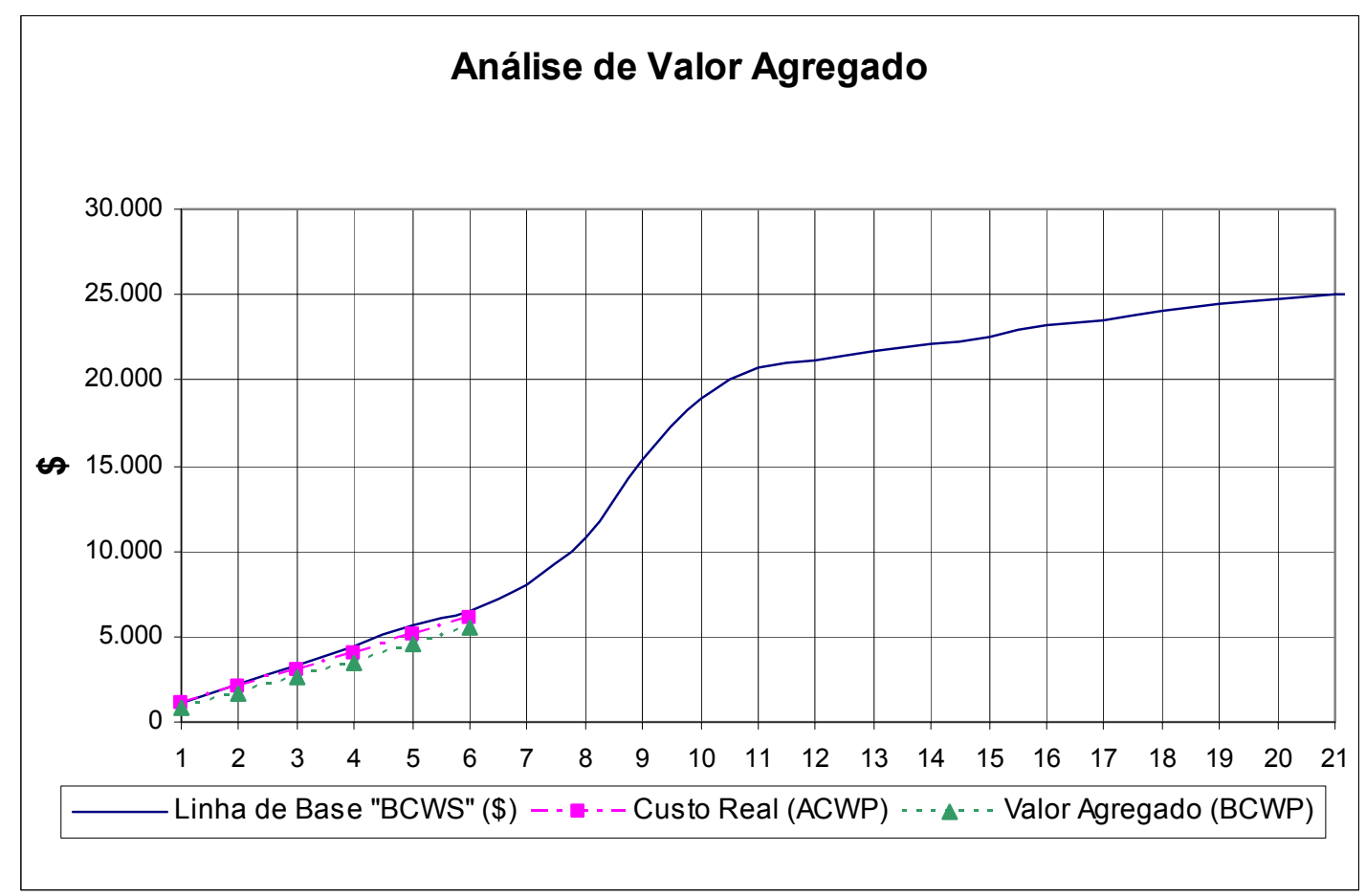

Figura 3.12 Gráfico para Análise de Valor Agregado (exemplo quantitativo)

Calculando os índices e correlações pré-definidos (vide capítulos 3.2) obtém-se:

- $\mathrm{CV}=\$ 5.500-\$ 6.150=-\$ 650$;

- $\mathrm{SV}=\$ 5.500-\$ 6.533=-\$ 1033$;

- $\quad$ TV (obtido graficamente) = 1,2 dia;

- $\quad \mathrm{CPI}_{\mathrm{c}}=\frac{\mathrm{BCWP}_{\mathrm{c}}}{\mathrm{ACWP}_{\mathrm{c}}}=\frac{\$ 5.500}{\$ 6.150}=0,89$;

- $\quad \mathrm{SPI}_{\mathrm{c}}=\frac{\mathrm{BCWP}_{\mathrm{c}}}{\mathrm{BCWS}_{\mathrm{c}}}=\frac{\$ 5.500}{\$ 6.533}=0,84$.

Observa-se por estes cálculos que o projeto está atrasado e custando mais do que o planejado até a presente data. 
Como exemplo de projeções futuras, podem ser utilizadas as formulações apresentadas no capítulo 3.3:

- $\quad \mathrm{TAC}=\frac{\mathrm{PAC}}{\mathrm{SPI}_{\mathrm{c}}}=\frac{21 \text { dias }}{0,84}=25$ dias

- $\mathrm{EAC}=\mathrm{ACWP}_{\mathrm{c}}+\frac{\left(\mathrm{BAC}-\mathrm{BCWP}_{\mathrm{c}}\right)}{\mathrm{CPI}_{\mathrm{c}}}=\$ 6.150+\frac{(\$ 25.000-\$ 5.500)}{0,89}=\$ 28.060$

As projeções indicam que, caso não seja tomada nenhuma ação corretiva, o projeto terminará em 25 dias (4 dias de atraso) e custará \$28.060 (\$3.060 de sobre-custo). 


\section{CRITÉRIOS NA APLICAÇÃO DA ANÁLISE DE VALOR AGREGADO}

\subsection{Motivação}

Ao mesmo tempo em que se tem na AVA uma relativa simplicidade de conceitos e a pura utilização do bom senso, ainda é muito grande a incidência de reclamações e descontentamentos por parte de Gerentes de Projeto com relação à mesma. Resta saber se este comportamento se deve à técnica em si ou a algum outro fator externo, e quais seriam as medidas necessárias para a melhoria na sua aplicação.

\subsection{Problemas Relatados sobre a Análise de Valor Agregado}

$\mathrm{Na}$ pesquisa de White; Fortune (2002) ficam evidentes as dificuldades que os gestores de projetos encontram para a aplicação das ferramentas de controle existentes.

\begin{tabular}{|l|c|}
\hline Principais limitaç̃es e efeitos colaterais na aplicaç̃o dos métodos, & Número de \\
\hline ferramentas e técnicas da gestão de projetos. & $\frac{\text { mencões }}{2}$ \\
\hline Inadequadas para projetos complexos & 32 \\
\hline Dificuldade para modelar o “mundo real” & 18 \\
\hline Exigência de muita documentação e dispêndio de tempo & 12 \\
\hline Outros & 11 \\
\hline Falha na previsão de problemas & 9 \\
\hline Atividades restritas, não permite uma visão holística & 9 \\
\hline Difícil utilização/manuseio & 9 \\
\hline Falta de treinamento, especialização & 6 \\
\hline Não aplicável - não há ferramentas aplicáveis disponíveis & 5 \\
\hline Muito focado em padrões & 5 \\
\hline Total & 122 \\
\hline
\end{tabular}

Figura 4.1 Limitações das ferramentas de GP (White; Fortune, 2002) 
Embora não esteja explícito nesta pesquisa, é certo de que a Análise de Valor Agregado figura como uma das ferramentas de difícil aplicação em projetos (Christensen, 1998), principalmente em projetos de grande porte e complexos.

Pela pesquisa, o maior número de reclamações se referem à inadequação das ferramentas para controle de projetos complexos. Conforme exposto no capítulo 2.6, o conceito de projeto complexo, ou de grande porte, é sempre bastante relativo. Todavia, será referenciado aqui, como projeto deste tipo, aquele que possui escopo de fornecimento extenso, multidisciplinar, longo período de implementação (maior que 1 ano), alto nível tecnológico e que possui muitas interfaces a serem integradas (internas, externas, culturais, comerciais, etc.). Esse é o tipo de projeto que definitivamente necessita de um gerenciamento específico e que justifica a utilização da Análise de Valor Agregado com o devido detalhamento e consistência, possibilitando análises precisas e confiáveis.

Flemming; Koppelman (2000) acreditam que a Análise de Valor Agregado tenha sido evitada (e algumas vezes até rejeitada) por muitos Gerentes de Projetos porque, nas últimas quatro décadas, a técnica foi "encapsulada" junto a várias regras que acrescentavam muito pouco ou nenhum valor prático a mesma (regras da C/SCSC). Este formato imposto gerou muita burocracia e distorções de interpretação, algumas vezes até desvirtuando o propósito principal de seu uso. Deste modo, o que se obteve não foi uma ferramenta para gerenciamento e controle de projetos, mas sim uma burocracia levada ao extremo que só fazia com que os Gerentes de Projeto despendessem boa parte de seu tempo coletando informações e elaborando relatórios, sem que isso levasse a um benefício ou retorno efetivo ao projeto.

Thamhain apud Vargas (2002) publicou em 1998 uma outra pesquisa realizada com profissionais ligados a projetos, porém focando mais diretamente na popularidade e no valor das diferentes técnicas de avaliação e controle de desempenho. A pesquisa contou com a participação de 400 profissionais, envolvidos em 180 projetos e o resultado pode ser visto na Figura 4.2. 
Pelos resultados da pesquisa, nota-se que embora a Análise de Valor Agregado tenha uma razoável popularidade (41\%), o valor que os profissionais dão para esta técnica ainda é muito baixo: apenas 1,75 em uma escala que vai de 0 (sem valor) a 5 (crucial).

\begin{tabular}{|c|c|c|}
\hline$\underline{\text { Técnica }}$ & $\frac{\text { Popularidade }}{(\%)}$ & $\frac{\text { Valor da }}{\text { Técnica }}$ \\
\hline Controle de prazos & 99 & 3,25 \\
\hline Definição do projeto & 98 & 3,75 \\
\hline Revisão do projeto & 93 & 3,15 \\
\hline Controle de orçamentos & 92 & 3,25 \\
\hline Revisão do Design & 87 & 3,50 \\
\hline Prototipação & 82 & 3,25 \\
\hline Verificação de status & 82 & 3,75 \\
\hline Relatório de deficiências & 68 & 2,50 \\
\hline Relatório de ações & 65 & 3,00 \\
\hline Análise de requerimentos & 52 & 3,20 \\
\hline Benchmarking & 52 & 1,50 \\
\hline PERT/COM & 42 & 1,50 \\
\hline$\underline{\text { Análise de Valor Agregado }}$ & $\underline{41}$ & $\underline{1,75}$ \\
\hline Análise de Caminho Crítico & 32 & 2,00 \\
\hline QFD (Quality Function Deployment) & 28 & 2,00 \\
\hline Análise de compressão de duração & 18 & 1,00 \\
\hline
\end{tabular}

Figura 4.2 Popularidade e valor das técnicas de gerenciamento de projetos (Thamhain apud Vargas, 2002)

Dentre as principais justificativas para a atribuição de tão baixo valor à AVA figuram:

- Não utilizável como ferramenta de controle e, sim, como ferramenta justificadora de atrasos e desvios;

- Utilização da ferramenta requerendo muito esforço e consumo de tempo; 
- Alto custo de implantação;

- Métodos de controle atuando como ameaçadores, no que diz respeito à liberdade da equipe;

- Falta de compreensão do funcionamento da técnica;

- Ansiedade quanto ao uso adequado da ferramenta;

- O seu propósito e o seu benefício sendo, muitas vezes, vagos ou imprecisos.

Na tentativa de também mensurar os "prós e contras" da AVA, Christensen (1998) compilou uma série de pesquisas da literatura, as quais consideravam a utilização formal da AVA em contratos americanos. O resultado deste estudo mostra que as empresas realmente vêem a EVA de maneira positiva, porém se queixam de que sua implantação e manutenção são muito custosas e exigem muito tempo e atenção de seus gestores. $\mathrm{O}$ estudo revela custos de implementação de EVA em uma faixa que vai de $0,5 \%$ a $5 \%$, e média entre $1 \%$ e $1,5 \%$ sobre o valor dos contratos. A pesquisa, entretanto, não revela o grau de maturidade em Valor Agregado das empresas envolvidas, o que certamente influi nos custos de implementação. Quanto aos benefícios, não foram encontrados resultados quantitativos a respeito, apenas de ordem qualitativa. Seguem os principais:

- Um sistema único de controle oferecendo dados confiáveis;

- A integração entre trabalho, custo e cronograma utilizando o WBS;

- Um banco de dados útil para análises comparativas entre projetos;

- Utilização do CPI e SPI como indicadores de progresso;

- Utilização do CPI como um "alarme” já nos primeiros estágios do projeto;

- Um método eficaz para previsão de custos finais e prazos através dos índices de desempenho (SPI e CPI);

- Utilização dos índices periodicamente como "benchmark". 


\subsection{Análise Sobre os Problemas Relatados}

Analisando as reclamações e problemas expostos em relação à Análise de Valor Agregado, percebe-se que as suas causas podem ser agrupadas em 3 grupos principais: falta de conhecimento adequado da ferramenta, alto custo de implementação/manutenção, e difícil utilização como ferramenta de controle, principalmente em projetos complexos. Deve-se, portanto, refletir sobre estes três grupos de reclamações.

A falta de conhecimento da ferramenta, ou a falta de uma cultura organizacional para utilizá-la adequadamente, não tem relação direta com a técnica em si, pois, conforme já exposto, não há complexidade no seu conteúdo e nem a necessidade de habilidades ou conhecimentos especiais para a sua utilização. Percebe-se, entretanto, que não se encontram treinamentos específicos para a AVA nas empresas; apenas rápidas menções dentro de algum outro treinamento gerencial. A simplicidade no conceito pode passar a impressão de que não há necessidade de treinamentos, mas estes são necessários sim, como em qualquer outra técnica ou metodologia. Nota-se também que existem poucas publicações comerciais a respeito, o que certamente dificulta a generalização do conhecimento.

É fato que, para se obter informações confiáveis na utilização da AVA, toda a equipe deve estar empenhada e em condições de fornecer tais informações. Deve haver a conscientização de que a métrica e as técnicas de controle de projetos não têm caráter punitivo, mas sim produtivo. Devem ser usadas como ferramentas administrativas e de controle por todos os envolvidos, e não apenas para relatórios burocráticos aos gerentes e demais superiores. Estes, por sua vez, devem ter o cuidado de utilizá-las para a avaliação do projeto e não dos indivíduos, evitando resistências por parte destes e preservando a transparência das informações.

Assim, o que se faz necessário para a minimização deste problema é uma melhor disseminação da técnica (com o devido treinamento) e um maior apoio das altas gerências na sua aplicação dentro das empresas. Uma vez ultrapassadas estas 
barreiras, torna-se apenas uma questão de tempo para que haja o amadurecimento das idéias e uma maior absorção dos conceitos pelos envolvidos, o que certamente contribuirá na divulgação das vantagens e resultados.

Quanto ao custo de implementação, este certamente deve ser levado em consideração pelos gestores e executivos das empresas. $\mathrm{Na}$ verdade, a melhor análise seria em função da relação custo/benefício da técnica, conforme já tentado por Christensen (1998). No entanto, essa análise fica um pouco prejudicada, pois ainda não se encontram exemplos, na literatura, quanto aos reais ganhos em termos financeiros ao se adotar esta técnica. Todos os autores concordam que a ferramenta pode trazer muitos benefícios, porém mensurá-los é muito difícil. O que se sabe é que, embora existam reclamações quanto ao seu alto custo de implementação (desde o início da Gestão de Projetos), a quantidade de empresas que vêm adotando a Análise de Valor Agregado cresce a cada dia.

É visível também que um dos agravantes para os altos custos de implementação é o fato de que muitas empresas não possuem uma ferramenta de contabilização de custos e progressos adaptada à AVA. Cada empresa, conhecendo o tipo de projeto em que trabalha deve procurar integrar as ferramentas de contabilidade e ERP à técnica da AVA. Hoje em dia, os sistemas se encontram cada vez mais informatizados e, em geral, possibilitam esta integração.

Por fim restam as reclamações quanto a não ser uma boa ferramenta de controle e a não ser aplicável a projetos complexos. Estas reclamações podem estar relacionadas a vários fatores, inclusive à falta de conhecimento e estrutura mencionados anteriormente. Porém o que salta aos olhos é que, muitas vezes, a aplicação e o uso desta ferramenta se dá de uma maneira mecânica, sem a correta adaptação ou racionalização levando em conta as características do projeto em questão.

Existe também uma constatação que pode estar relacionada a estas reclamações: observa-se atualmente que, fora dos contratos do governo americano, os maiores índices de sucesso na aplicação da AVA acontecem em alguns tipos específicos de 
projetos, como projetos de TI, projetos financeiros e bancários e projetos de reestruturação interna de empresas. No entanto este sucesso não vem sendo registrado, ou divulgado, com esta magnitude em outros tipos de projeto. A situação se agrava em projetos de grande porte na indústria, onde se tem alto grau de complexidade e muitas variáveis envolvidas.

Considerando que o conceito de valor agregado não tem nada que o restrinja de ser utilizado em projetos complexos, e que a causa dos referidos insucessos possa estar ligada a uma má aplicação da ferramenta, serão analisadas as peculiaridades de um projeto de engenharia e/ou industrial de grande porte e complexidade, visando identificar possíveis complicadores e obstáculos a esta aplicação.

\subsection{Algumas Características de Grandes Projetos da Indústria}

Serão considerados, neste trabalho, os grandes projetos da indústria de produtos sob encomenda, os quais se utilizam em maior escala da Gestão de Projetos. Em geral, estes projetos possuem particularidades que demandam maiores cuidados por parte dos gestores. Dentre as inúmeras, podemos citar algumas (oriundas de observações práticas e manifestações informais entre gestores deste tipo de indústria):

1. Diferentes fases com características e desempenhos próprios que podem se sobrepor;

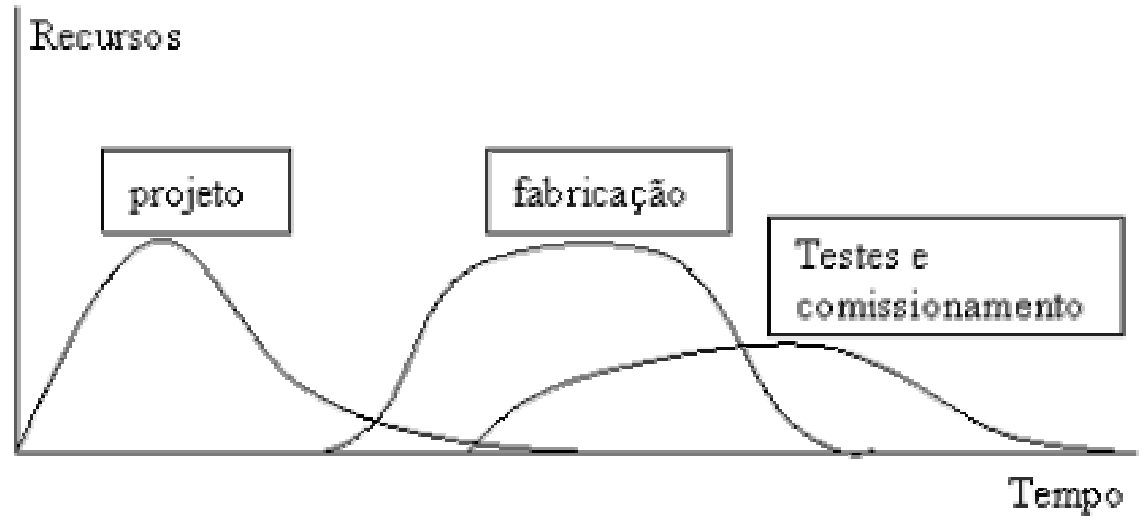

Figura 4.3 Exemplo das fases principais de um projeto na indústria 
2. Difícil definição do nível de detalhamento adequado para o WBS;

3. Difícil mensuração de progresso físico;

4. Grande quantidade de sub-fornecimentos com fluxos de caixa defasados (pagamentos em tempo diferente da execução do trabalho);

A AVA realmente pode levar a resultados não adequados, ou ainda de baixo cunho prático, se forem ignorados os fatores acima. As diferentes características entre as fases podem levar a interpretações e projeções futuras enganosas, o fluxo de caixa defasado pode distorcer os índices de desempenho, o mau detalhamento do WBS e a má escolha da métrica para avaliação do progresso podem gerar distorções no progresso ou inviabilidade de controle, etc. Enfim, as variáveis envolvidas são muitas e podem impactar a confiabilidade da análise.

Isto posto, é de vital importância que, para a utilização da AVA neste tipo de ambiente, o Gerente de Projetos faça uma análise crítica do projeto antes da sua execução, de modo a adaptar a ferramenta às características do projeto.

Flemming; Koppelman (2000) já apontavam que o juízo do Gerente de Projetos deve se sobrepor à ferramenta e este deve adequá-la ao seu projeto. Portanto serão sugeridas algumas medidas para a aplicação da AVA, no intuito de minimizar estes problemas. Parte delas serão medidas para estruturação da ferramenta e outras para a análise dos dados. 


\subsection{Medidas para Aplicação da AVA em Projetos Complexos}

Ter o controle sobre um projeto significa possuir informações confiáveis e que permitam avaliar claramente o seu progresso e tomar ações adequadas para a sua correção ou melhoria. Visando melhorar a qualidade destas informações, e baseado nas já mencionadas características dos projetos complexos, serão aqui sugeridas 6 medidas a serem consideradas na aplicação da AVA. São elas:

\section{Identificação das macro-fases e áreas do projeto;}

Cada projeto possui uma determinada seqüência de fases, que podem se sobrepor e que são muitas vezes realizadas por áreas diferentes da empresa (logo, possuem comportamentos diferentes). É importante que estas fases sejam identificadas, procurando levar em consideração as suas magnitudes e relevâncias perante todo o projeto, a natureza das suas operações, bem como os níveis de riscos em que estarão operando (dados históricos relativos a fontes de atraso em outros projetos são muito úteis). A intenção é poder analisar não só o projeto como um todo, mas também estas macro-fases e seus progressos independentes, de modo a possibilitar futuras intervenções e melhores interpretações sobre o progresso geral do projeto.

Exemplo: em um projeto de fornecimento de robôs para indústria automobilística podem ser identificadas como macro fases:

- Desenvolvimento do projeto (fase criativa e intelectual - Eng. do produto);

- Fabricação das ferramentas e jigs de teste (fase de aplicação e produtiva Eng. Industrial e Fábrica);

- Fabricação do protótipo (fase produtiva e de refinamento do projeto mecânico - Fábrica e Eng. do produto);

- Validação (fase produtiva e de refinamento do projeto funcional - Assist. Técnica e Eng. do produto);

- Fabricação do lote final (fase produtiva - Fábrica) 
2. Confecção das curvas de orçamento (BCWS) para cada grupo de atividades do projeto e para o empreendimento como um todo;

É muito comum a curva global do projeto indicar um certo desempenho, mas a realidade ser diferente se suas atividades forem analisadas individualmente. As curvas individuais para cada grupo de atividades agregam informações qualitativas que possibilitam avaliar onde estão os maiores problemas. Assim, a interpretação sobre os números fica mais fácil e a tomada de decisão mais consistente.

Para auxiliar ainda mais na visualização, pode-se traçar retas verticais nos principais marcos do projeto (ex.: início do período de compras, fabricação do protótipo, validação do projeto,...). Deste modo tem-se a visualização de pontos que interagem com várias fases e o progresso dos mesmos.

Recomenda-se também que se crie uma curva exclusiva para fornecimentos que possuam fluxo de caixa defasado. Estes podem ser fontes de muitas distorções nos valores de SPI e CPI. Obviamente, devem ser escolhidos apenas aqueles que possuem valor relevante e grande defasagem entre o benefício físico e o seu pagamento (Vargas, 2002).

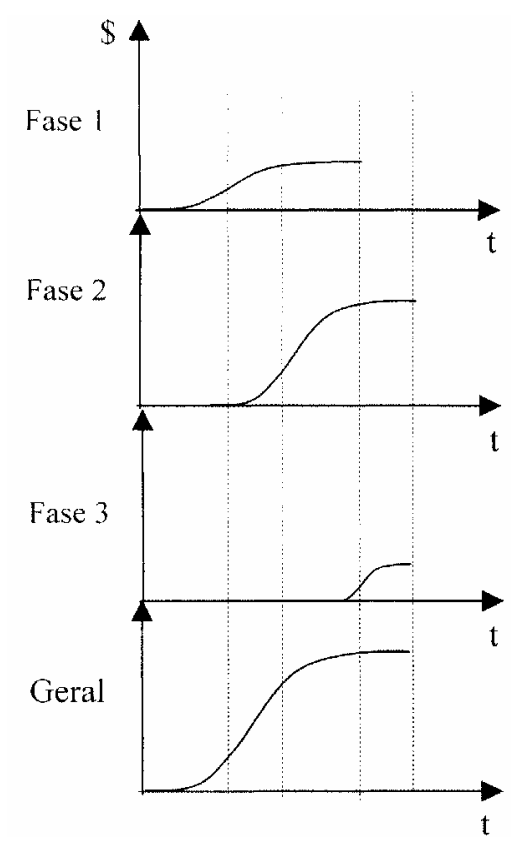

Figura 4.4 Gráficos para acompanhamento simultâneo de cada fase do projeto 
3. Estimar EAC em função da curva global e em função da fase do projeto (estudo dos índices)

Com os custos e progressos físicos coletados para cada grupo de atividades, podem ser realizadas estimativas de diversas maneiras, combinando dados globais e individuais, dependendo da fase do projeto e de suas características.

O Gerente de Projetos deve ter em mente que a precisão das projeções baseadas em índices também dependem da precisão dos dados de entrada. De qualquer maneira, Abba apud Christensen (1993) sugere que seja feita uma análise gráfica dos custos e suas projeções. Por definição, no fim do projeto BCWP se iguala a BCWS e ACWP se iguala a EAC. Se uma simples projeção dos custos e performance física feita "a mão livre" não refletir estes fatos, vale avaliar novamente os cálculos de EAC. Em outras palavras, as curvas de custo e progresso físico acumulados devem permanecer com um formato de $\mathrm{S}$ e razoavelmente suaves, sem grandes alterações em relação ao formato previamente planejado.

\section{Definição do WBS e das Células de Controle (CAPs) de todo o projeto;}

Conforme já mencionado, o WBS deve conter todas as atividades a serem executadas no projeto e o seu grau de detalhamento deverá ser definido pelo Gerente de Projetos.

Uma escolha adequada da dimensão de cada Pacote de Trabalho (Work Package $W P$ ) é de fundamental importância para assegurar uma boa discretização da Linha de Base (BCWS). Deve-se evitar a presença de grandes degraus na curva, pois estes podem gerar más interpretações quando se calcularem os índices de desempenho.

Em grandes e longos projetos é natural também que se definam Pacotes de Trabalho (WPs) longos. Entretanto, em termos de controle é preferível se ter WPs curtos e bem distribuídos no tempo do que WPs longos e sobrepostos entre si (vide Figura 4.5). As estimativas de prazos e custos (cronograma e "orçamentação") em Pacotes 
de Trabalho menores também se tornam mais precisas, o que pode ser demonstrado matematicamente (Raz; Globerson, 1998).

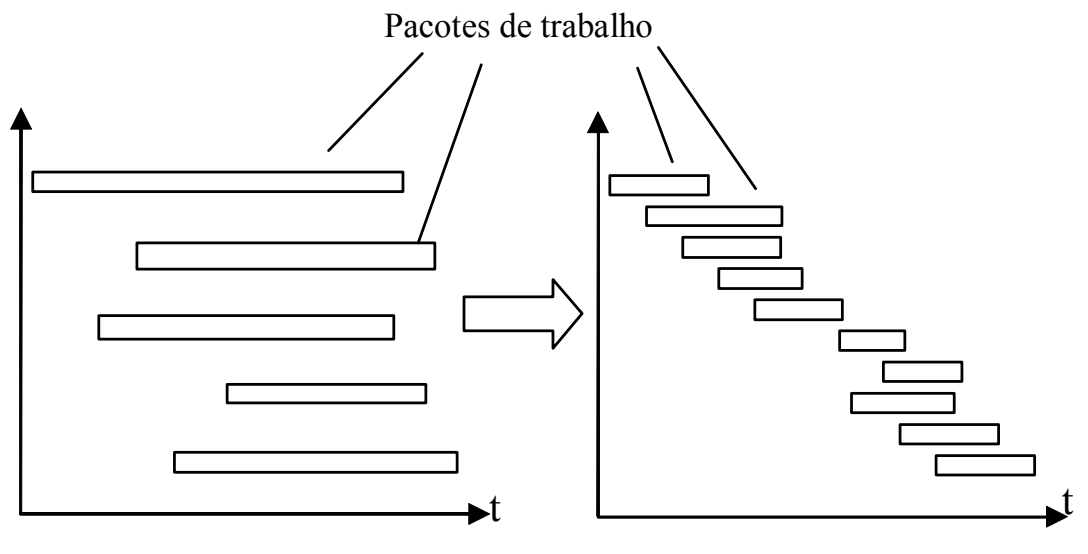

Figura 4.5 Determinação e distribuição de Pacotes de Trabalho

Sabe-se também que Pacotes de Trabalho muito curtos levarão a maiores esforços e custos gerenciais. Por outro lado se forem muito grandes, causarão maiores distorções nas medições de progresso. O detalhamento do WBS e o conseqüente dimensionamento dos CAPs são muito particulares a cada empresa, e dependem fortemente da periodicidade com que o Gerente de Projetos pretende avaliar o progresso do projeto. Esta periodicidade, por sua vez, está normalmente relacionada com a natureza do projeto, com as características da empresa e com o nível de controle necessário (considerando os riscos envolvidos).

Um critério que pode ser adotado é o de procurar definir WPs com o máximo de uniformidade em termos de custos e duração, pelo menos dentro das macro-fases definidas anteriormente. Deste modo, o controle fica mais homogêneo e eventuais erros em estimativas de progresso físico terão efeitos mais previsíveis e, deste modo, de mais fácil compensação.

De um modo geral, é aconselhável também que se definam WPs com durações não muito maiores do que o período de amostragem para avaliação. Isto possibilita a adoção de critérios mais grosseiros (ex.: fórmula fixa 50\%/100\%) no lugar de critérios subjetivos para estimativa de progresso físico, sem grandes prejuízos nas 
estimativas de progresso global do projeto. Percebe-se, portanto, que a precisão nas estimativas está relacionada com a duração das atividades e o período de avaliação de progresso.

Segue exemplo ilustrando esta inter-relação:

- Orçamento total do projeto (BAC): \$2.000.000;

- Duração total do projeto (PAC): 2 anos (24 meses ou aprox. 104 semanas);

- Período de avaliação de progresso (PA): 1 quinzena (2 semanas);

- Total de Pacotes de Trabalho no WBS (NP): 1040;

- Média de Pacotes de Trabalho por período de medição (MPP): 1040/52 = 20

- Custo médio de um pacote de trabalho (CMP): $\$ 2.000 .000 / 1040=\$ 1923$

- Critério para medição (tipo fórmula fixa):

- $50 \%$ - Atividade em progresso;

- $100 \%$ - Atividade finalizada;

Considerando que um pacote de trabalho tem duração de 1 quinzena, o máximo erro na estimativa seria de $50 \%$. Considerando também que todos os pacotes serão estimados erroneamente no mesmo sentido, ou seja, todos superestimados ou subestimados (a favor da segurança), podemos calcular o erro total da seguinte forma:

$$
\text { Erro máximo }=\frac{\mathrm{MPP} \cdot \mathrm{CMP} \cdot 50 \%}{\mathrm{BAC}}=\frac{20 \cdot 1.923 \cdot 50 \%}{2.000 .000}=0,96 \%
$$

Aumentando o período de avaliação para 1 mês o erro ainda é inferior a $2 \%$.

Portanto, este é o tipo de avaliação que o Gerente de Projetos deve fazer antes de iniciar o detalhamento do WBS e a definição dos CAPs. O cálculo acima é bastante simplista, mas exemplifica como se chegar em um parâmetro útil para a definição do tamanho dos Pacotes de Trabalho e a periodicidade de avaliação de progresso. Resultados mais precisos (e possivelmente, sem muitos esforços) podem ainda ser conseguidos através da Teoria dos Erros (Vuolo, 1996). 
5. Definir o sistema de avaliação de desempenho do projeto (métrica e coletores);

Novamente, devido às diferenças entre as fases e especialmente entre as áreas envolvidas, o Gerente de Projetos deve dispor de métricas diferentes para cada tipo de atividade. Como exemplo: itens de desenvolvimento e engenharia devem possuir critérios de medida de desempenho diferentes dos itens de produção, haja vista a diferença existente na natureza destas atividades.

Grandes e complexos projetos também são mais susceptíveis ao que aqui chamaremos de "síndrome dos 90\%". Como o Gerente de Projetos não tem condições de acompanhar todas as atividades, ele deve depositar sua confiança nos relatórios dos responsáveis pelo acompanhamento do progresso físico das mesmas. E não é raro acontecer de o progresso ser superestimado pelos seus responsáveis, não por incompetência ou má intenção, mas sim pela natureza do ser humano, que tende a ser otimista. Em outras palavras, o tempo necessário para alcançar $90 \%$ de progresso é relativamente curto, porém é seguido de um longo período (de convergência quase assintótica) até completar $100 \%$ da atividade.

Este tipo de problema ocorre mais comumente em atividades menos determinísticas, como as de Engenharia, onde muitas vezes não se têm eventos concretos balizando todas as atividades, o que torna a medição de desempenho mais difícil e subjetiva. Portanto é de vital importância que se criem ou identifiquem eventos concretos intermediários nestas atividades, principalmente nas mais longas. Deste modo, a estimativa de progresso é mais palpável e sólida, não dependendo unicamente da interpretação subjetiva dos profissionais (Flemming; Koppelman, 2000).

Mas a "síndrome do 90\%" não é exclusividade das atividades de engenharia, elas também ocorrem nas fases de produção e testes, porém não devido a superestimativas iniciais, mas sim devido a repetições e retrabalhos induzidos por erros nos estágios de desenvolvimento do projeto (engenharia). Para minimizar surpresas como estas, é necessário que a finalização (100\%) das atividades mais relevantes de engenharia esteja vinculada a algum critério de qualidade ou validação. 
Exemplos:

a) Atividades de produção devem usar métrica do tipo "unidades equivalentes" ou "fórmula fixa" que são bem objetivos e adequados quando se tem eventos claramente identificáveis ou tangíveis.

Um painel estrutural de um navio é composto por 50 peças iguais e custo total de $\$ 100$. Deste modo, cada peça teria um custo de \$2. Em um determinado momento verificou-se que haviam 30 peças completas produzidas, portanto o progresso alcançado foi de $60 \%$, ou $\$ 60$.

b) Atividades de engenharia devem usar métrica do tipo "porcentagem completo com marcos de controle" associando a subjetividade de um trabalho de engenharia com a objetividade necessária para o devido controle e os demais estágios do projeto.

O projeto do mesmo painel estrutural é mensurado subjetivamente, porém deve ter marcos de controle como limitadores, por exemplo:

- 30\% ao atingir um nível de informação que possibilite a compra do aço;

- $50 \%$ ao atingir um nível que possibilite a construção de ferramentas e jigs;

- $90 \%$ ao finalizar os desenhos;

- $100 \%$ ao ser validado pela Eng. Industrial.

Em um determinado momento o engenheiro apresentou ao Gerente de Projetos um progresso de $40 \%$, alegando que o aço já havia sido comprado (30\%), e que o projeto estava em detalhamento, justificando a adição de mais $10 \%$. 
6. Tratamento sobre a aquisição de materiais e de serviços subcontratados;

Outro grande problema dos gestores na medição de progresso dos projetos está relacionado com a aquisição de materiais e com a utilização de serviços subcontratados.

Em geral estes itens possuem uma defasagem no tempo entre a data de realização do trabalho (ou agregação de valor) e o respectivo desembolso financeiro. Como exemplos podem ser citadas duas situações:

a) Um determinado material (exemplo: aço) é recebido na fábrica e logo entra na linha de produção, agregando valor ao projeto. Porém a sua compra prevê pagamentos a 30 e 60 dias.

b) Uma empresa é subcontratada para fornecer o sistema de transmissão de dados para o projeto. Embora ainda não haja nenhum valor agregado ao projeto, foi necessário desembolsar um adiantamento para que a referida empresa pudesse se estruturar e atender a necessidade do projeto.

Estas duas situações podem gerar distorções nos índices de desempenho do projeto. Aconselha-se, então, que os itens sujeitos a grandes defasagens de fluxo de caixa sejam colocados em CAPs isolados e tratados com a devida compensação, conforme figura abaixo.

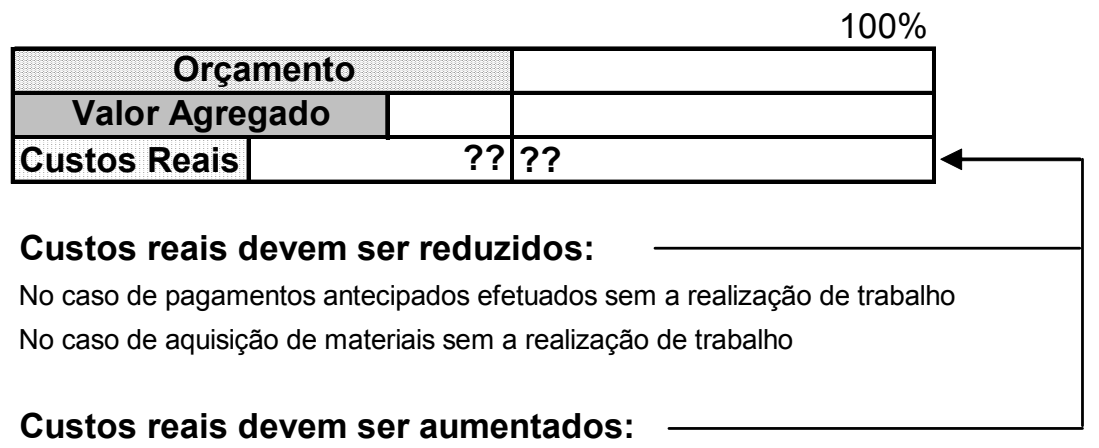

No caso de trabalhos realizados por terceiros sem pagamento realizado

No caso de atrasos em pagamentos (faturas atrasadas, etc)

Figura 4.6 Ajuste nos custos devido ao fluxo de caixa (Vargas, 2002) 
Este é um trabalho bastante oneroso e portanto deve-se procurar escolher somente aqueles itens que podem causar maiores distorções nas curvas de desempenho. Devido a este tratamento especial, é razoável que se tenha também uma curva para análise de valor agregado apenas sobre estes itens (conforme medida número 2).

Segue abaixo tabela resumindo as medidas para uma melhor aplicação da AVA.

\begin{tabular}{|c|c|}
\hline MEDIDA & DESCRIÇÃO SUCINTA \\
\hline 1 & $\begin{array}{l}\text { IDENTIFICAR AS MACRO-FASES E GRUPOS DE ATIVIDADES } \\
\text { PRINCIPAIS DO PROJETO }\end{array}$ \\
\hline 2 & $\begin{array}{l}\text { LEVANTAR AS CURVAS GERAIS E INDIVIDUAIS } \text { PARA } \\
\text { ANÁLISE, DE UMA FORMA ORDENADA, E } \\
\text { INFORMAÇÕES ADICIONAIS SOBRE OS EVENTOS FÍSICOS } \\
\text { MAIS RELEVANTES }\end{array}$ \\
\hline 3 & $\begin{array}{l}\text { ATRAVÉS DOS ÍNDICES DE DESEMPENHO DE CADA FASE, } \\
\text { LEVANTAR AS PROJEÇOES INDIVIDUAIS, AS GLOBAIS E } \\
\text { FAZER COMPARAÇÕES PARA A ESCOLHA DA MAIS } \\
\text { ADEQUADA }\end{array}$ \\
\hline 4 & 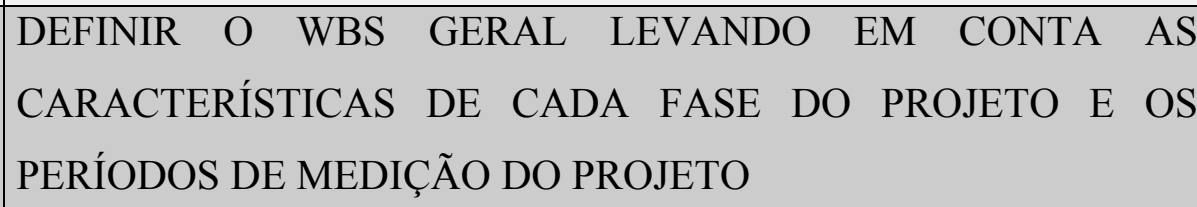 \\
\hline 5 & $\begin{array}{l}\text { DEFINIR OS CRITÉRIOS DE MEDIÇÃO DE PROGRESSO } \\
\text { (MÉTRICA) DE CADA PACOTE DE TRABALHO DE ACORDO } \\
\text { COM A NATUREZA DAS ATIVIDADES }\end{array}$ \\
\hline 6 & $\begin{array}{l}\text { DEFINIR CÉLULAS DE CONTROLE EXCLUSIVAS PARA } \\
\text { MEDIÇÃO DE PROGRESSO DE ITENS COM FLUXO DE CAIXA } \\
\text { DEFASADOS, PERMITINDO AS DEVIDAS COMPENSAÇÕES }\end{array}$ \\
\hline
\end{tabular}

Figura 4.7 Tabela resumo para aplicação da AVA em grandes projetos 


\subsection{Aplicação em um Caso Real da Indústria Brasileira}

\subsubsection{Escopo}

As medidas relativas à identificação das macro-fases e principais atividades do projeto (medidas 1, 2 e 3) serão aplicadas em um projeto real de grande porte e complexidade da indústria brasileira.

Os resultados serão apresentados através de gráficos e tabelas, com os devidos comentários e análises críticas.

As demais medidas $(4,5$ e 6$)$ se fundamentam na racionalidade e não serão focos de apresentações práticas nesta dissertação. Seus benefícios decorrem de uma extensiva aplicação nos pacotes de trabalho dos projetos e são de difícil mensuração, pois requereriam uma comparação entre projetos similares, com e sem as suas considerações.

\subsection{2 $\underline{\text { Ambiente }}$}

Como referência básica sobre o contexto e o panorama do projeto, será apresentada a estrutura organizacional da referida indústria. Sua identidade será preservada, porém algumas características principais podem ser citadas: trata-se de uma empresa multinacional da área de transportes de massa, fabricante de veículos metroferroviários e uma das líderes mundiais em tecnologia e mercado.

Embora a empresa possua seu faturamento originado exclusivamente por projetos, sua estrutura organizacional não pode ser considerada totalmente "Orientada a Projetos”, conforme definições atuais do $\mathrm{PMBoK}^{\circledR}$. A classificação que mais se aproxima é a de uma "Organização Composta ou Matricial". Do total de 
profissionais, apenas alguns são alocados integralmente a cada projeto, os demais são compartilhados entre os vários projetos existentes, e com relação aos recursos, equipamentos e facilidades da empresa, pode-se dizer que, em sua maioria, também são compartilhados.

Outra característica marcante é a de que a empresa não trabalha através de "escritórios de projetos" ou "project management offices", ou seja, todos os profissionais permanecem situados em seus setores funcionais originais e se reportam tanto aos Gerentes de Projetos quanto aos Gerentes Funcionais. Também não existem diferenças hierárquicas explícitas entre os Gerentes de Projetos e os Gerentes Funcionais.

Segue abaixo o modelo da estrutura organizacional desta empresa (Figura 4.8), onde se verifica o compartilhamento de recursos por mais de um projeto, o que é uma fonte potencial para geração de conflitos.

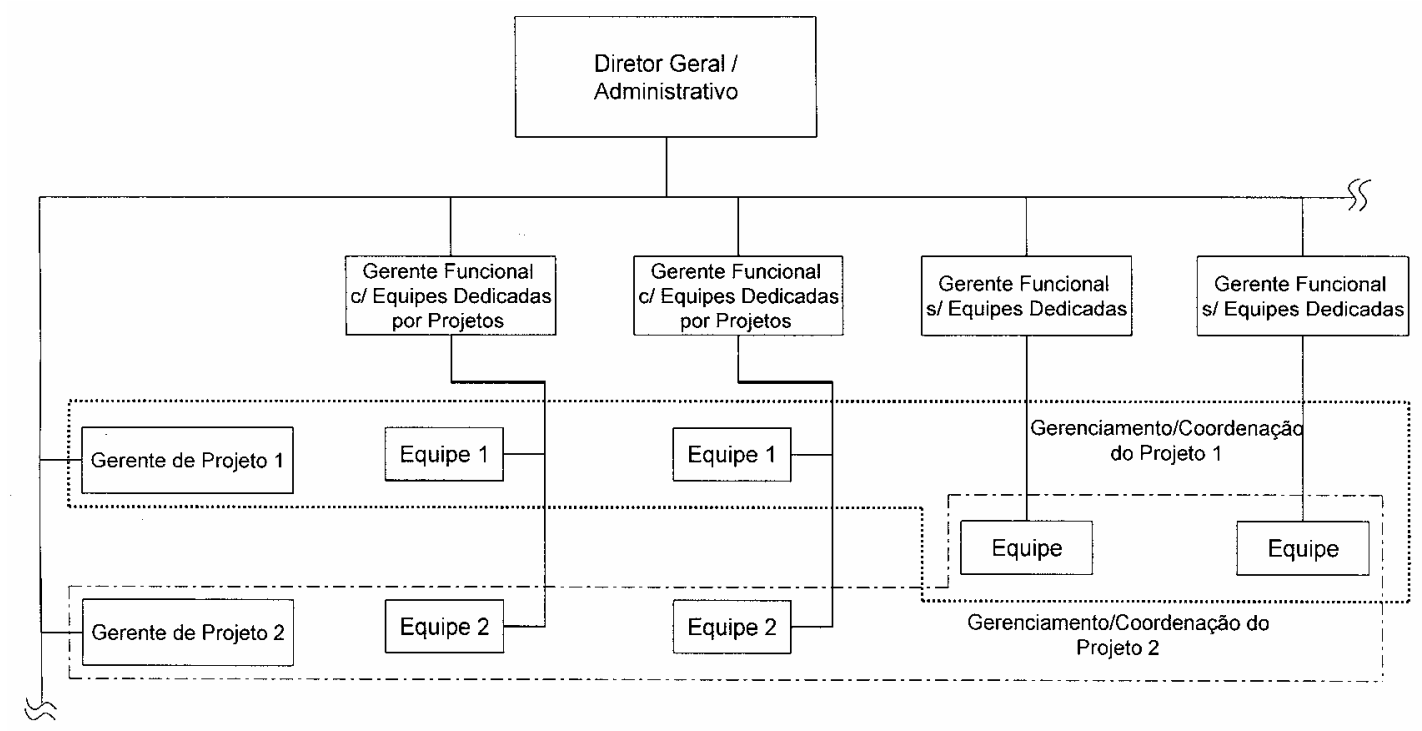

Figura 4.8 Estrutura organizacional da empresa (Matricial/Composta)

Dentre os departamentos que possuem profissionais exclusivos para cada projeto, destacam-se: Engenharia de Projeto, Linha de Montagem Final, Gestão de Projetos, Controle de Qualidade e Assistência Técnica. Dentre os profissionais e recursos 
compartilhados com outros projetos e atividades estão aqueles relativos aos departamentos de Compras, Planejamento, Engenharia Industrial, Linha de Produção Inicial, Financeiro/Contábil, Recursos Humanos e outros de menor porte.

Quanto à natureza de sua operação, a empresa pode ser considerada como uma "integradora" ou "montadora" de trens. Ela desenvolve o projeto de acordo com a especificação técnica do cliente, fabrica as estruturas dos trens, define e especifica os sub-fornecimentos (materiais e sub-sistemas), executa a montagem destes itens nos trens e, finalmente, valida o projeto através dos testes e do comissionamento.

\subsubsection{Características Básicas do Projeto}

O projeto em questão trata do fornecimento de 8 composições ferroviárias (trens), compostas de 6 carros cada. Além deste fornecimento, a empresa deve prestar serviços de manutenção (operação assistida) por um período de 6 meses após a entrega do oitavo trem

O prazo de entrega do primeiro trem, completamente montado e testado, é de 16 meses a partir da assinatura do contrato, que se deu em Outubro/00. Os demais trens devem ser entregues a cada 25 dias aproximadamente, o que totaliza um prazo contratual máximo para entrega dos 8 trens de 22 meses. Considerando o período de operação assistida, tem-se 28 meses de prazo total.

O cliente é uma empresa estatal operadora de trens metropolitanos, com vasta experiência no mercado, e que também possui um gestor e uma equipe técnica para o projeto.

O valor do contrato é de R \$ 69.000.000,00. Entre este valor (preço sem impostos) e o orçamento total de custos (BAC) estão a margem de lucro prevista e as contingências gerenciais para a administração dos riscos do projeto. A Figura 4.9 mostra esta relação. 


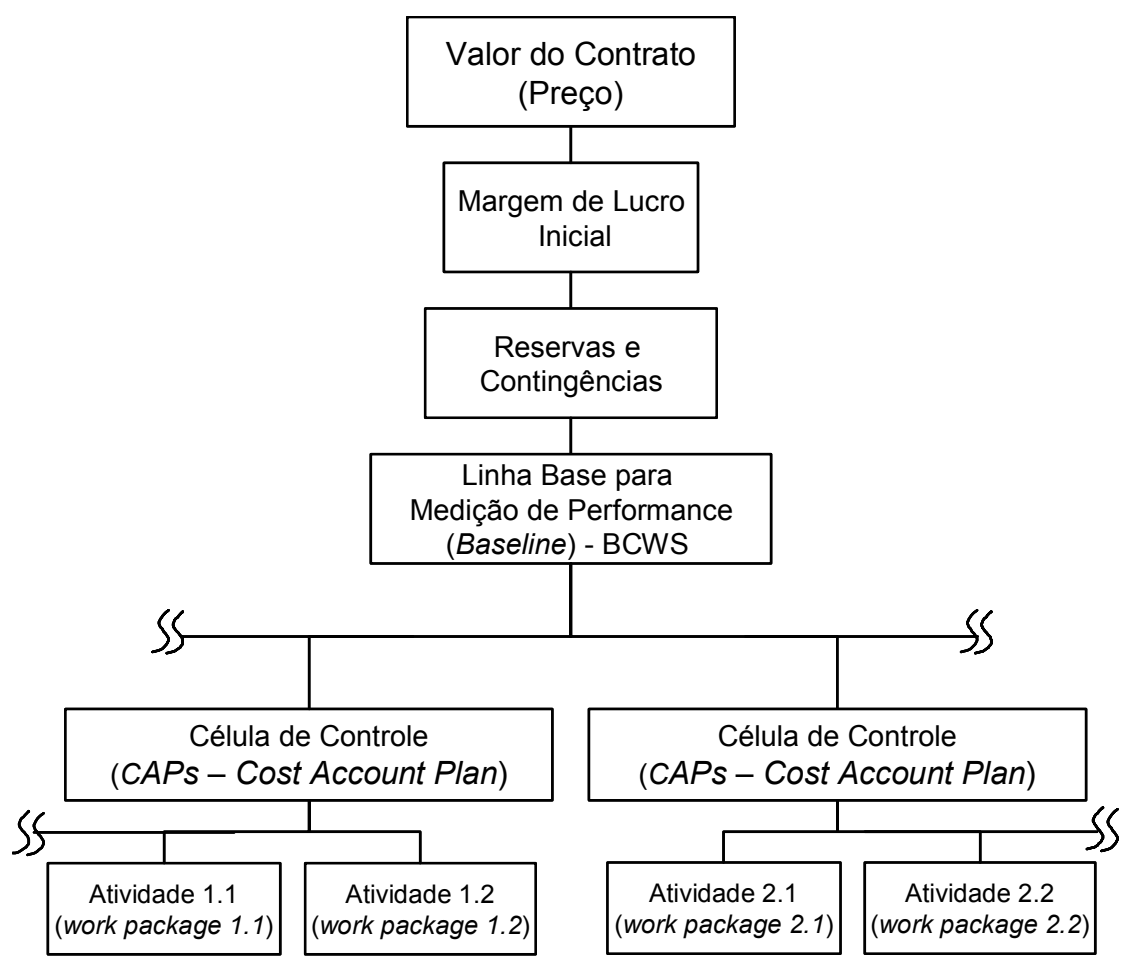

Figura 4.9 Relação entre o preço final do contrato e a linha de base para medição de performance (Flemming; Koppelman, 2000)

Assim como qualquer veículo de transporte de massa, um trem é composto por uma série de grandes conjuntos e sistemas que interagem entre si e proporcionam um funcionamento integrado ao mesmo.

A título de referência, um trem possui aproximadamente 20.000 itens diferentes, das mais diversas procedências, quantidades e graus de complexidade. Associadas a estes itens, existem diversas tecnologias de fabricação, manuseio, montagem e testes, requerendo assim uma ampla gama de profissionais qualificados. Estes itens, devido às suas naturezas, acabam sendo agrupados em três grupos de trabalho: estrutura, revestimentos e equipamentos. Estes agrupamentos são visíveis tanto na fase de projeto, como na fase de fabricação dos trens

Vale ressaltar que a maior parte dos materiais e sub-sistemas que compõem os trens é importada e atende padrões internacionais específicos para o mercado ferroviário. 
A Figura 4.10 apresenta o que seriam os primeiros níveis de um PBS:

\begin{tabular}{|c|c|}
\hline \multicolumn{2}{|r|}{ PBS } \\
\hline Cod. & Descrição \\
\hline 1.0 & Estrutura \\
\hline 1.1 & |------ Estrutura primária \\
\hline 1.2 & |------ Estrutura secundária (suporte equipamento/revestimento) \\
\hline 2.0 & Revestimento \\
\hline 2.1 & l-o--- Revestimento interno \\
\hline 2.2 & |----- Revestimento externo (máscara, spoiler, pintura) \\
\hline 3.0 & Sistemas e Equipamentos \\
\hline 3.1 & |---o---sistemas de Energia \\
\hline 3.1.1 & | | \\
\hline 3.1.2 & |------:Sistema de suprimento auxiliar de energia \\
\hline 3.1.2.1 & | |------- Inversores auxiliares \\
\hline 3.1.2.2 & |------o- Baterias \\
\hline 3.2 & |------- Sistemas Auxiliares \\
\hline 3.2.1 & |------o--Sistema pneumático \\
\hline 3.2 .2 & |----:-Sistema de monitoramento e comunicação \\
\hline 3.3 & |------ Sistemas de Climatização \\
\hline 3.3.1 & |---:-Unidade de Ar Condicionado \\
\hline 3.3.1.1 & I l-a-oradora \\
\hline 3.3.1.2 & |--- Unidade Condensadora \\
\hline 3.4 & |------ Sistemas de Tração e Frenagem \\
\hline 3.4.1 & |---Sistema de freios \\
\hline 3.4.2 & |-----: Sistema de tração e frenagem elétrica \\
\hline 3.5 & |------- Sistemas de Acessibilidade \\
\hline 3.5 .1 & | |----:Sistema de portas \\
\hline 3.6 & |------ Sistemas Dinâmicos e de Comportamento em Via \\
\hline 3.6.1 & I l-o-:-Truques \\
\hline 3.6.2 & |---------:- Suspensões \\
\hline
\end{tabular}

Figura 4.10 Primeiros níveis do PBS (exemplo de aplicação)

A interdependência técnica entre os sistemas de um trem é muito grande. Como exemplo, pode-se considerar o sistema de tração do trem, que trabalha em sincronia com o sistema de freio/antideslizamento que, por sua vez, depende do sistema pneumático e das pressões nas suspensões do trem. Há ainda um intertravamento entre o sistema de tração e o de portas, o qual também depende do sistema pneumático e do sistema de monitoramento e comunicação do trem. Enfim, caso um destes sistemas não esteja adequadamente dimensionado, pode haver um comprometimento no funcionamento global do trem. Como na indústria Naval, um projeto deste tipo passa por várias etapas que se repetem ao longo do tempo no 
intuito de serem refinadas e de convergirem para um resultado integrado final. Este processo seria o equivalente à tradicional "espiral de projeto".

Deste modo, percebe-se que a quantidade de variáveis existentes e inter-relacionadas é muito grande e, por conseguinte, grande também é a dificuldade na visualização de progresso do projeto e na projeção de custos e prazos.

\subsubsection{Aplicação}

Para a aplicação do valor agregado em um projeto como exposto no capítulo 4.6.3 devemos iniciar pela análise de suas fases.

Trata-se de um típico projeto de engenharia e fabricação. Portanto, é de se esperar que os maiores pesos, em termos de custo e desafio, estejam na engenharia de projeto, nos materiais e na montagem dos trens. Logo em seguida vem a fase de testes, que também tem papel importante no progresso do projeto. Obviamente existem outras atividades que se sobrepõem às acima citadas, por exemplo, eng. industrial, controle de qualidade, compras, pesquisa e desenvolvimento, etc. Estas atividades são estruturalmente muito importantes para a empresa, mas em termos de avaliação do desempenho do projeto acabam sendo muito menos impactantes e/ou significativas do que as outras, principalmente pela dimensão de seus escopos (obviamente pode haver casos em que estes itens sejam primordiais: desenvolvimento de novos produtos ou novos processos de fabricação, etc.).

A fase de engenharia é caracterizada por profissionais especialistas, em geral engenheiros e técnicos coordenando equipe de projetistas e desenhistas. É um trabalho de cunho intelectual e cuja mensuração de progresso pode ser difícil, uma vez que desenhos e procedimentos podem não representar todo o trabalho intelectual depositado. 
A fase de fabricação é caracterizada por alguns profissionais especialistas (engenheiros, técnicos e tecnólogos), porém a maior parte do seu efetivo é de operários fabris. É um trabalho menos abstrato e mais prático, cujo progresso é de fácil mensuração e acompanhamento. Pode ser bastante impactada por atrasos no recebimento de materiais, má qualidade de informações oriundas da Engenharia e conflitos de recursos com outros projetos.

A fase de testes é caracterizada também por profissionais especializados, em geral engenheiros e técnicos. É um trabalho cunho prático e muito importante pois é onde são validadas todas as fases anteriores do projeto. É, portanto, uma fase cheia de surpresas, onde o cliente faz uma rigorosa inspeção do produto e de suas funções. Seu progresso seria de fácil mensuração, porém, é nesta fase em que se detectam os erros de projeto (aspectos funcionais) e portanto seu comportamento pode não ser tão previsível.

Por possuírem uma grande proporção nos custos do projeto (acima de 50\%), existem mais dois elementos a serem levados em consideração:

- Materiais nível A (grandes subcontratados com defasagem em fluxo de caixa);

- Materiais níveis B e C (materiais de menor valor agregado e sem defasagem relevante no fluxo de caixa).

Estes itens também terão curvas individuais para análise.

Como referência da caracterização dos custos do projeto, segue um resumo dos principais grupos considerados no orçamento:

\begin{tabular}{|c|c|c|c|c|c|c|c|}
\hline Grupo & $\begin{array}{c}\text { Sub - } \\
\text { Contratados }\end{array}$ & Materiais & Fabricação & Eng $^{\mathbf{a}}$ & $\begin{array}{c}\text { Comissionamento e } \\
\text { Ass. Tec. }\end{array}$ & Outros & Total (BAC) \\
\hline Valor $(\mathrm{kR} \$)$ & 12.549 & 24.713 & 12.561 & 6.988 & 1.000 & 1.900 & 59.711 \\
\hline$\%$ & $21,0 \%$ & $41,4 \%$ & $21,0 \%$ & $11,7 \%$ & $1,7 \%$ & $3,2 \%$ & $100,0 \%$ \\
\hline
\end{tabular}

Figura 4.11 Caracterização dos custos do projeto conforme orçamento 
Vale alertar que uma análise simplista dos valores apresentados na Figura 4.11 pode levar a conclusões errôneas. Em uma comparação apenas de custos, pode-se imaginar que as atividades de "Engenharia" e "Comissionamento/Assistência Técnica" não são tão relevantes no projeto quanto "Subcontratados" e "Materiais". Entretanto, a Engenharia é quem dá o ritmo inicial ao projeto e a sua influência se dá em todos os outros grupos. Da mesma forma, o Comissionamento também é muito importante pois, conforme já mencionado, nesta fase todo o projeto é avaliado, os erros de todas as fases anteriores são corrigidos e é a fase que concretiza a aceitação por parte do cliente (em geral estas aceitações estão vinculadas a eventos de pagamento).

Seguindo os critérios anteriormente expostos, serão confeccionados gráficos para a análise do projeto como um todo e dos seus principais grupos individualmente (Engenharia, Fabricação, Aquisição de Materiais, Subcontratados e Comissionamento \& Assistência Técnica).

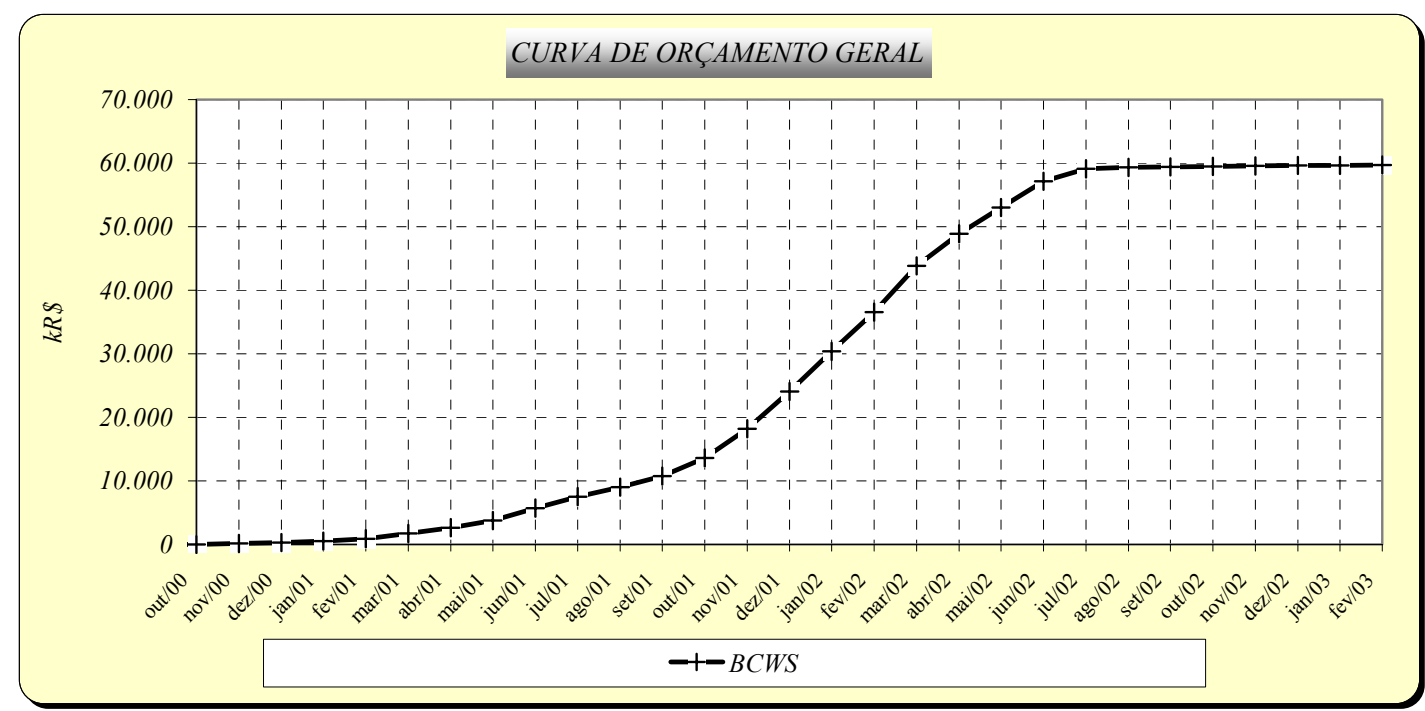

Figura 4.12 Linha de Base do Orçamento (baseline - BCWS) geral

Para uma análise financeira, esta curva de orçamento (Figura 4.12) já seria suficiente, pois agrega valores, prazos e indica a tendência de gastos (importante para análises de fluxo de caixa). Porém, para um Gerente de Projetos que quer ter controle efetivo do projeto através da AVA e sem recorrer constantemente a outras ferramentas, faz- 
se necessário agregar elementos que indiquem eventos físicos principais. Alguns exemplos podem ser observados na Figura 4.13.

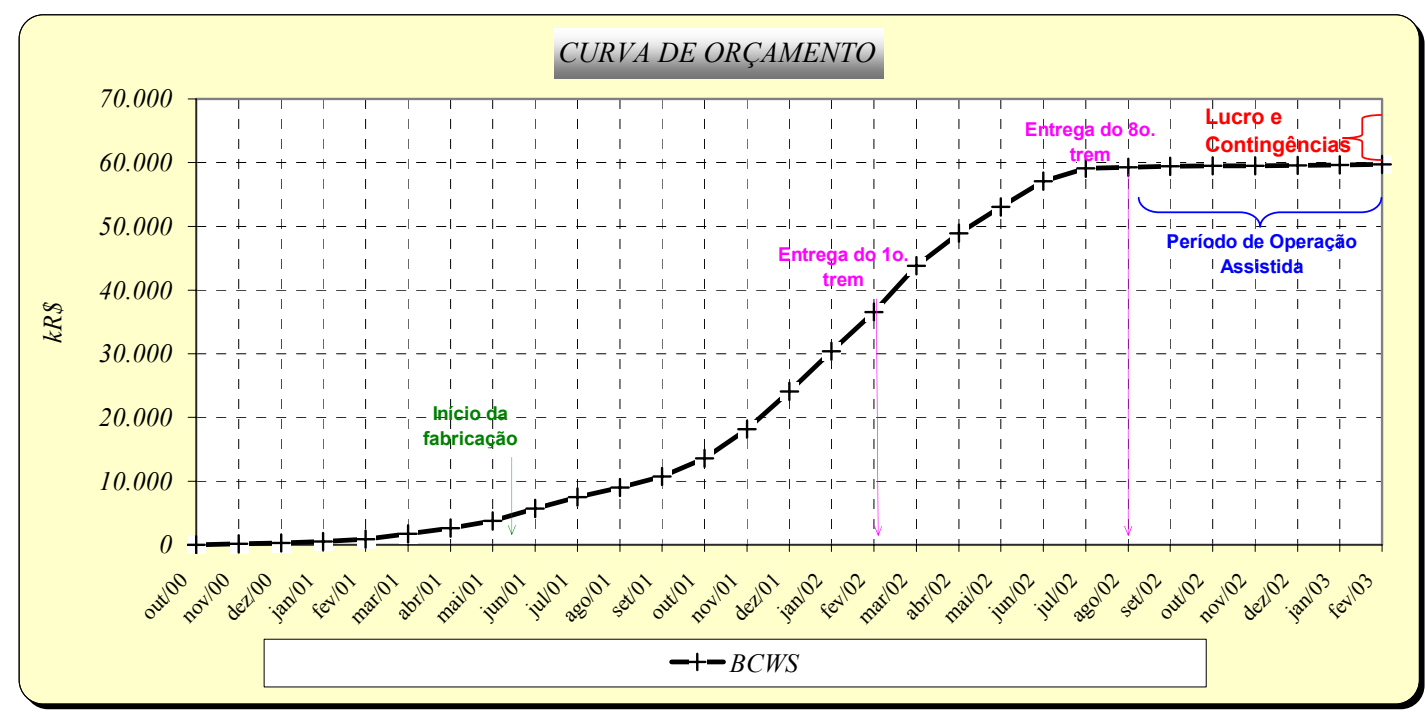

Figura 4.13 Curva de orçamento geral com eventos físicos

Através da identificação destes eventos físicos pode-se visualizar os esforços necessários previstos para alcançar os principais marcos do projeto. Exemplo: para se entregar o $1^{\circ}$ trem, é necessário que se despenda aproximadamente $60 \%$ dos recursos planejados para todo o projeto.

Com os dados utilizados para a confecção da curva de orçamento torna-se possível analisar a natureza dos custos ao longo do projeto.

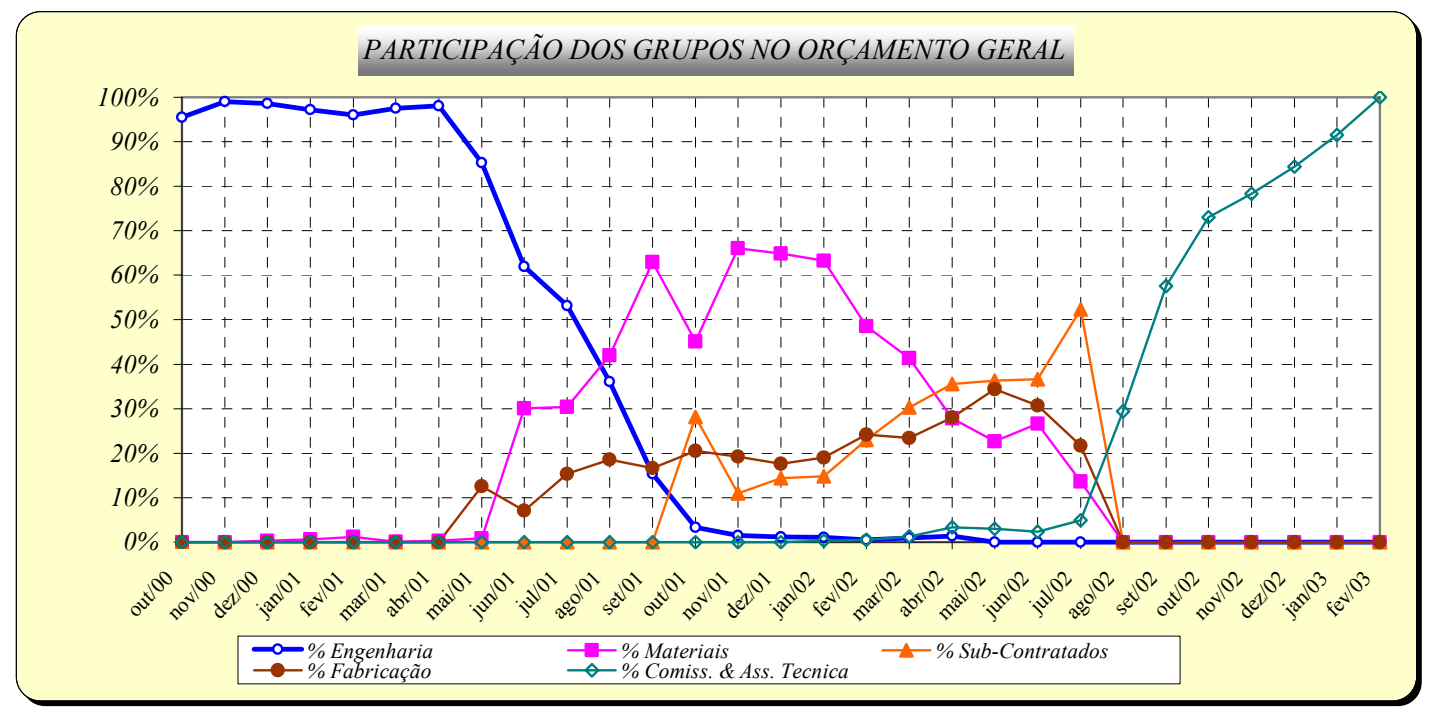

Figura 4.14 Participação dos principais grupos de atividade no orçamento 
A Figura 4.14 confirma a preponderância das atividades de Engenharia no início do projeto e as de Comissionamento no seu fim. Já entre os meses de Junho/01 e Julho/02 existe uma sobreposição de vários grupos de atividades, sobre a qual deve ser dada atenção especial, pois o progresso macro do projeto pode não revelar deficiências em um destes grupos. Se o gestor não tiver informações sobre cada grupo, problemas podem ser "mascarados", passando despercebidos e, no futuro, aparecerem de maneira irreversível. Aplicar a Análise de Valor Agregado a cada grupo de atividades passa a ser importante para um melhor controle do projeto.

Serão levantadas portanto as curvas dos principais grupos de atividades do projeto (vide Figura 4.15).

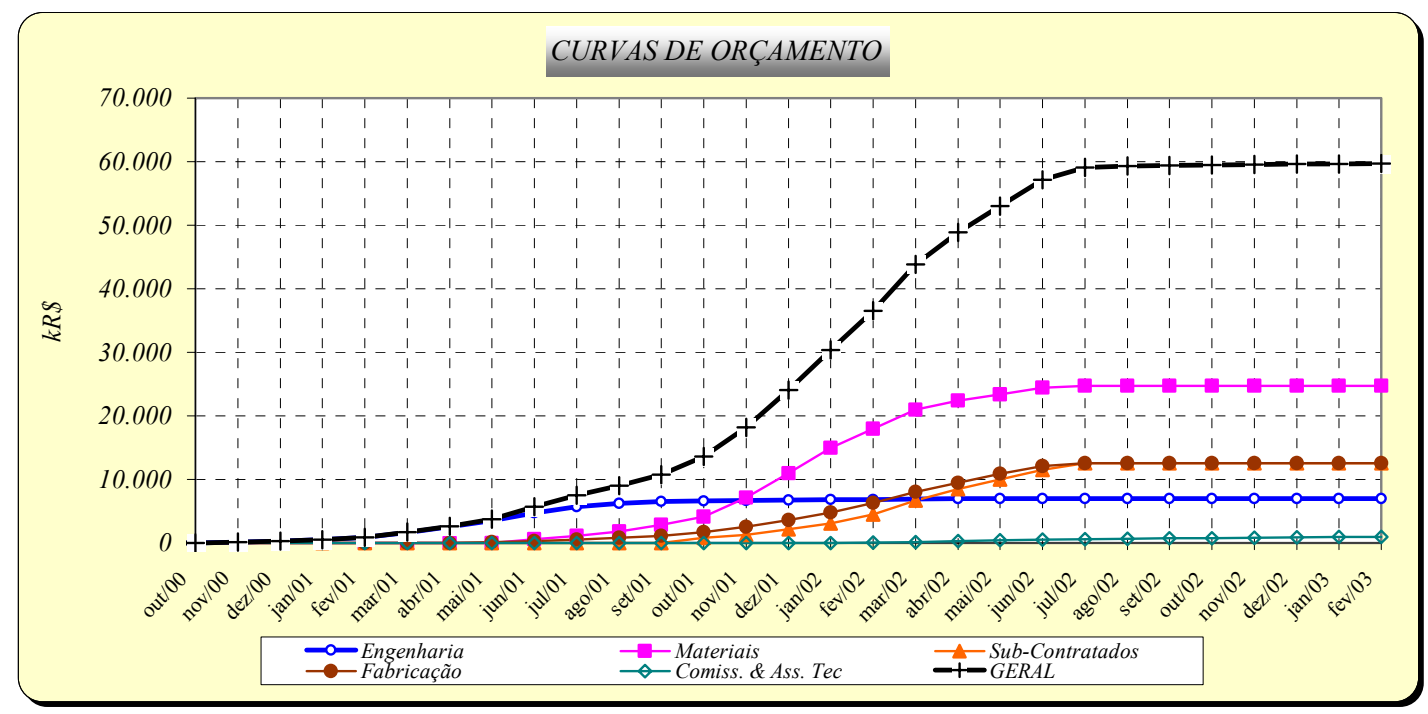

Figura 4.15 Orçamento geral e de cada grupo principal

Para as análises dos dados serão calculados os índices $\mathrm{CPI}_{\mathrm{c}}$ e $\mathrm{SPI}_{\mathrm{c}}$ (acumulados) por serem os mais simples e de interpretação imediata. 


\subsubsection{Análise do progresso - 20\% de execução}

Embora os progressos sejam medidos mensalmente desde o início do projeto, será analisado primeiramente o progresso a aproximadamente $20 \%$ de sua execução conforme planejamento original. Esta data foi escolhida, pois é muito referenciada na literatura como uma data em que o índice CPIc se estabiliza (Christensen, 1993). Como o projeto foi iniciado em Outubro/00, 20\% de execução planejada representa aproximadamente 6 meses, portanto, a referência mais próxima para análise será o mês de Abril/01.

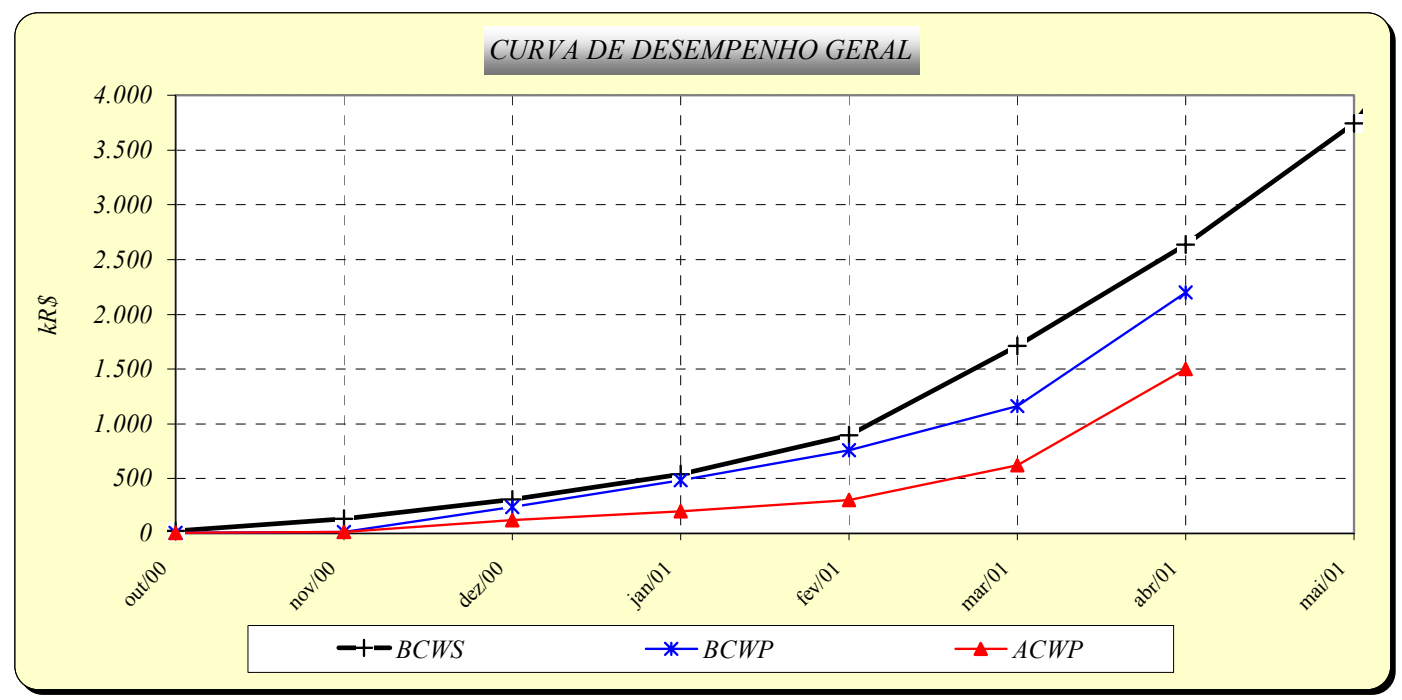

Figura 4.16 Desempenho geral - 20\% de execução

Através do gráfico nota-se que o projeto está progredindo com um certo atraso $(\mathrm{TV}=$ 15 dias), porém, para surpresa geral, seu desempenho em custos está bom $(\mathrm{CV}=$ kR \$700). Isto se confirma pelos índices apresentados abaixo (Figura 4.17):

\begin{tabular}{|c|r|r|r|r|r|r|r|}
\cline { 2 - 8 } \multicolumn{1}{c|}{} & \multicolumn{1}{c|}{ out/00 } & nov/00 & \multicolumn{1}{c|}{ dez/00 } & jan/01 & fev/01 & mar/01 & abr/01 \\
\hline CPIc & 1,59 & 1,47 & 1,96 & 2,39 & 2,48 & 1,87 & 1,47 \\
\hline SPIc & 0,28 & 0,09 & 0,77 & 0,90 & 0,85 & 0,68 & 0,83 \\
\hline
\end{tabular}

Figura 4.17 Índices de desempenho - 20\% de execução 
Através dos índices apresentados, podem ser calculadas as projeções futuras de custos e prazos.

- $\mathrm{TAC}=\frac{\mathrm{PAC}}{\mathrm{SPI}_{\mathrm{c}}}=\frac{28 \text { meses }}{0,83}=34$ meses

- $\mathrm{EAC}=\mathrm{ACWP}_{\mathrm{c}}+\frac{\left(\mathrm{BAC}-\mathrm{BCWP}_{\mathrm{c}}\right)}{\mathrm{CPI}_{\mathrm{c}}}=\$ 1.502+\frac{(\$ 57.509)}{1,47}=\$ 40.742$

Deste modo, caso o projeto permaneça com o mesmo desempenho, haveria um atraso final de 6 meses e uma economia de aproximadamente $31 \%$ nos seus custos previstos.

Este bom desempenho em termos de custos, e que vem desde o início do projeto, induz o Gerente de Projetos a implementar recursos adicionais para recuperar o atraso existente, uma vez que ele teria folga no orçamento para tal ação.

Através das figuras 4.14 e 4.15 confirma-se também que, até a referida data, a grande maioria das atividades planejadas eram de Engenharia. Não há, portanto, a necessidade de se examinar as curvas individuais dos demais grupos. $\mathrm{O}$ desempenho do projeto como um todo é praticamente o mesmo da Engenharia.

No entanto, é difícil acreditar, neste caso, que as projeções de custos e prazos acima calculadas sejam confiáveis. Ainda existem muitas atividades de naturezas diferentes por vir, e que certamente influenciarão no desempenho do projeto. A probabilidade de o CPIc não estar estabilizado ainda é muito grande. 
A próxima data para avaliação do progresso do projeto será Agosto/01 (aprox. 33\% da sua execução planejada). Esta data foi escolhida baseada na figura 4.14, pois é uma data onde se previa um consumo de recursos de Engenharia, Fabricação e Aquisição de Materiais em proporções semelhantes.

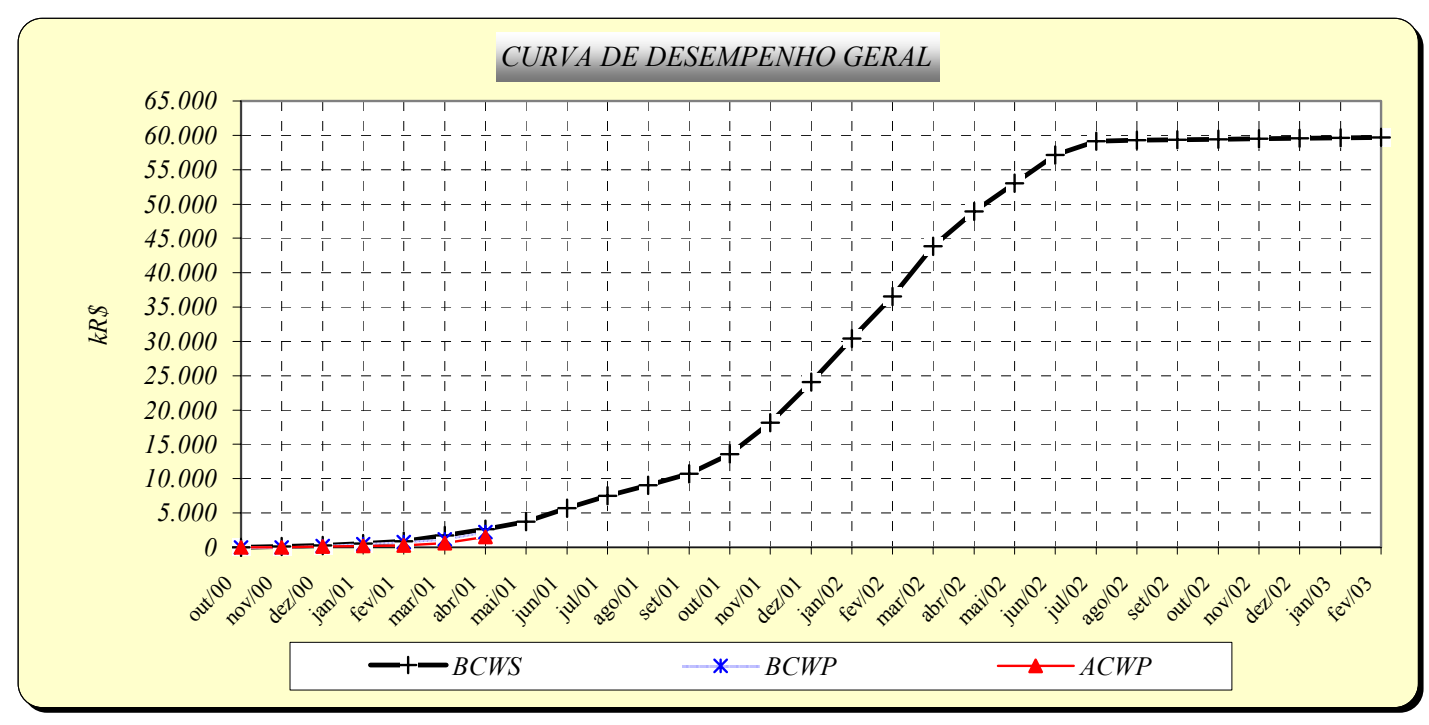

Figura 4.18 Desempenho geral - 33\% de execução

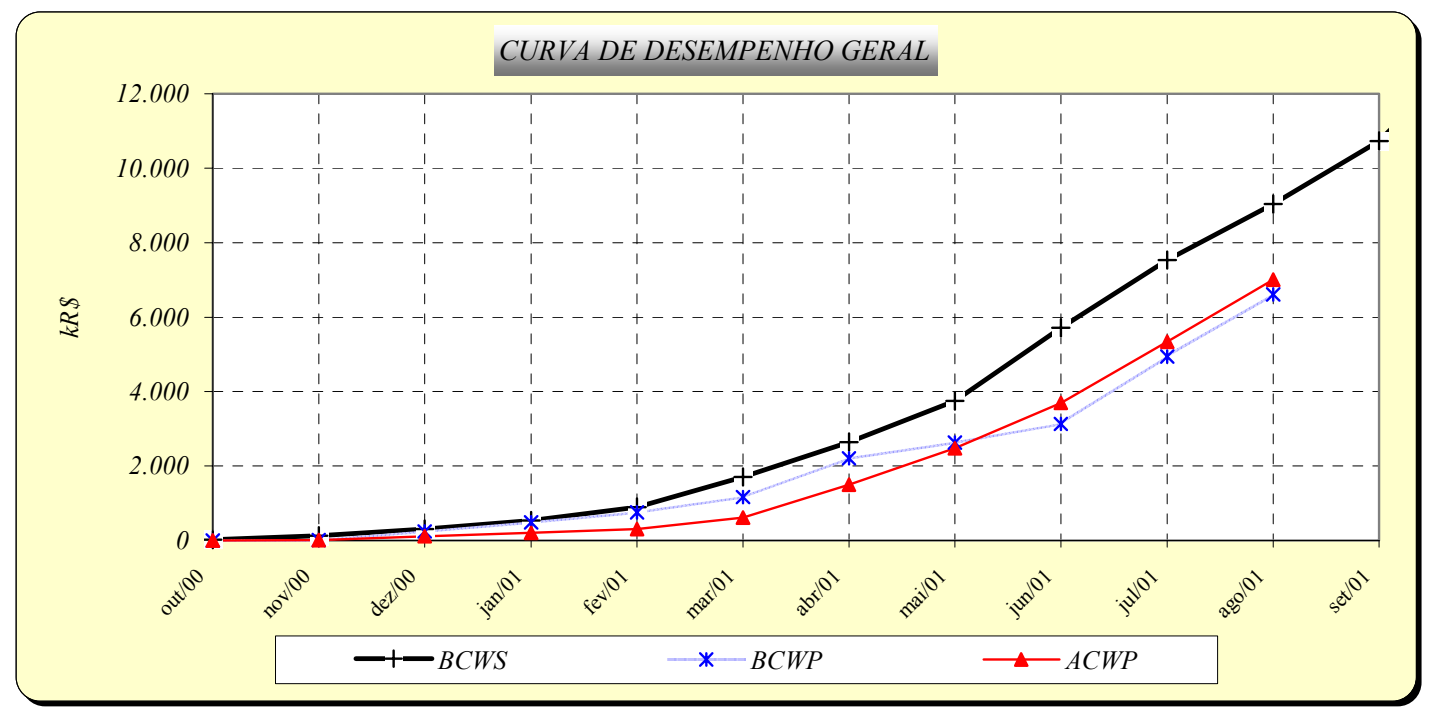

Figura 4.19 Desempenho geral - 33\% de execução (detalhe) 


\begin{tabular}{|r|r|r|r|r|}
\cline { 2 - 5 } \multicolumn{1}{c|}{} & mai/01 & jun/01 & jul/01 & ago/01 \\
\hline CPIc & 1,06 & 0,85 & 0,93 & 0,94 \\
\hline SPIc & 0,70 & 0,55 & 0,66 & 0,73 \\
\hline
\end{tabular}

\section{Figura 4.20 Índices de desempenho geral - 33\% de execução}

Através dos gráficos e dos índices apresentados, percebe-se que o projeto permanece atrasado e que passou a apresentar índices de desempenho de custos (CPI) degradados.

Assim, surgem as dúvidas: Qual é a causa da degradação no índice CPI? Por que a curva de progresso físico (BCWP) teve uma variação brusca na sua inclinação (entre os meses de Abril/01 e Junho/01)? Por que o atraso do projeto aumentou sendo que mais recursos foram adicionados para recuperá-lo? Onde estará o problema: na Engenharia, na Fabricação ou na Aquisição de Materiais?

Este diagnóstico fica muito difícil através dos gráficos e dos índices gerais de desempenho. Pela atualização do cronograma e redes PERT/CPM pode também não ser possível mensurar quem está causando o maior impacto. Entretanto, é possível que a resposta se encontre nas curvas individuais de cada fase.

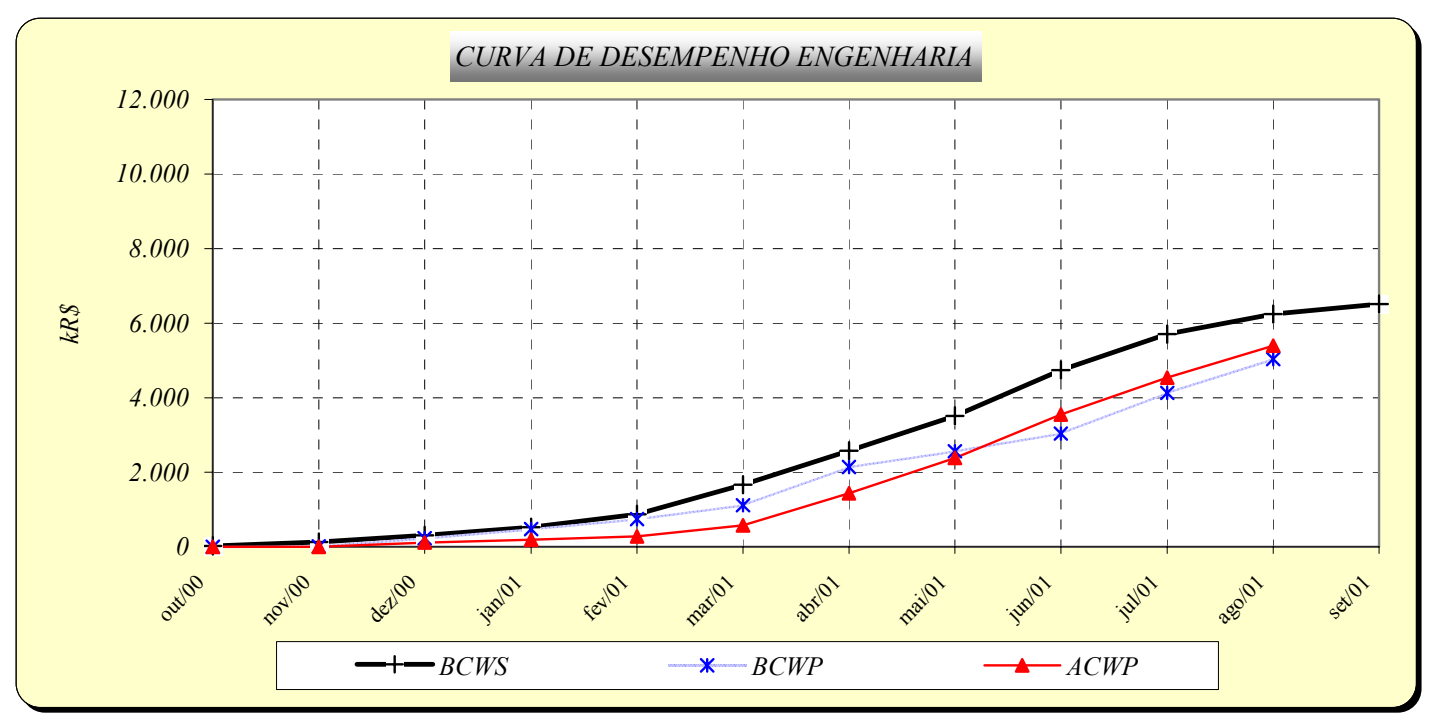

Figura 4.21 Desempenho da Engenharia - 33\% de execução 


\begin{tabular}{|r|r|r|r|r|}
\cline { 2 - 5 } \multicolumn{1}{c|}{} & mai/01 & jun/01 & jul/01 & ago/01 \\
\hline CPIc & 1,07 & 0,85 & 0,91 & 0,94 \\
\hline SPIc & 0,73 & 0,64 & 0,72 & 0,81 \\
\hline
\end{tabular}

Figura 4.22 Î́ndices de desempenho de Engenharia - 33\% de execução

Observa-se que o CPI de Engenharia está realmente se degradando e, pelo SPI percebe-se que ainda não há recuperação de atrasos em relação à avaliação de Abril/01. Os recursos adicionais alocados parecem não terem sido suficientes para a recuperação do atraso.

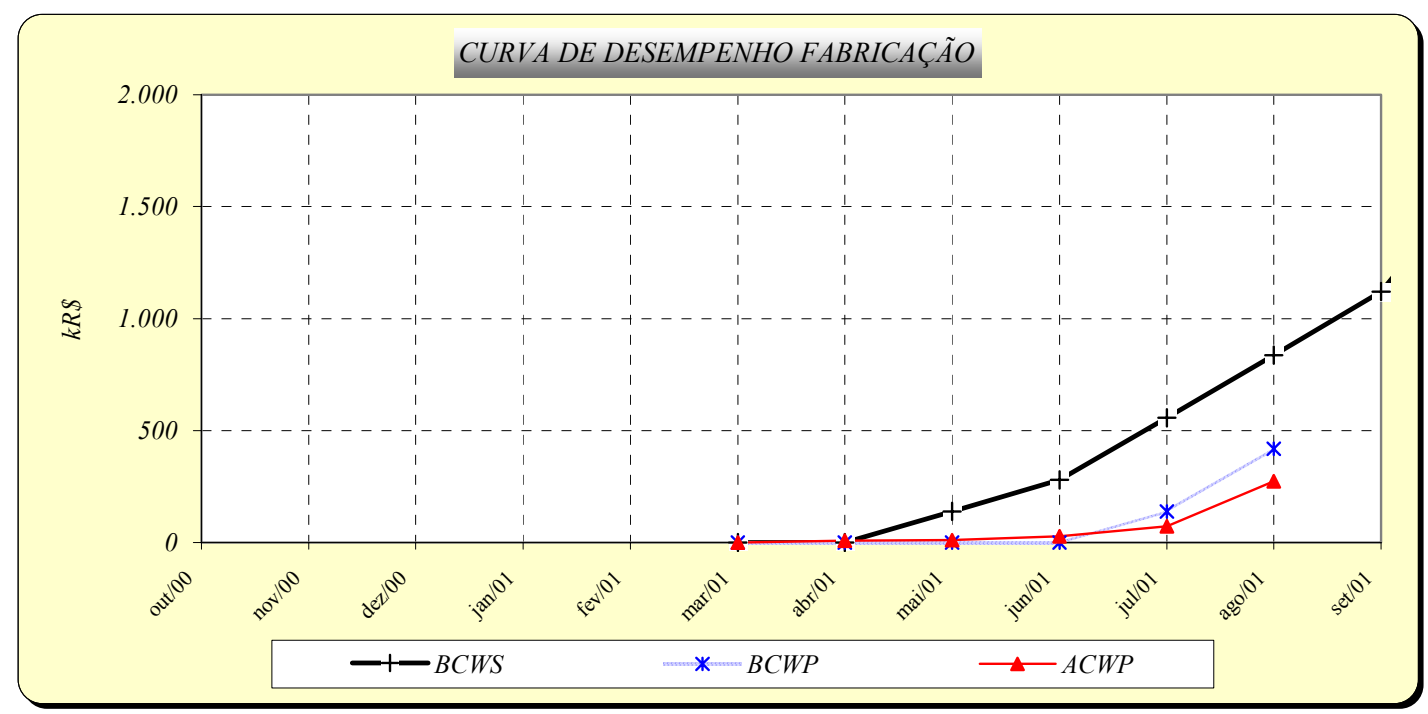

Figura 4.23 Desempenho da Fabricação - 33\% de execução

\begin{tabular}{|c|c|c|r|r|}
\cline { 2 - 5 } \multicolumn{1}{c|}{} & mai/01 & jun/01 & jul/01 & ago/01 \\
\hline CPIc & - & - & 1,91 & 1,53 \\
\hline SPIc & - & - & 0,25 & 0,50 \\
\hline
\end{tabular}

Figura 4.24 Índices de desempenho de Fabricação - 33\% de execução

A Fabricação está bastante atrasada, porém o seu desempenho em custos está bom. Nota-se, entretanto, que o maior atraso se deu no início da fabricação (a previsão era iniciar em Abril/01, porém só foi iniciada em meados de Maio/01). Este atraso não 
pode estar ligado exclusivamente ao desempenho da Fabricação e sim à falta de informações da Engenharia ou à falta de Materiais.

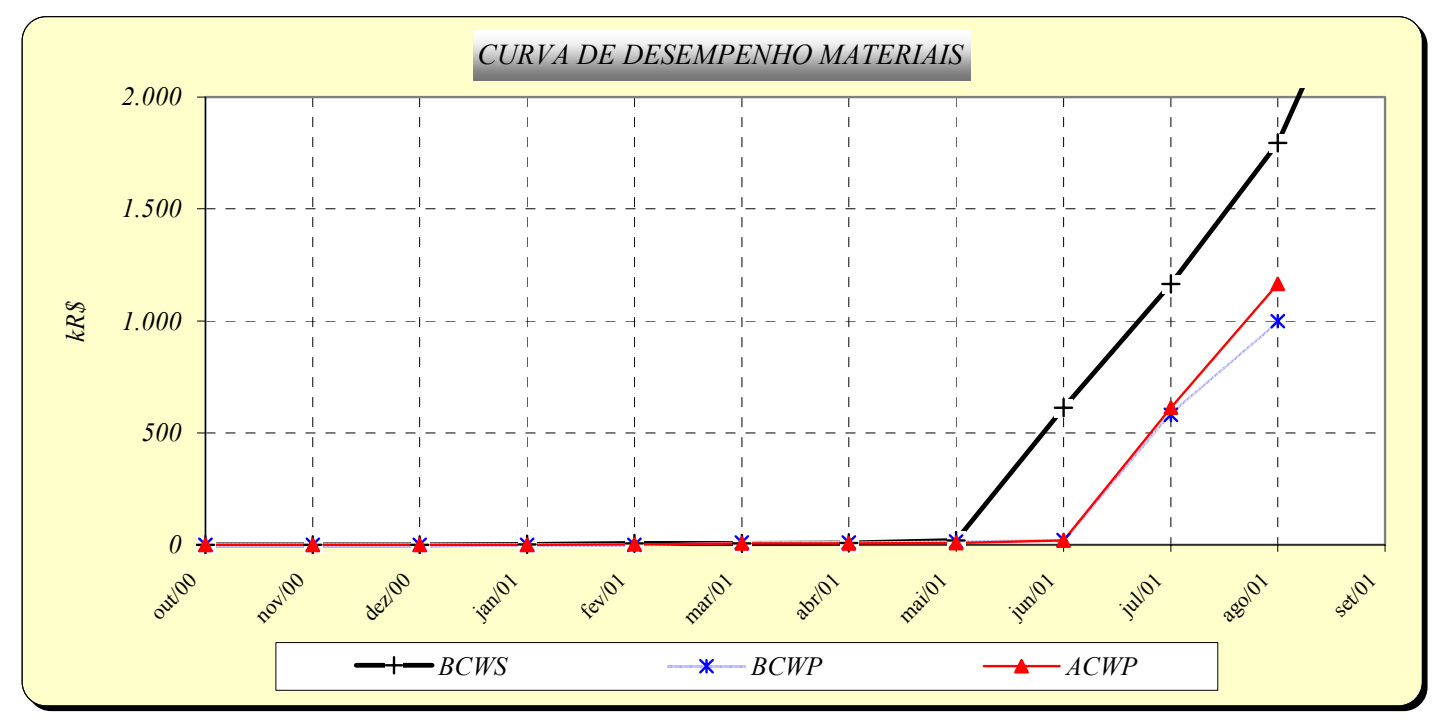

Figura 4.25 Desempenho da Aquisição de Materiais - 33\% de execução

\begin{tabular}{|r|r|r|r|r|}
\cline { 2 - 5 } \multicolumn{1}{c|}{} & mai/01 & jun/01 & jul/01 & ago/01 \\
\hline CPIc & 1,56 & 1,09 & 0,95 & 0,86 \\
\hline SPIc & 0,78 & 0,03 & 0,50 & 0,56 \\
\hline
\end{tabular}

Figura 4.26 Índices de desempenho de Materiais - 33\% de execução

A Aquisição de Materiais também teve início tardio (muito provavelmente devido ao atraso nas informações de Engenharia). Seu desempenho de custos também está se degradando com o tempo. Este último pode estar relacionado a aumentos não previstos nos preços (reajustes) ou à má "orçamentação" em termos de quantidade de material e/ou de custos.

Os gráficos indicam também que existem atrasos em todas as atividades, porém as que exercem até agora a maior influência geral no projeto são as de Engenharia (justificável pela proporção entre os montantes envolvidos de cada tipo de atividade). 
E quanto aos questionamentos da página 99, sabe-se agora que a resposta para eles é uma só: o progresso das atividades no início do projeto foi superestimado, pois não haviam critérios adequados para a sua medição. Trata-se da já mencionada “síndrome dos 90\%" (vide página 82), que ocorreu nas atividades de Engenharia. Este erro na medição de progresso físico provocou um enorme equívoco na avaliação global do projeto. De fato, na $1^{a}$ avaliação realizada ( $20 \%$ de execução), o projeto estava mais atrasado do que parecia e seu desempenho em custos também estava pior do que parecia. Esta situação ressalta a importância da escolha de um bom sistema de avaliação de desempenho (métrica e coletores).

A partir de então, foi elaborada junto à Engenharia, e em consenso com os demais departamentos funcionais da empresa (Fabricação, Compras, etc.), uma nova métrica para a medição de progresso da Engenharia, procurando evitar novas distorções. Originalmente a avaliação ficava totalmente sob a responsabilidade do Engenheiro Líder, que utilizava somente critérios subjetivos para esta avaliação. Procurou-se, portanto, definir pontos de controle que limitavam a subjetividade desta avaliação (vide página 82). Esta re-estruturação no sistema de avaliação de desempenho foi bastante extensa e detalhada, porém aqui podemos citar algumas premissas adotadas:

- O projeto de um sistema só pode ter $50 \%$ de progresso se todos os materiais deste sistema foram especificados e liberados para a devida aquisição;

- O projeto de um sistema só pode atingir 95\% de progresso quando o mesmo for liberado no sistema ERP e distribuído aos demais envolvidos na empresa;

- O projeto só atinge $100 \%$ de progresso quando houver algum tipo de validação do mesmo (pela Eng. de Processos, Fabricação ou Testes).

Além de critérios deste tipo, a porcentagem de progresso é definida sempre em comum acordo entre os principais envolvidos.

Para as projeções de custo e prazos finais serão realizados dois cálculos, para fins de comparação: o primeiro com os índices gerais, e o segundo com os índices de 
Aquisição de Materiais, pois é esta atividade, juntamente com a Fabricação, que passará a dominar, em breve, os custos e prazos do projeto.

1) Projeções com os índices gerais:

- $\mathrm{TAC}=\frac{\mathrm{PAC}}{\mathrm{SPI}_{\mathrm{c}}}=\frac{28 \text { meses }}{0,73}=38$ meses

- $\mathrm{EAC}=\mathrm{ACWP}_{\mathrm{c}}+\frac{\left(\mathrm{BAC}-\mathrm{BCWP}_{\mathrm{c}}\right)}{\mathrm{CPI}_{\mathrm{c}}}=\$ 2.201+\frac{(\$ 59.711-\$ 1.502)}{0,94}=\$ 64.126$

2) Projeções com os índices de Aquisição de Materiais

- $\mathrm{TAC}=\frac{\mathrm{PAC}}{\mathrm{SPI}_{\mathrm{c}}}=\frac{28 \text { meses }}{0,56}=50$ meses

- $\quad \mathrm{EAC}=\mathrm{ACWP}_{\mathrm{c}}+\frac{\left(\mathrm{BAC}-\mathrm{BCWP}_{\mathrm{c}}\right)}{\mathrm{CPI}_{\mathrm{c}}}=\$ 2.201+\frac{(\$ 59.711-\$ 1.502)}{0,86}=\$ 69.885$

Conforme previsto, em ambos os casos haverá sobre-custos ao projeto e, o mais importante é que, caso não seja melhorada a política de aquisição de materiais, o prazo do projeto pode praticamente dobrar.

Com este intuito, procurou-se avaliar quais ações poderiam auxiliar na antecipação de prazos para aquisição de materiais. Dentre elas, podem ser citadas a renegociação de prazos com fornecedores, a utilização de transporte aéreo para itens importados e a emissão de listas de material antecipadas pela Engenharia (assumindo-se os riscos quanto aos erros de quantidade e especificação que poderiam surgir). 
A próxima data para avaliação do projeto é Jan/02 (aprox. 50\% da sua execução planejada). Esta data foi escolhida por estar muito próxima de um evento importante: a entrega do $1^{\circ}$. Trem, prevista para Fevereiro/02. Nesta fase, o planejamento original previa poucas atividades de Engenharia, porém muitas de Fabricação, Aquisição de Materiais e Fornecimentos Subcontratados.

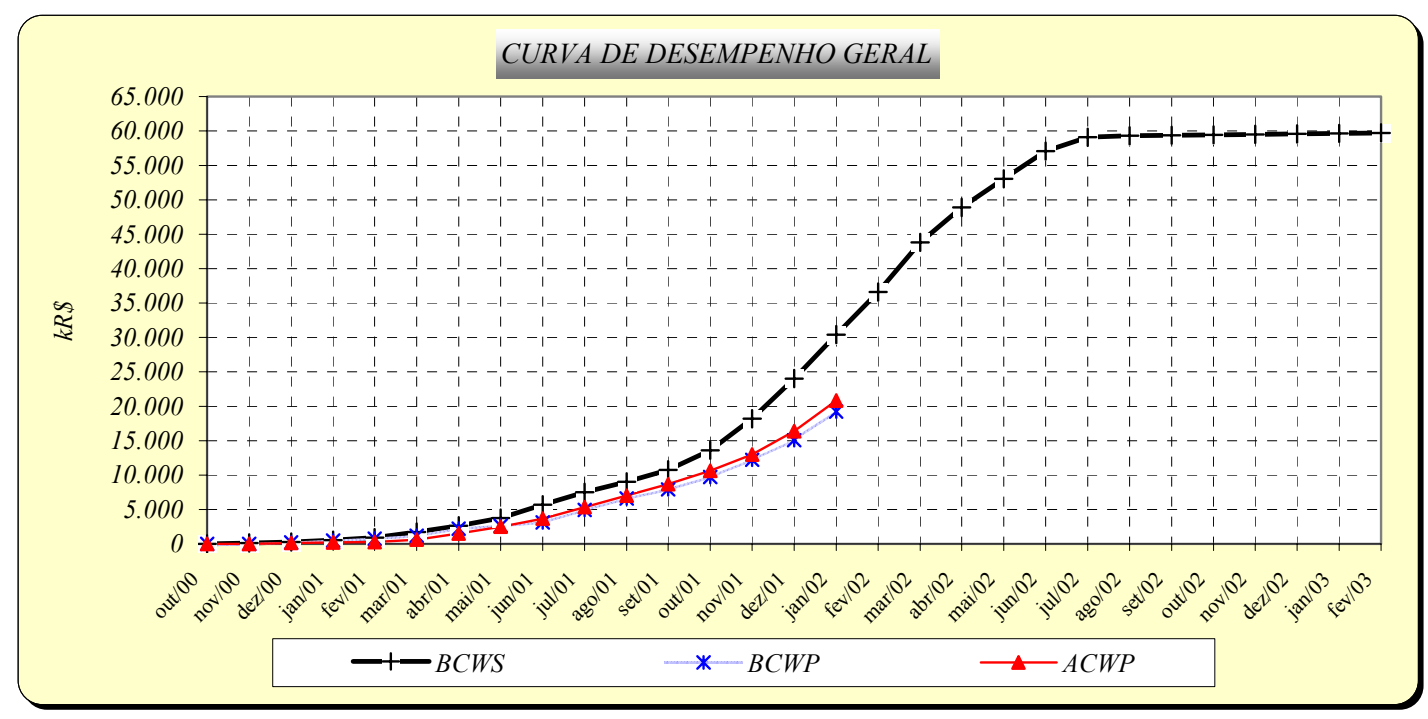

Figura 4.27 Desempenho geral - 50\% de execução

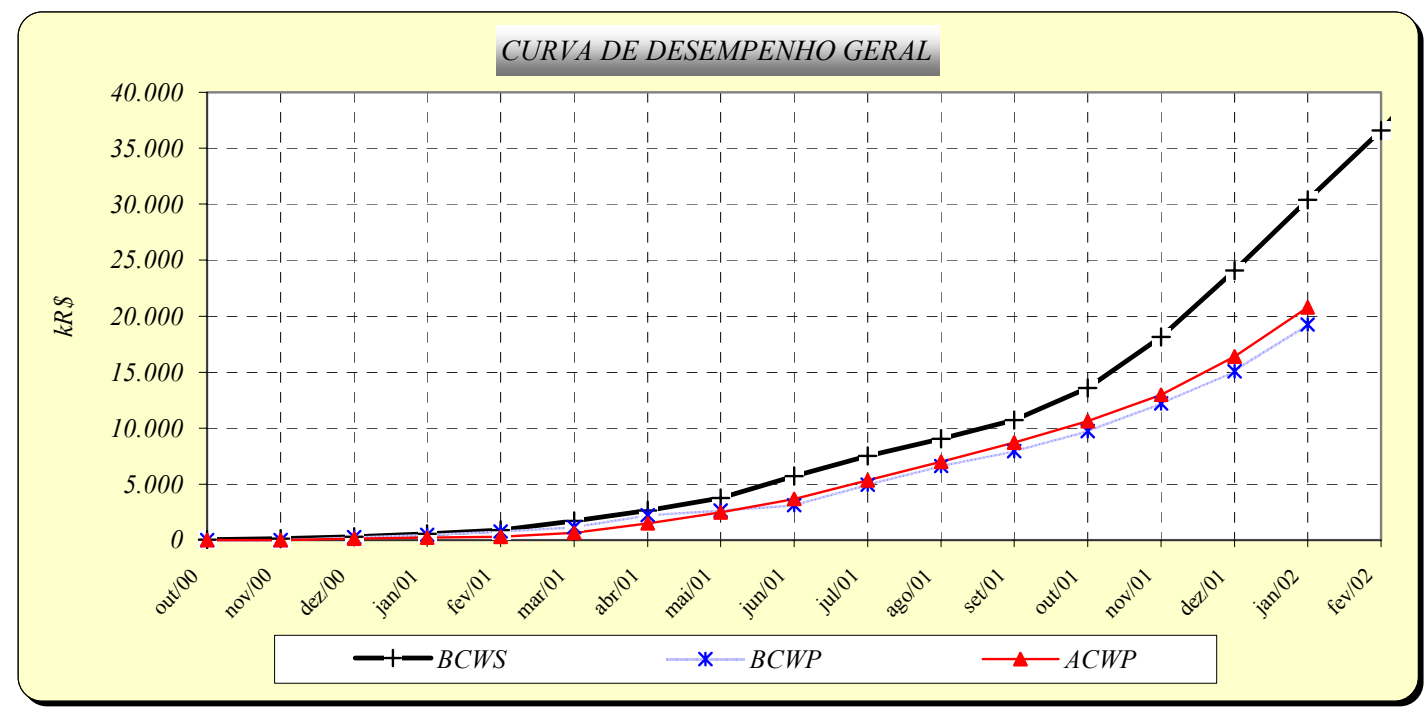

Figura 4.28 Desempenho geral - 50\% de execução (detalhe) 


\begin{tabular}{|c|r|r|r|r|r|}
\cline { 2 - 6 } \multicolumn{1}{c|}{ Geral } & set/01 & out/01 & nov/01 & dez/01 & jan/02 \\
\hline CPIc & 0,91 & 0,91 & 0,94 & 0,92 & 0,92 \\
\hline SPIc & 0,74 & 0,72 & 0,67 & 0,63 & 0,63 \\
\hline
\end{tabular}

Figura 4.29 Índices de desempenho geral - 50\% de execução

Em contrapartida às avaliações anteriores, o índice $\mathrm{CPI}_{\mathrm{c}}$ parece estar se estabilizando. Por outro lado, o índice $\mathrm{SPI}_{\mathrm{c}}$ continua se degradando.

Pelo progresso físico e por averiguações in loco, já se sabe que o $1^{\circ}$ trem não poderá ser entregue no prazo original (Fev/02) totalmente testado.

Vale analisar os progressos individuais de cada grupo de atividade para um melhor diagnóstico sobre quem pode estar causando os maiores impactos.

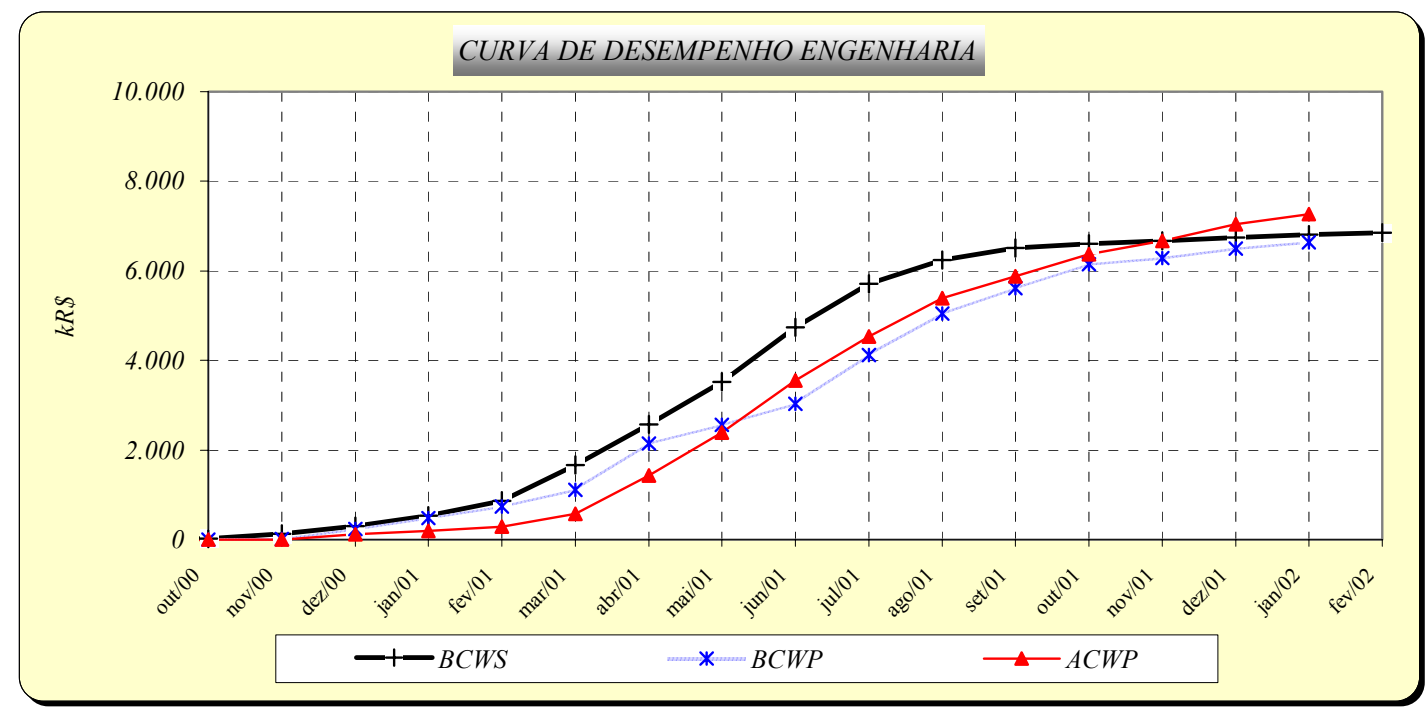

Figura 4.30 Desempenho de Engenharia - 50\% de execução

\begin{tabular}{|r|r|r|r|r|r|}
\cline { 2 - 6 } \multicolumn{1}{c|}{} & set/01 & out/01 & nov/01 & dez/01 & jan/02 \\
\hline CPIc & 0,95 & 0,97 & 0,94 & 0,92 & 0,91 \\
\hline SPIc & 0,86 & 0,93 & 0,94 & 0,96 & 0,97 \\
\hline
\end{tabular}

Figura 4.31 Índices de desempenho de Engenharia - 50\% de execução 
Estas informações já registram um sobre-custo efetivo de, no mínimo, kR \$278 (4\%) nas atividades de Engenharia. E mesmo já estando em atividades avançadas, o índice $\mathrm{CPI}_{\mathrm{c}}$ de Engenharia vem se degradando progressivamente. Uma provável causa é o excesso de revisões de projeto cujas necessidades surgiram durante as montagens do $1^{\mathrm{o}}$ trem e seus respectivos testes. Caso seja esta a razão, este índice acaba retratando o impacto que a não-qualidade das atividades de Engenharia produz no projeto.

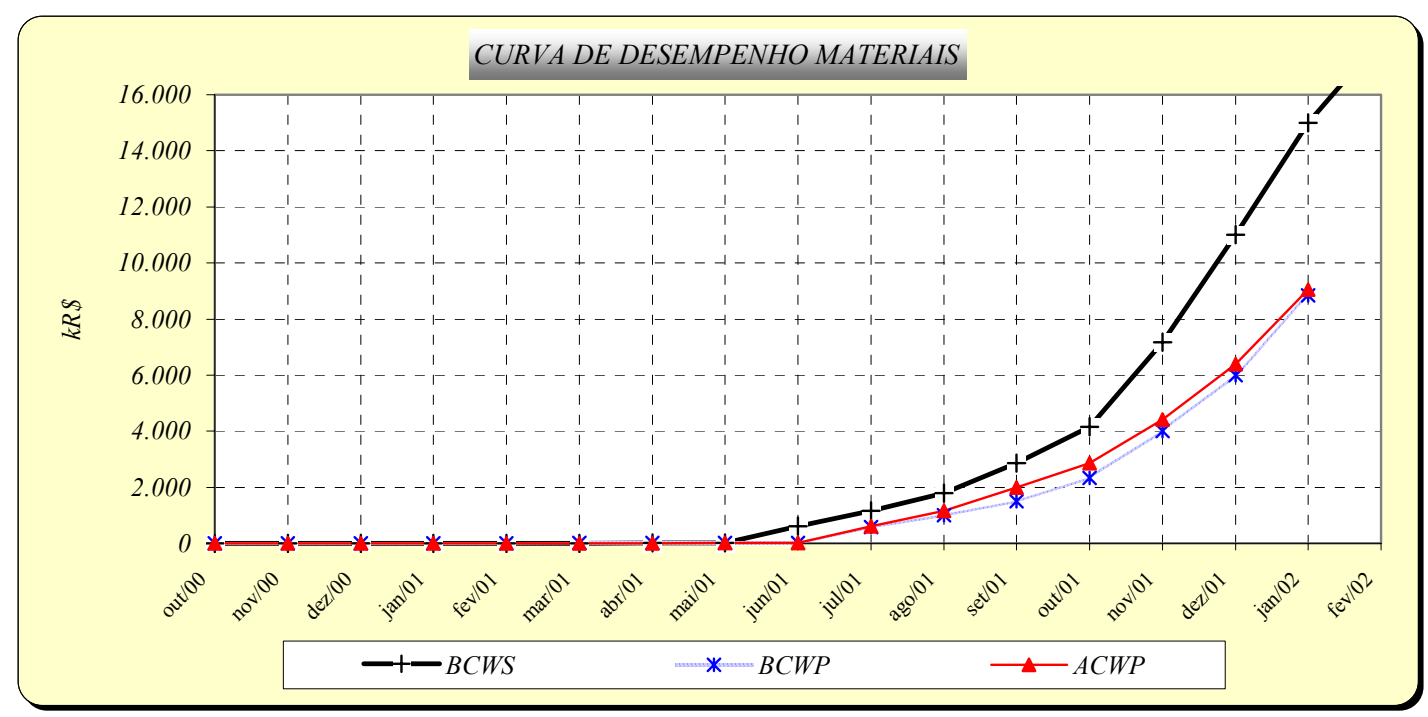

Figura 4.32 Desempenho de Materiais - 50\% de execução

\begin{tabular}{|r|r|r|r|r|r|}
\cline { 2 - 6 } \multicolumn{1}{c|}{} & set/01 & out/01 & nov/01 & dez/01 & jan/02 \\
\hline CPIc & 0,75 & 0,82 & 0,90 & 0,94 & 0,98 \\
\hline SPIc & 0,52 & 0,56 & 0,56 & 0,55 & 0,59 \\
\hline
\end{tabular}

Figura 4.33 Índices de desempenho de Materiais - 50\% de execução

Pelas informações da Figura 4.33, a Aquisição de Materiais continua sendo também um ponto crítico no projeto, em termos de prazos. Certamente continuará impactando a fabricação dos trens.

Novamente, deve-se melhorar a política de recuperação de prazos, conforme mencionado na Análise de Desempenho a 33\% de Execução. 


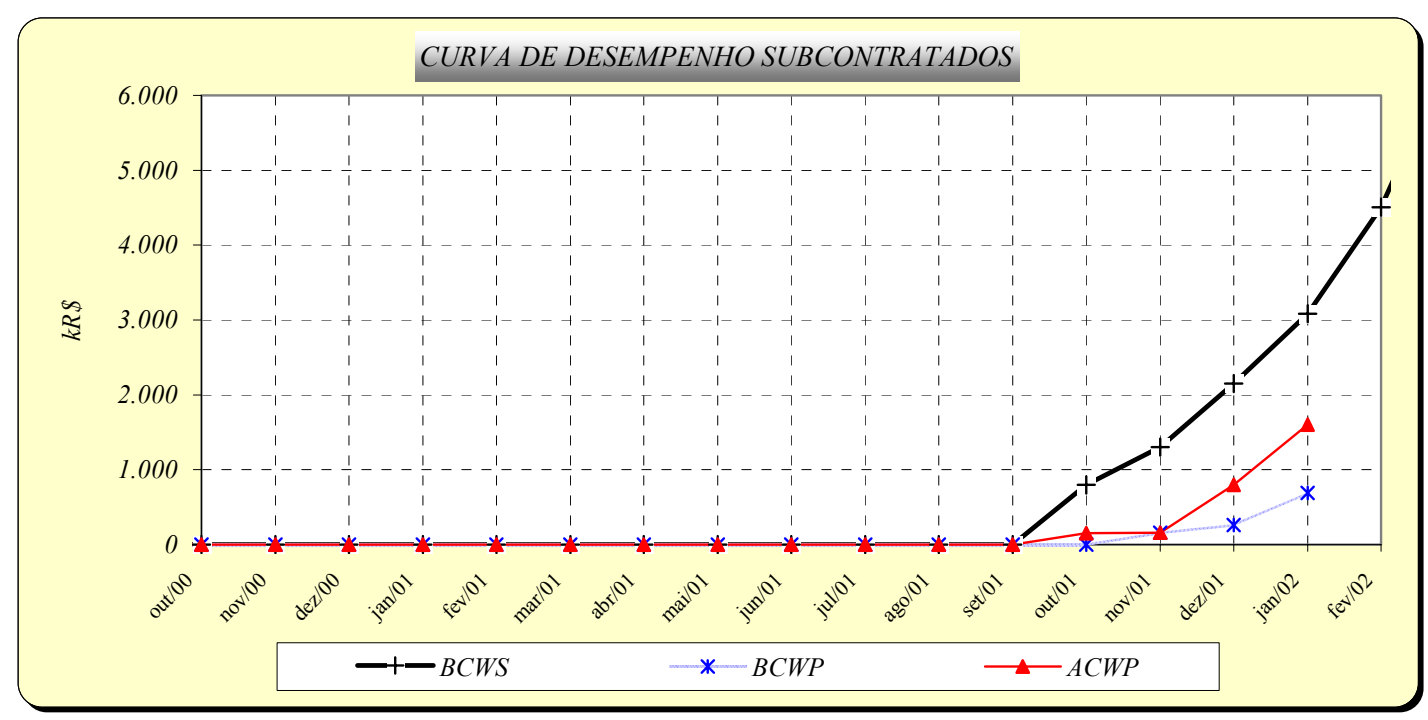

Figura 4.34 Desempenho de Subcontratados - 50\% de execução

\begin{tabular}{|l|l|c|r|r|r|}
\cline { 2 - 6 } \multicolumn{1}{c|}{} & set/01 & out/01 & nov/01 & dez/01 & jan/02 \\
\hline CPIc & - & - & 1,00 & 0,33 & 0,43 \\
\hline SPIc & - & - & 0,12 & 0,12 & 0,22 \\
\hline
\end{tabular}

Figura 4.35 Índices de desempenho de Subcontratados - 50\% de execução

Assim como na Aquisição de Materiais, o mau desempenho em prazos dos Subcontratados deve impactar a fabricação. No entanto, este é um grupo onde existem grandes defasagens no tempo entre os progressos físicos e financeiros. $\mathrm{O}$ gestor deve avaliar se estas defasagens estão sendo devidamente compensadas (vide página 84) e se os índices $\mathrm{CPI}_{\mathrm{c}}$ e $\mathrm{SPI}_{\mathrm{c}}$ aqui calculados (Figura 4.35) realmente têm significado físico. Caso contrário, devem ser ignorados e excluídos da análise geral.

Por último, através da Figura 4.36, será feita a análise dos dados referentes à fabricação dos trens. 


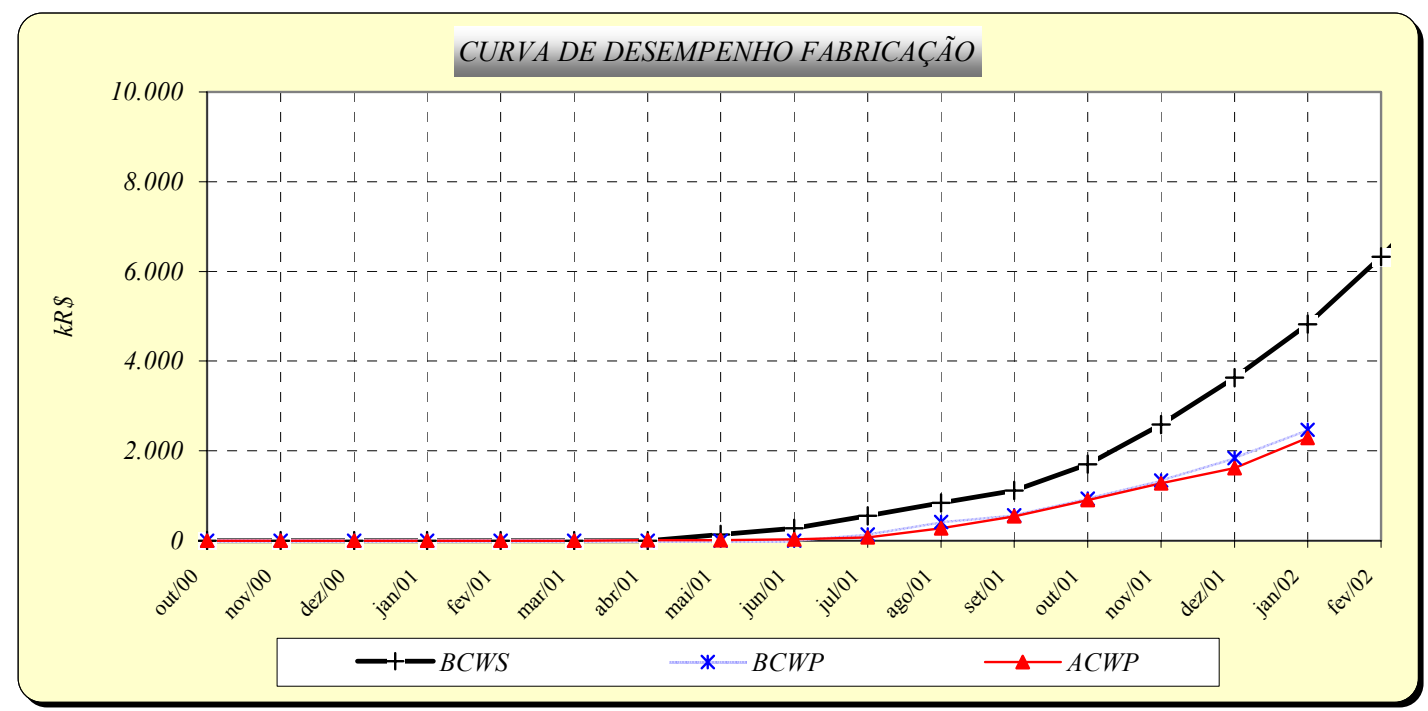

Figura 4.36 Desempenho de Fabricação - 50\% de execução

\begin{tabular}{|r|r|r|r|r|r|}
\cline { 2 - 6 } \multicolumn{1}{c|}{} & set/01 & out/01 & nov/01 & dez/01 & jan/02 \\
\hline CPIc & 1,05 & 1,03 & 1,05 & 1,13 & 1,08 \\
\hline SPIc & 0,50 & 0,55 & 0,52 & 0,51 & 0,51 \\
\hline
\end{tabular}

Figura 4.37 Índices de desempenho de Fabricação - 50\% de execução

A Fabricação apresenta, na Figura 4.37, um bom desempenho em termos de custos, porém permanece bastante prejudicada em termos de prazos. Entretanto, nem toda a culpa por este mau desempenho em relação ao planejamento é da Fabricação. Boa parte dos atrasos se deve também à demora no recebimento de materiais e de serviços subcontratados. Deste modo, para que se tenha uma efetiva análise sobre o real desempenho de prazos da Fabricação, deve-se procurar, se possível, descontar estes atrasos, os quais podem ser estimados, neste caso, em aproximadamente 1 mês.

Para as projeções de custo e prazos finais serão utilizados os índices gerais, pois estes têm apresentado comportamento mais estável. Seguindo o mesmo raciocínio dos cálculos anteriores obtém-se:

- $\mathrm{TAC}=44$ meses

- $\mathrm{EAC}=\$ 64.511$ 
Novamente, a necessidade de ações corretivas para se recuperar os atrasos ainda é grande portanto deve-se: continuar o tratamento especial junto aos fornecedores de Materiais e Subcontratados e, se possível, efetuar nova programação de atividades, antecipando a participação das equipes de montagem final (através de sub-montagens externas e independentes) e comissionamento (efetuando testes e validações parciais nos sistemas). 
Para uma última análise, tomaremos o mês de Julho/02 como referência, pois se encontra próximo da entrega prevista para o $8^{\circ}$ trem (Agosto/02). Seria também o último mês com despesas de Materiais, Subcontratados e Fabricação.

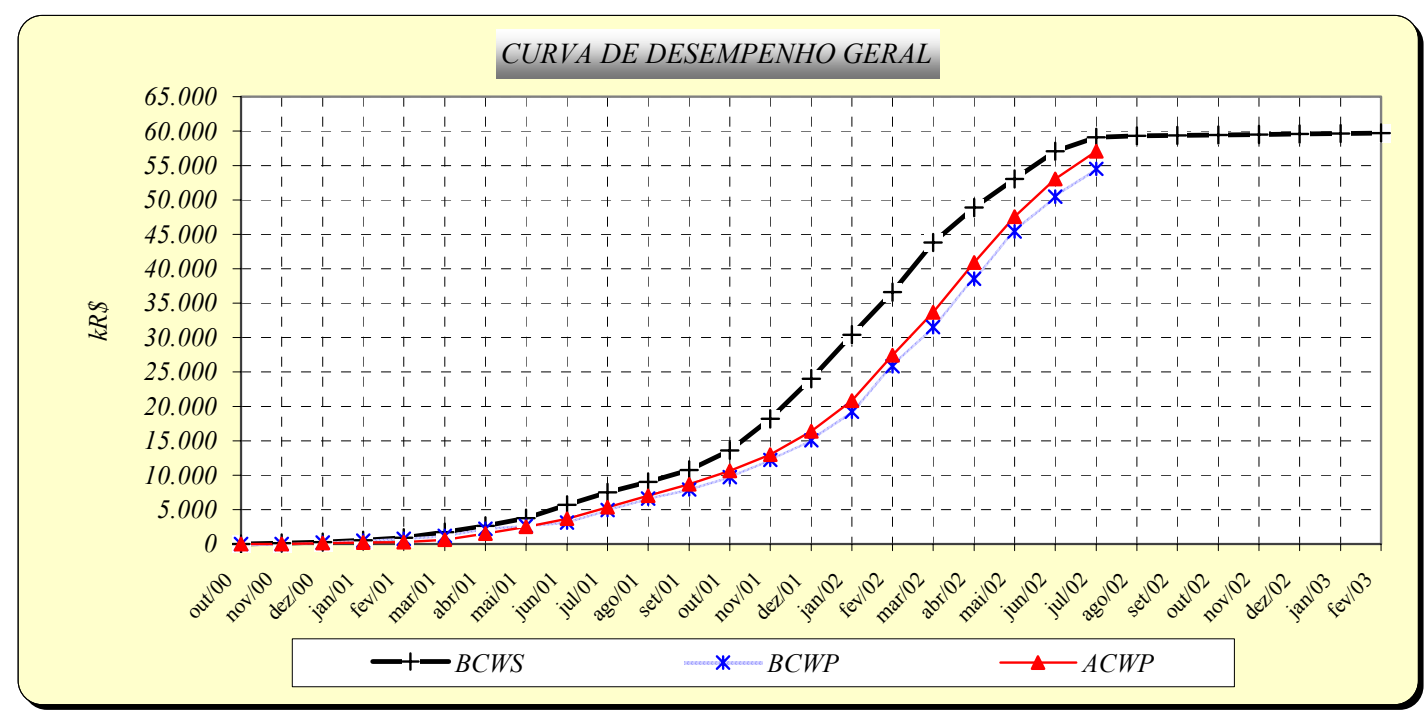

Figura 4.38 Desempenho geral - 70\% de execução

\begin{tabular}{|l|r|r|r|r|r|r|}
\cline { 2 - 7 } \multicolumn{1}{c|}{} & fev/02 & mar/02 & abr/02 & mai/02 & jun/02 & jul/02 \\
\hline CPIc & 0,94 & 0,94 & 0,94 & 0,95 & 0,95 & 0,96 \\
\hline SPIc & 0,71 & 0,72 & 0,79 & 0,86 & 0,88 & 0,92 \\
\hline
\end{tabular}

Figura 4.39 Índices de desempenho geral - 70\% de execução

Percebe-se que houve uma recuperação considerável nos índices $\mathrm{CPI}_{\mathrm{c}}$ e $\mathrm{SPI}_{\mathrm{c}}$. Através dos gráficos individuais, será possível determinar quais foram os responsáveis por esta melhoria. 


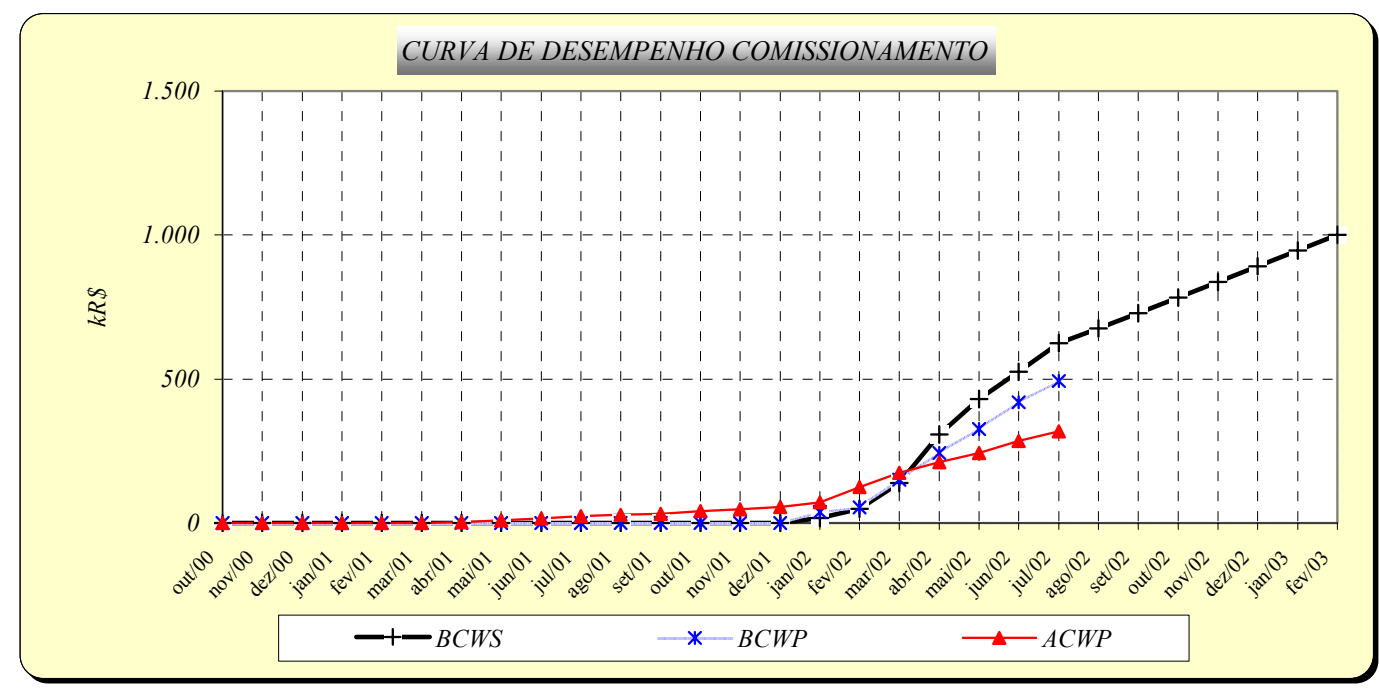

Figura 4.40 Desempenho do Comissionamento - 70\% de execução

\begin{tabular}{|r|r|r|r|r|r|r|}
\cline { 2 - 7 } \multicolumn{1}{c|}{} & fev/02 & mar/02 & abr/02 & mai/02 & jun/02 & jul/02 \\
\hline CPIc & 0,43 & 0,86 & 1,15 & 1,34 & 1,48 & 1,55 \\
\hline SPIc & 1,08 & 1,07 & 0,80 & 0,76 & 0,80 & 0,79 \\
\hline
\end{tabular}

Figura 4.41 Índices de desempenho do Comissionamento - 70\% de execução

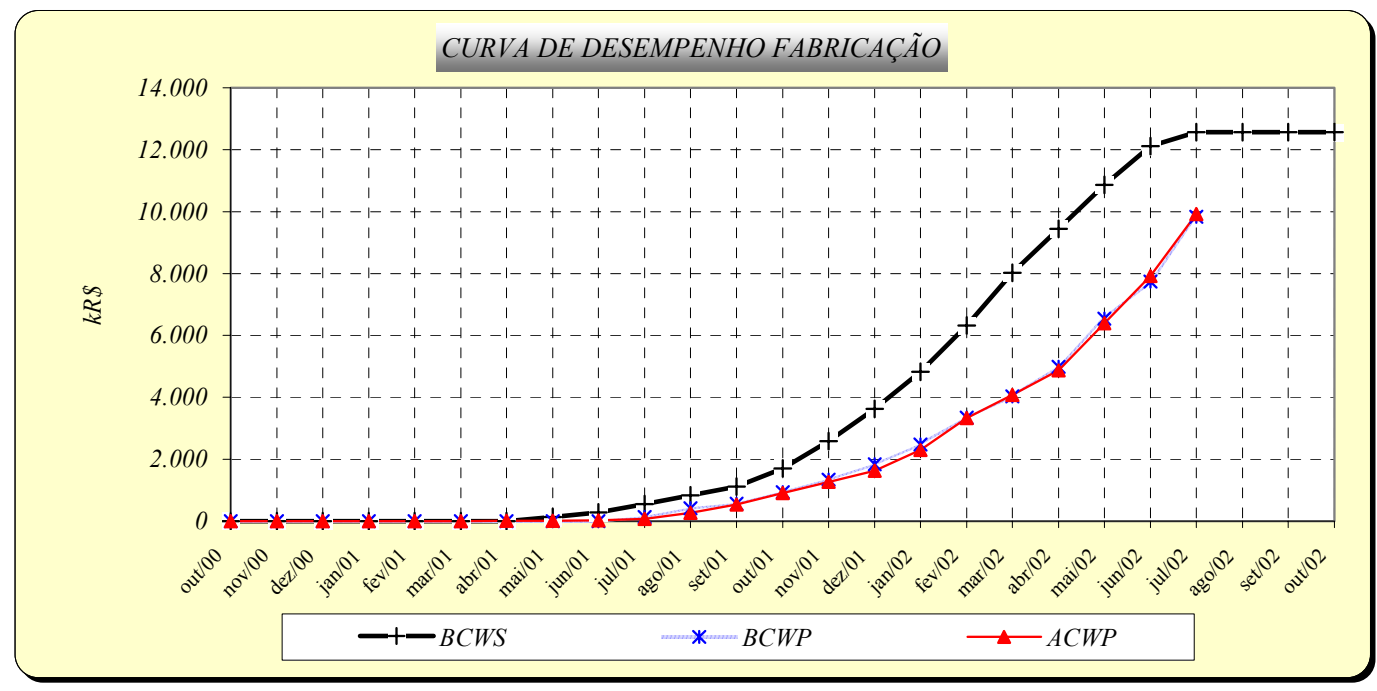

Figura 4.42 Desempenho da Fabricação - 70\% de execução

\begin{tabular}{|l|r|r|r|r|r|r|}
\cline { 2 - 7 } \multicolumn{1}{c|}{} & fev/02 & mar/02 & abr/02 & mai/02 & jun/02 & jul/02 \\
\hline CPIc & 1,01 & 0,99 & 1,02 & 1,02 & 0,98 & 0,99 \\
\hline SPIc & 0,53 & 0,50 & 0,53 & 0,60 & 0,64 & 0,78 \\
\hline
\end{tabular}

Figura 4.43 Índices de desempenho da Fabricação - 70\% de execução 


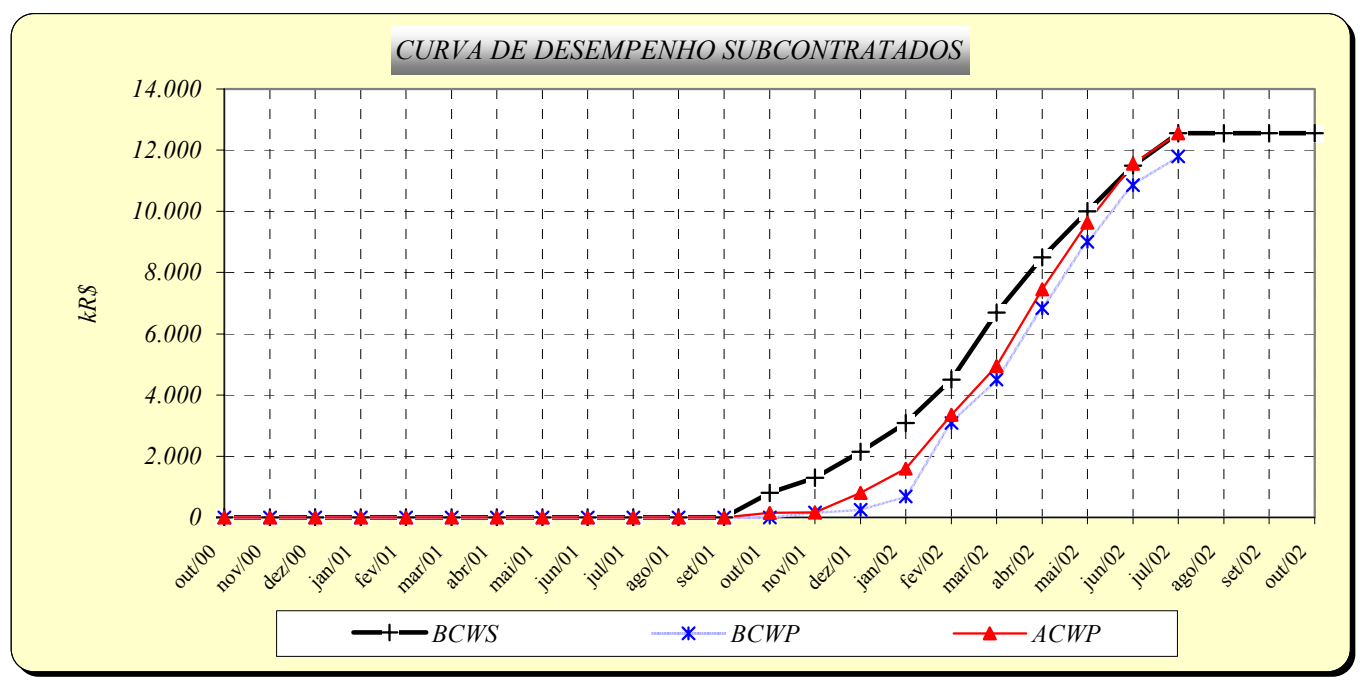

Figura 4.44 Desempenho dos Subcontratados - 70\% de execução

\begin{tabular}{|r|r|r|r|r|r|r|}
\cline { 2 - 7 } \multicolumn{1}{c|}{} & fev/02 & mar/02 & abr/02 & mai/02 & jun/02 & jul/02 \\
\hline CPIc & 0,92 & 0,91 & 0,92 & 0,93 & 0,94 & 0,94 \\
\hline SPIc & 0,69 & 0,67 & 0,81 & 0,90 & 0,94 & 0,94 \\
\hline
\end{tabular}

Figura 4.45 Índices de desempenho dos Subcontratados - 70\% de execução

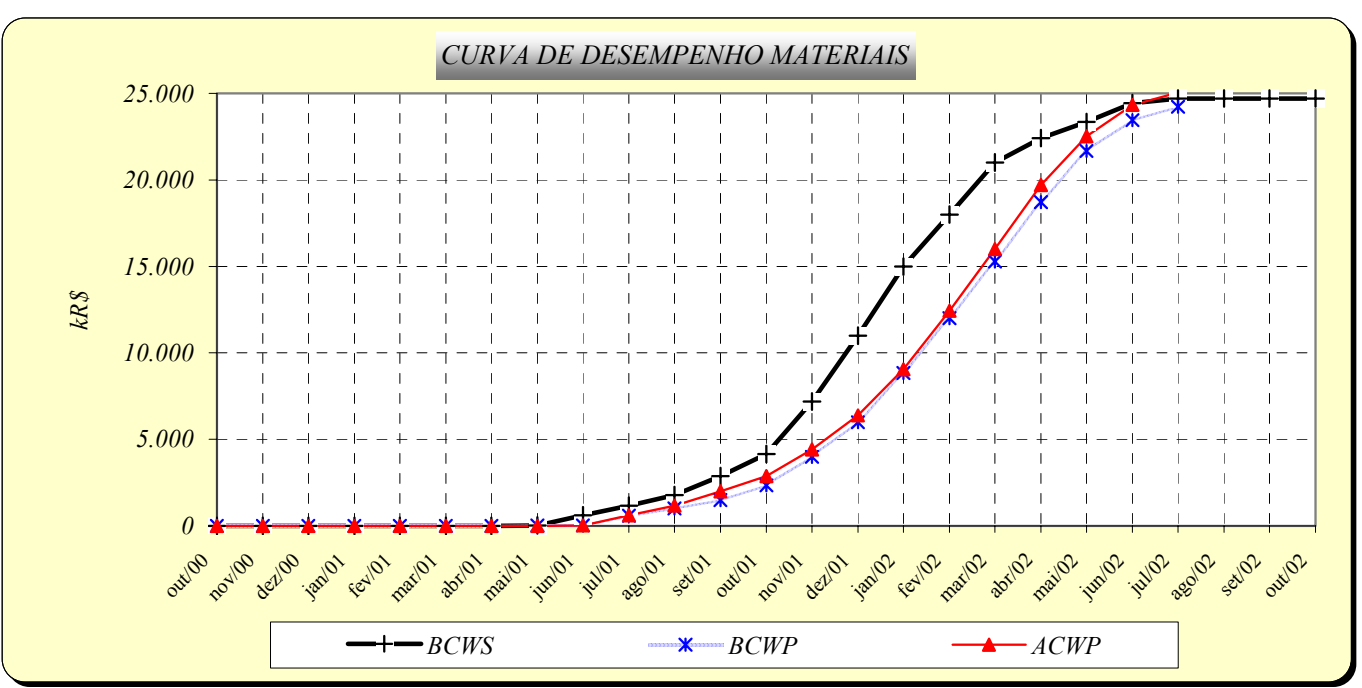

Figura 4.46 Desempenho dos Materiais - 70\% de execução

\begin{tabular}{|r|r|r|r|r|r|r|}
\cline { 2 - 7 } \multicolumn{1}{c|}{} & fev/02 & mar/02 & abr/02 & mai/02 & jun/02 & jul/02 \\
\hline CPIc & 0,97 & 0,96 & 0,95 & 0,96 & 0,96 & 0,97 \\
\hline SPIc & 0,67 & 0,73 & 0,84 & 0,93 & 0,96 & 0,98 \\
\hline
\end{tabular}

Figura 4.47 Índices de desempenho dos Materiais - 70\% de execução 
Através dos índices apresentados conclui-se que a melhora no progresso do projeto se deve aos seguintes fatores:

- Recuperação do atraso dos Materiais e Subcontratados, originada por ações tomadas junto aos fornecedores;

- Melhoria na produtividade da Fabricação devido ao início da produção seriada dos trens;

- Bom desempenho na fase de Comissionamento.

Até a referida data haviam sido entregues 5 trens. Como ainda existem atividades de todas os tipos a serem realizadas, serão adotados os índices gerais para as projeções futuras. Deste modo, tem-se:

$\mathrm{TAC}=31$ meses

$\mathrm{EAC}=\$ 62.480$

Pode-se observar que a projeção de prazos foi reduzida drasticamente desde a última avaliação. A projeção de custos também teve uma redução, porém não tão acentuada. 


\subsubsection{Análise do projeto ao seu término}

Os atrasos acumulados do projeto determinavam que o seu término se daria em Agosto/03, com a finalização da operação assistida do $8^{\circ}$ trem (conforme cláusulas contratuais). Deste modo, seriam totalizados 34 meses para finalização do projeto (6 meses de atraso final). No entanto, através de um acordo de antecipação entre as partes envolvidas, as atividades se encerraram em Maio/03 conforme Figura 4.48.

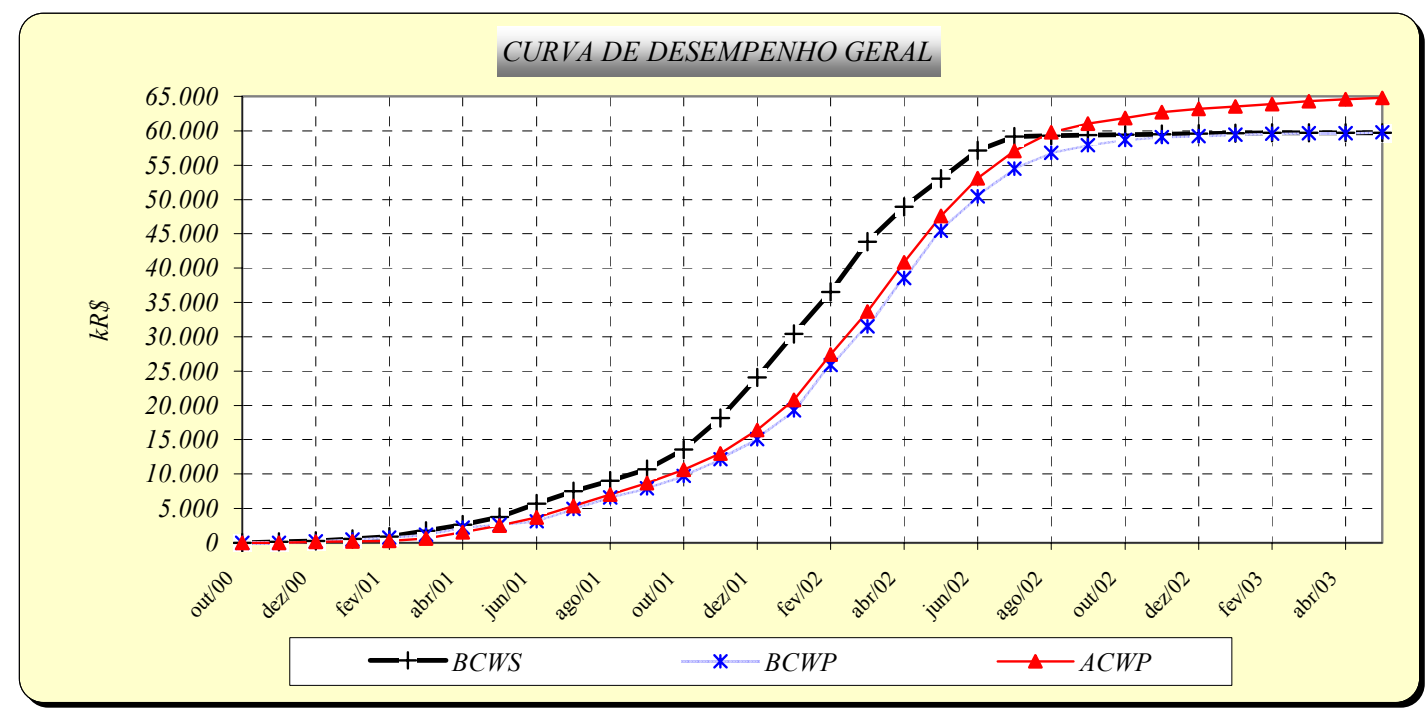

Figura 4.48 Desempenho geral ao término do projeto

Ao término do projeto verificou-se que o $\mathrm{CPI}_{\mathrm{c}}$ teve uma nova queda e terminou em 0,92. Esta queda pode ser justificada pelos retrabalhos não previstos e que foram necessários para o encerramento do projeto. O custo final do projeto foi de aproximadamente $\mathrm{R} \$ 64.719 .000,00$, o que corresponde a um sobre-custo em torno de $\mathrm{R} \$ 5.000 .000,00$, ou 8,4\% em relação ao orçamento de custos original $(\mathrm{BAC}=$ R\$59.711). Segue abaixo a configuração de custos do projeto após o seu término:

\begin{tabular}{|c|c|c|c|c|c|c|c|}
\hline Grupo & $\begin{array}{c}\text { Sub- } \\
\text { Contratados }\end{array}$ & Materiais & Fabricação & Eng $^{\mathbf{a}}$ & $\begin{array}{c}\text { Comissionamento e } \\
\text { Ass. Tec. }\end{array}$ & Outros & $\begin{array}{c}\text { Total } \\
\text { (ACWP) }\end{array}$ \\
\hline Valor (kR\$) & 13.292 & 25.691 & 14.965 & 8.319 & 603 & 1.849 & $\mathbf{6 4 . 7 1 9}$ \\
\hline \% Participação & $20,5 \%$ & $39,7 \%$ & $23,1 \%$ & $12,9 \%$ & $1 \%$ & $2,9 \%$ & $\mathbf{1 0 0 , 0 \%}$ \\
\hline \% Sobre-custo & $5,9 \%$ & $4,0 \%$ & $19,1 \%$ & $19,0 \%$ & $-39,7 \%$ & $-2,7 \%$ & $\mathbf{8 , 4} \%$ \\
\hline
\end{tabular}

Figura 4.49 Caracterização dos custos reais do projeto 
Nota-se que praticamente todas as atividades incorreram em sobre-custos, exceto as de Comissionamento/Assist. Técnica e as classificadas como Outros. Abaixo, na Figura 4.50, podem ser observados as curvas de custos reais (ACWP) de cada grupo de atividade ao longo do projeto.

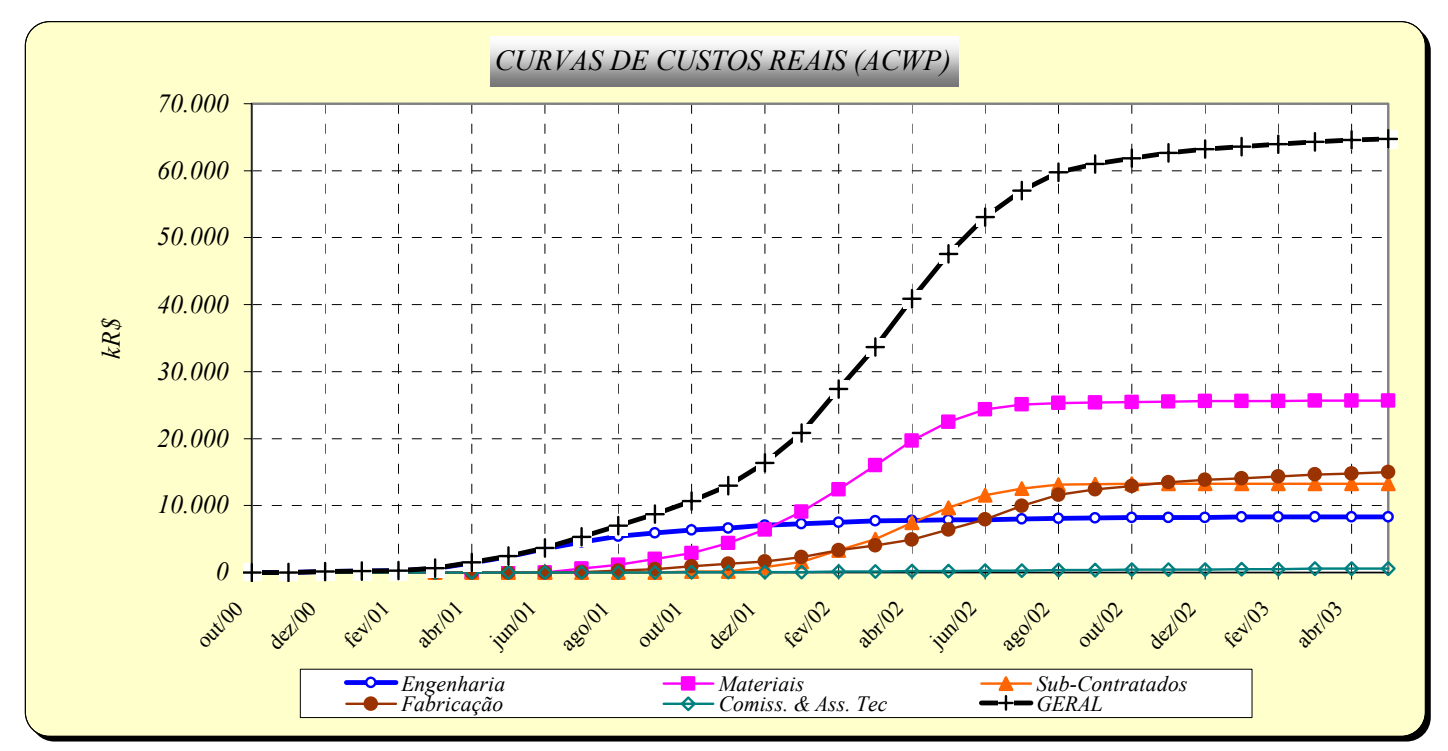

Figura 4.50 Curvas dos custos reais do projeto

Seguem também os índices CPIc e SPIc gerais do projeto obtidos ao longo de sua execução.

\begin{tabular}{|l|r|r|r|r|r|r|r|r|r|r|r|}
\cline { 2 - 11 } \multicolumn{1}{c|}{} & Oct-00 & Nov-00 & Dec-00 & Jan-01 & Feb-01 & Mar-01 & Apr-01 & May-01 & Jun-01 & Jul-01 & Aug-01 \\
\hline CPIc & 1.59 & 1.47 & 1.96 & 2.39 & 2.48 & 1.87 & 1.47 & 1.06 & 0.85 & 0.93 & 0.94 \\
\hline SPIc & 0.28 & 0.09 & 0.77 & 0.90 & 0.85 & 0.68 & 0.83 & 0.70 & 0.55 & 0.66 & 0.73 \\
\hline
\end{tabular}

\begin{tabular}{|r|r|r|r|r|r|r|r|r|r|r|r|}
\cline { 2 - 20 } \multicolumn{1}{c|}{} & Sep-01 & Oct-01 & Nov-01 & Dec-01 & Jan-02 & Feb-02 & Mar-02 & Apr-02 & May-02 & Jun-02 & Jul-02 \\
\hline CPIc & 0.91 & 0.91 & 0.94 & 0.92 & 0.92 & 0.94 & 0.94 & 0.94 & 0.95 & 0.95 & 0.96 \\
\hline SPIc & 0.74 & 0.72 & 0.67 & 0.63 & 0.63 & 0.71 & 0.72 & 0.79 & 0.86 & 0.88 & 0.92 \\
\hline
\end{tabular}

\begin{tabular}{|r|r|r|r|r|r|r|r|r|r|r|}
\cline { 2 - 11 } \multicolumn{1}{c|}{} & Aug-02 & Sep-02 & Oct-02 & Nov-02 & Dec-02 & Jan-03 & Feb-03 & Mar-03 & Apr-03 & May-03 \\
\hline CPIc & 0.95 & 0.95 & 0.95 & 0.94 & 0.94 & 0.93 & 0.93 & 0.93 & 0.92 & 0.92 \\
\hline SPIc & 0.96 & 0.98 & 0.99 & 0.99 & 0.99 & 1.00 & 1.00 & 1.00 & 1.00 & 1.00 \\
\hline
\end{tabular}

\section{Figura 4.51 Índices $\mathrm{CPI}_{\mathrm{c}} \mathrm{e} S \mathrm{SI}_{\mathrm{c}}$ ao longo do projeto}

Pode-se verificar que o índice $\mathrm{CPI}_{\mathrm{c}}$ se estabilizou entre $33 \%$ e $50 \%$ da execução planejada. $\mathrm{O} \mathrm{SPI}_{\mathrm{c}}$, por sua vez só passou a apresentar melhoria acentuada após $50 \%$ de progresso, refletindo as ações corretivas que vinham sendo tomadas. 


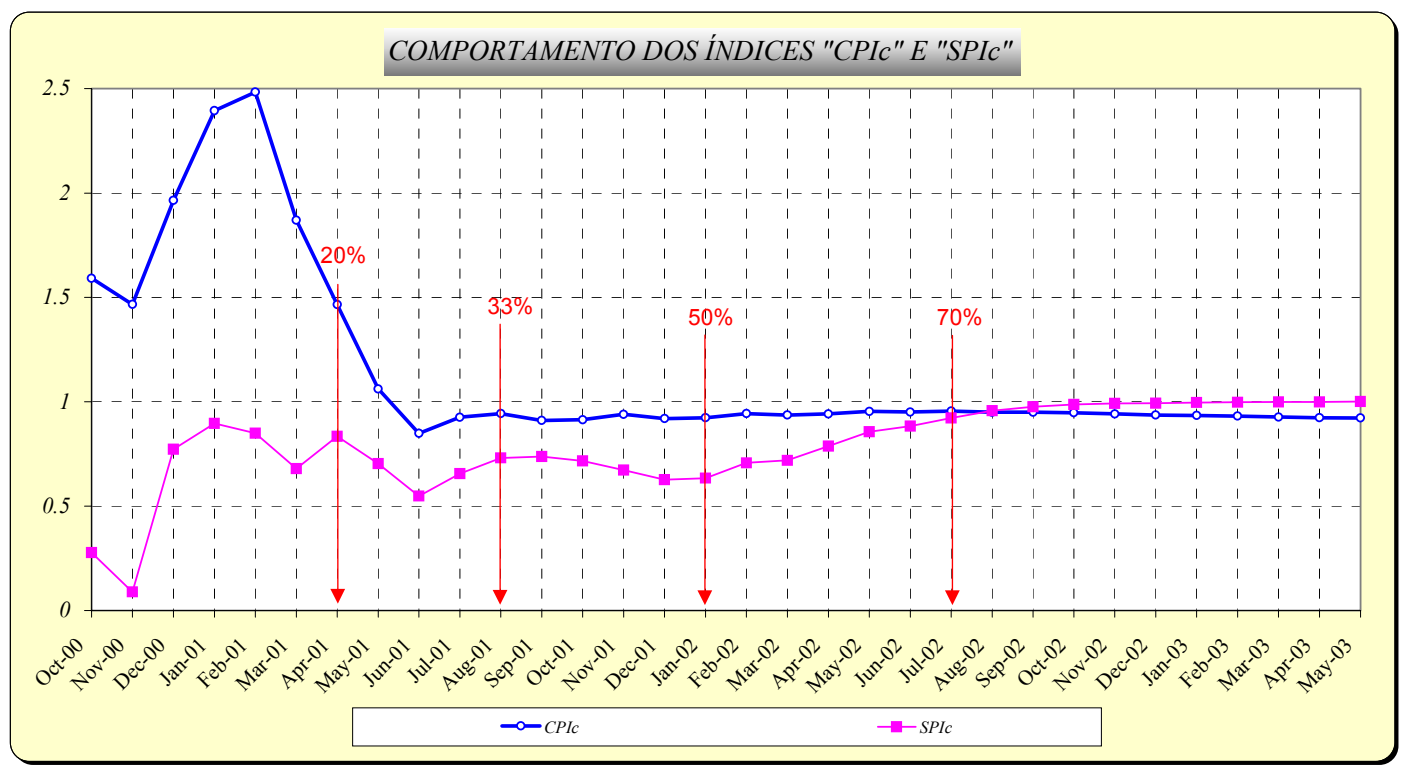

Figura 4.52 Comportamento dos índices $\mathrm{CPI}_{\mathrm{c}} \mathrm{e} \mathrm{SPI}_{\mathrm{c}}$ ao longo do projeto

Vale lembrar, portanto, que o comportamento destes índices foi influenciado por uma série de ações corretivas ao longo de todo o projeto (conforme mencionado em cada uma das análises apresentadas). Sem estas ações, estes índices estariam, muito provavelmente, com um comportamento mais degradado e instável.

Por fim, seguem os índices CPIc e SPIc de cada grupo de atividade (Figura $4.53 \mathrm{e}$ Figura 4.54)

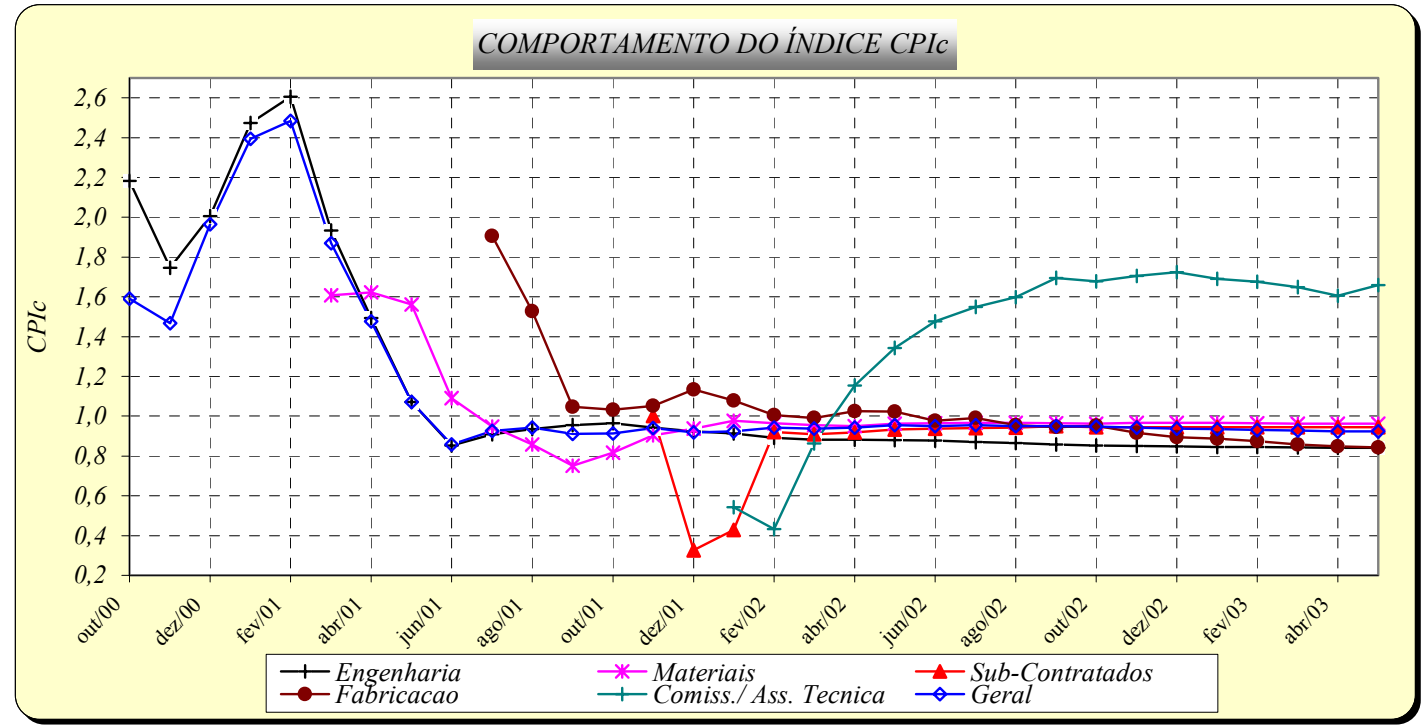

Figura 4.53 Comportamento do índice $\mathrm{CPI}_{\mathrm{c}}$ de cada grupo ao longo do projeto 
Conforme esperado, o índice $\mathrm{CPI}_{\mathrm{c}}$ Geral do Projeto se adere inicialmente ao índice $\mathrm{CPI}_{\mathrm{c}}$ de Engenharia, e mais ao fim passa a assumir valores próximos ao $\mathrm{CPI}_{\mathrm{c}}$ de Fabricação (porém sempre abaixo deste, devido aos demais grupos que também possuíam índices degradados).

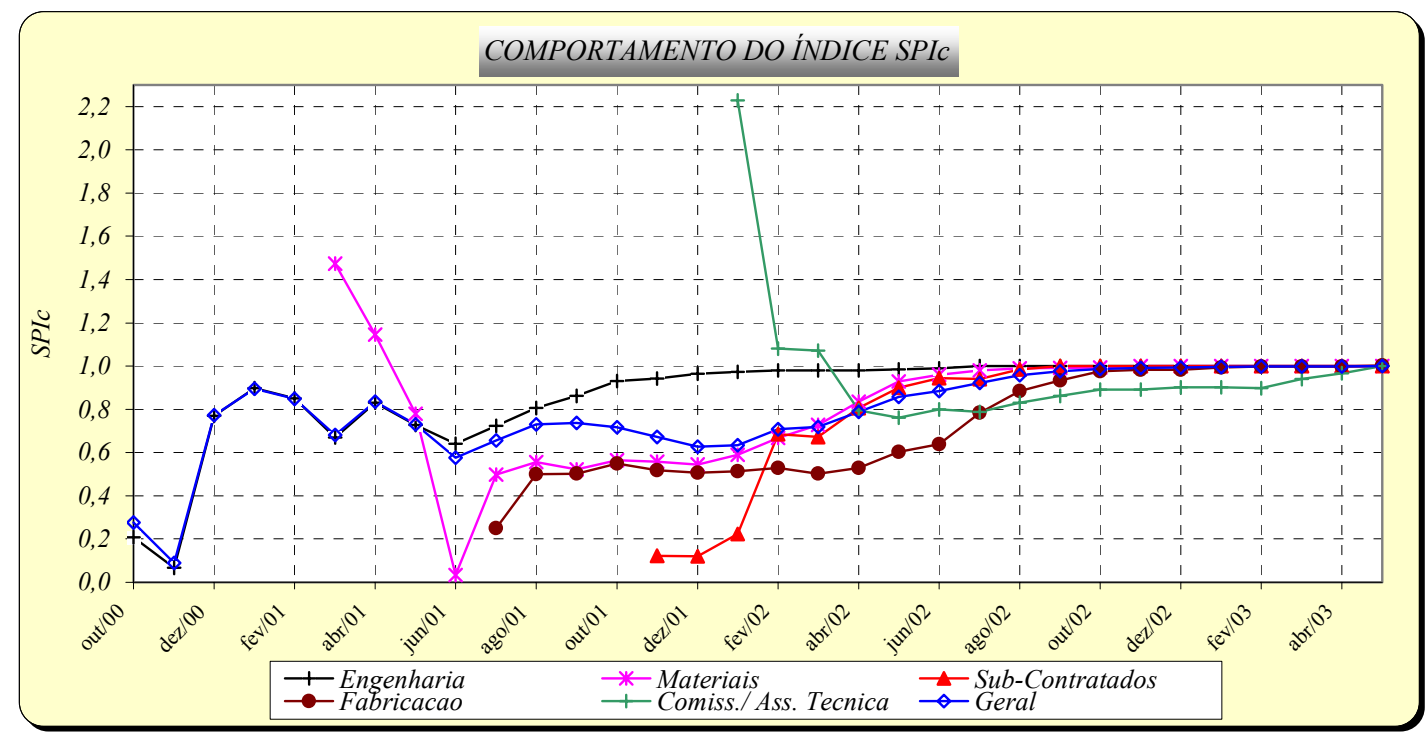

Figura 4.54 Comportamento do índice $S P I_{c}$ de cada grupo ao longo do projeto

Os índices $\mathrm{SPI}_{\mathrm{c}}$ são de análise mais complexa pois, na medida em que o projeto se aproxima de seu término, eles sempre tendem ao valor 1. Deve ser levado em consideração também o fato de que os atrasos em um grupo de atividades (neste caso, Engenharia) pode ter provocado atrasos em outros. Percebe-se, entretanto, que todas as atividades contribuíram para o atraso total do projeto.

De um modo geral, todos os índices $\mathrm{CPI}_{\mathrm{c}}$ e $\mathrm{SPI}_{\mathrm{c}}$ apresentaram valores iniciais (picos e vales) que não se mantiveram ao longo do projeto. $O$ gestor deve ser bastante cauteloso com estes valores, pois podem representar distorções provocadas por erros na "orçamentação" (BCWS) ou na contabilização de progresso (BCWP). 


\subsubsection{Comentários}

A aplicação das medidas 1, 2 e 3 à AVA proporcionou um aumento considerável na quantidade de informações disponíveis e na qualidade das análises realizadas. Ao se analisar individualmente as atividades principais do projeto, o Gerente de Projetos passa a ter um melhor diagnóstico e controle sobre o progresso deste. Por conseguinte, passa a ter também mais segurança para a tomada de decisão, escolha das ações corretivas e projeções futuras. Para que tivesse este mesmo nível de informação quando se utilizam apenas as curvas gerais do projeto, o Gerente de Projetos seria obrigado a recorrer mais freqüentemente a outras ferramentas ou fontes de informação.

A grande vantagem destas medidas é que não há acréscimo de esforço relevante para a obtenção destes benefícios, pois a estrutura de coleta de dados permanece praticamente a mesma.

Ficaram patentes também os problemas causados pela falta de critério na medição do progresso físico, principalmente nas atividades iniciais de Engenharia. É de fundamental importância que se tenha o devido cuidado na determinação dos pacotes de trabalho e de suas métricas. São estes cuidados que determinarão a qualidade das informações coletadas ao longo do projeto.

As projeções de custos a partir de $50 \%$ de execução do projeto se apresentaram confiáveis. Só não foram mais precisas devido aos retrabalhos não previstos no fim do projeto.

As análises apresentadas foram as mínimas necessárias para justificar o melhor nível de controle adquirido com a adoção das medidas 1, 2 e 3. Existe uma infinidade de outras informações e análises que poderiam ser realizadas, e que acrescentariam ainda mais ao bom controle do projeto. A experiência e o conhecimento dos gestores irão determinar quantas e quais análises serão necessárias. 


\section{CONCLUSÕES E RECOMENDAÇÕES}

\subsection{Conclusões}

O presente trabalho buscou identificar as principais características e qualidades do Gerenciamento de Projetos, as quais justificariam o seu crescente papel no cenário mundial. Procurou ainda avaliar as dificuldades encontradas na utilização de uma de suas principais ferramentas de controle, a Análise de Valor Agregado, pois ainda é grande a resistência dos gestores na sua aplicação.

A Gestão de Projetos está em franca ascensão e é apontada como uma prática que ainda tem muito a acrescentar ao mundo dos negócios. Em geral, os autores são unânimes quanto às suas vantagens e não se encontram na literatura pontos negativos quanto ao desempenho e à aplicabilidade da mesma. O que se encontra, por vezes, é a existência de muitos conflitos entre o Gerente de Projetos e os demais Gerentes Funcionais, o que ocorre quando não se tem uma estrutura organizacional totalmente voltada para projetos. É fato também que não se trata apenas de um "modismo", como acontece com inúmeras outras técnicas de gerenciamento. A Gestão de Projetos formal já é divulgada e aplicada há algumas décadas e vem se aperfeiçoando aos poucos, na medida em que as necessidades surgem. A sua crescente procura nos dias de hoje se justifica pelo fato de que a complexidade dos projetos e a competição pelo mercado aumentaram muito, demandando uma maior eficiência e capacidade de integração por parte das empresas, o que as fez buscarem um tipo de gerenciamento adaptado a esta realidade.

Também foram apresentadas características que fazem com que a Gestão de Projetos evolua de uma simples prática operacional de controle de projetos, para se tornar um conceito estratégico dentro das empresas, onde as mudanças e as atividades estratégicas passam a ser encaradas como projetos. A sua aplicação também possibilita um melhor rendimento aos processos, um melhor retorno de experiência e, sobretudo, uma maior flexibilidade à organização. No lado comportamental, a Gestão 
de Projetos faz com que as atividades da empresa sejam conduzidas de uma maneira mais íntima pelos seus envolvidos, prevalecendo os espíritos empreendedores e de equipe. É mais fácil o profissional se identificar com os projetos do que com a empresa em si ou com um trabalho rotineiro, sem personalidade.

Hoje, a Gestão de Projetos e a Análise de Valor Agregado se encontram tão intimamente ligadas, que dificilmente se fala de uma sem falar da outra. O que não poderia ser diferente, pois os principais elementos que surgem à mente, quando se fala em Gestão de Projetos, são os mesmos que balizam a AVA: escopo, custos e prazos!

A Análise de Valor Agregado obteve bastante reconhecimento nos contratos do governo americano e, mais recentemente, nos ramos de TI e Telecomunicações. Os primeiros pela tradição no uso da ferramenta (o uso da AVA em contratos do governo americano é obrigatório há décadas) e os demais talvez pela natureza de seus projetos. No caso das empresas de TI, e de sistemas de informática em geral, os projetos lidam basicamente com um tipo de "matéria prima": dados e informações. Sabe-se também que, nestes projetos, aproximadamente $90 \%$ dos custos são oriundos de mão de obra especializada (Thoren, 2000), em geral engenheiros e analistas. Estas características fazem com que o ambiente de controle dos projetos seja mais homogêneo, regular e mais próximo ao Gerente de Projetos, propiciando uma aplicação direta da AVA.

Em outros tipos de projetos já não se divulga o mesmo nível de sucesso. Na literatura também se encontram pesquisas que indicam limitações e dificuldades genéricas quanto ao seu uso. Foram analisadas estas limitações e concluiu-se que parte das causas não está relacionada com a técnica em si, mas sim com a falta de conhecimento sobre a mesma ou com a falta de uma estrutura adequada para a contabilização de custos e progresso físico. As demais causas remetem ao questionamento dos gestores quanto à sua eficiência como ferramenta para controle de projetos. 
Um projeto para a construção de um navio, por exemplo, possui uma gama de profissionais muito grande (engenheiros de diversas áreas, projetistas, operários, planejadores, analistas, etc.), as fases são muito peculiares (projeto, fabricação, aprovisionamento, etc.) e existem muitas interfaces externas, causando grande susceptibilidade a desvios no progresso. Este é um ambiente em que a AVA se torna de difícil aplicação.

Para que se consiga alcançar maiores níveis de sucesso nestes projetos, foram propostas 6 medidas simples para uma melhor aplicação da AVA em projetos complexos da indústria. Dentre estas, a que mais se sobressai é de que além da visão e análise global do projeto, o Gerente de Projetos precisa dispor de análises individuais de suas principais fases e grupos de atividades.

A Análise de Valor Agregado é uma ferramenta que consegue consolidar muitas informações sobre o projeto utilizando uma única unidade (em geral moeda). Ela é muito eficiente por trazer uma visão macro dos projetos e, por isso, é muito usada nos relatórios para clientes e altas gerências. Porém, esta característica não é suficiente para um Gerente de Projetos que quer utilizá-la como ferramenta de controle, e não como um simples meio de se reportar. Em projetos complexos, se a AVA for utilizada apenas considerando o projeto como um todo (conforme exemplificado na literatura), fica difícil a obtenção de diagnósticos precisos e confiáveis (o bom desempenho de uma das partes do projeto pode mascarar o mau desempenho de outra, não há indicações sobre onde está o problema, etc.).

Deste modo, nota-se que a Análise de Valor Agregado possui um poder de concisão tão grande que, para se ter um controle efetivo em projetos onde não há homogeneidade no progresso e nas variáveis, é necessário que se "quebre" novamente esta análise em partes menores.

Os exemplos de aplicação em um caso real mostram que a AVA, se bem aplicada, pode ser uma boa ferramenta de controle ativo em projetos complexos. Porém deve ficar claro que a AVA não substitui ou impede a utilização de ferramentas como 
PERT/CPM, "Critical Chain" e outras. A AVA apenas consolida uma maior quantidade de informações, facilitando a visualização do progresso, possibilitando projeções futuras e contribuindo para a tomada de decisões. Logo, ela só tem a se fortalecer se conciliada com estas outras ferramentas de controle.

Mas os benefícios da AVA não se restringem aos indicadores de progresso e às projeções futuras para o projeto. Existe um benefício indireto muito importante que advém da interação entre o Gerente de Projetos e os demais envolvidos na construção do WBS e da linha de base do projeto (baseline). Esta interação cria um comprometimento muito grande e benéfico entre os envolvidos, uma vez que todos passam a entender os seus devidos papéis e responsabilidades no projeto. Além disso, permite ao Gerente de Projetos absorver um enorme conhecimento sobre o projeto (seus gargalos, pontos fracos, etc.), proporcionando um senso crítico que é imprescindível para a sua gestão. Um projeto é um organismo vivo e dinâmico, e o seu bom desempenho depende de muitas outras variáveis, além das que são mostradas pelas cifras e índices.

Vale ressaltar também que as pesquisas citadas, e que identificaram resistências à aplicação da AVA, não são claras quanto aos tipos de projetos envolvidos e nem ao nível de maturidade das empresas envolvidas. Estes fatores podem influenciar fortemente a impressão deixada nos usuários (ex.: projetos baseados em trabalho criativo não se beneficiam com a AVA pois são muito susceptíveis a alterações de escopo; ao se aplicar pela primeira vez a AVA certamente ocorrerão inúmeras dificuldades e resistências por parte dos envolvidos, etc.).

Por último, vale enfatizar novamente o que a maioria dos autores diz sobre o Gerenciamento de Projetos e a Análise de Valor Agregado: ambos têm muitas qualidades e vantagens, porém, como a maioria das técnicas e metodologias existentes, devem ser aplicadas com o devido cuidado e racionalização que as empresas e os projetos requerem. A ferramenta sozinha não produz resultados, a sua aplicação e conhecimento é que os produzem. 


\subsection{Recomendações}

Seguem alguns temas que podem trazer contribuições complementares ao que foi apresentado nesta dissertação:

- Realizar uma pesquisa formal entre profissionais ligados à Gestão de Projetos e à Análise de Valor Agregado para identificar como estas são aplicadas no mercado brasileiro. A maioria das pesquisas existentes retrata o comportamento de sociedades com culturas diferentes e com maior tradição na Gestão de Projetos (EUA, Inglaterra, Austrália). As diferenças e similaridades certamente contribuirão para a adaptação da técnica à nossa realidade;

- Muito se fala e estuda sobre a análise e a projeção de custos através da AVA. No entanto, o mesmo não ocorre com relação às projeções de prazos nos projetos. Isto talvez pelo fato de que outras ferramentas tradicionais (CPM, $\mathrm{CCM}, . .$.$) possam se apresentar mais eficientes, ou práticas. Vale, portanto,$ estudar especificamente a precisão das estimativas de prazos através da AVA e, se justificável, a possibilidade de sua integração com outras ferramentas existentes. Peterson; Filiatrault (2000) e Steyn (2002) chegam a sugerir uma interessante integração entre Valor Agregado e os conceitos de "Critical Chain Management" buscando conciliar as vantagens de cada ferramenta;

- Aplicar as medidas aqui sugeridas em uma série de projetos, no intuito de mensurar quantitativamente os seus benefícios;

- Estudar as características de outros tipos de projetos, procurando levantar restrições e problemas específicos quanto à aplicação da AVA;

- Estudar a integração da AVA com o Gerenciamento de Riscos e os processos de tomada de decisão, para que se tenha uma ação conjunta e dinâmica sobre as contingências e reservas dos projetos. 


\section{REFERÊNCIAS BIBLIOGRÁFICAS}

ALSTOM TRANSPORT S.A. Project management manual. [s.1.] : [s.n.] , 2000.

ATKINSON, R. Project management: cost, time and quality, two best guesses and a phenomenon, it's time to accept other success criteria. International Journal of Project Management, v. 17, n. 6, p.337-342, 1999.

BACHMAN, D. Single point adjustments: a new definition with examples. Acquisition Review Quarterly. p. 177-195, 2001.

BADIRU, A. B. Project management in manufacturing and high technology operations. 2.ed. New York : John Wiley, 1996.

BAGULEY, P. Project management. Londres: Hodder \& Stoughton, 1999.

BUARQUE C. Avaliação econômica de projetos: uma apresentação didática. Rio de Janeiro : Editora Campus, 1984.

CHRISTENSEN, D. S. Determining an accurate estimate at completion. National Contract Management Journal, n.25. p. 17-25, 1993.

CHRISTENSEN, D. S.; ANTOLINI, R. C.; MCKINNEY, J. C. A review of estimate at completion research. Journal of Cost Analysis and Management, p. 41-62, 1995.

CHRISTENSEN, D. S. Project advocacy and the estimate at completion problem. Journal of Cost Analysis, p. 35-60, 1996.

CHRISTENSEN, D. S. The costs and benefits of earned value management process. Acquisition Review Quarterly. 1998. 
CHRISTENSEN, D. S.; TEMPLIN, C. EAC evaluation methods: do they still work? Acquisition Review Quarterly, n.9. p. 105-116, 2002.

CLELAND, D. I; IRELAND, L. R. Gerência de projetos. Rio de Janeiro: Reichmann \& Affonso, 2002.

COHEN, D. J.; GRAHAM, R. J. The project manager's MBA: how to translate project decisions into business success. [s.1.] : Jossey-Bass, 2000.

CONTADOR, J. C. et al. Gestão de operações. 2.ed. São Paulo: Edgard Blucher, 1998.

DINSMORE, P. C., The AMA handbook of project management. New York: American Management Association, 1993.

DRUCKER, P. F. The coming of the new organization. Harvard Business Review, jul-ago. 1987.

DUNCAN, W. R. A Guide to the project management body of knowledge (PMBOK guide). Philadelphia: Project Management Institute, 1996.

FERREIRA, A. B. H. Novo aurélio século XXI : dicionário da língua portuguesa. 4.ed. Rio de Janeiro : Nova Fronteira, 2000.

FLEMING, Q. W.; KOPPELMAN, J. M. The Earned value body of knowledge. PM Network, maio, 1996.

FLEMING, Q. W.; KOPPELMAN, J. M. The Earned value body of knowledge. In: Annual Project Management Institute / Seminar Symposium, 30, Philadelphia, 1999. Proceedings. Philadelphia: Project Management Institute, 1999. 
FLEMING, Q. W.; KOPPELMAN, J. M. Earned value project management. 2.ed. Newton Square, Philadelphia: Project Management Institute, 2000.

GADDIS, P. O. The Project Manager. Harvard Business Review. p.29-37, 1995.

HOU, W. C.; SHEANG, L. K.; HIDAJAT, B. W. Sun Tzu: a arte da guerra e do gerenciamento. Rio de Janeiro : Objetiva, 2003.

HOUAISS, A. ; VILLAR, M. S. Dicionário Houaiss da língua portuguesa. Rio de Janeiro : Objetiva, 2003.

HUMPHREYS, G.; TROOP, G. Industry ownership of earned value management systems (EVMS). In: Annual Project Management Institute / Seminar Symposium, Houston, 2000. Proceedings. [s.1.] : Project Management Institute, 2000.

KEELING, R. Gestão de Projetos: uma abordagem global. São Paulo: Saraiva, 2002.

KERZNER, H. Project Management: a system approach to planning, scheduling, and controlling. [s.1.], John Wiley, 1998.

KERZNER, H. Gestão de projetos: as melhores práticas. Porto Alegre: Bookman, 2002 .

KLEIM, R. L.; LUDIN, I. S. Project management practitioner's handbook. New York : Amacom Books, 1998.

KNUDSON, J.; BITZ, I. Project management. New York: Amacom Books, 1991.

LEWIS, J. P. Fundamentals of project management. New York: Amacom Books, 1995. 
MAXIMINIANO, A. C. A. Administração de projetos. São Paulo: Atlas, 1997.

MENEZES, L. C. M. Administração de projetos: apostila do curso de extensão em administração industrial. São Paulo: Fundação Vanzolini, s.d.

MICROSOFT User's guide for Microsoft Project 98: complete project communication and control. [s.1.] Microsoft Corporation, 1997.

PAHL, G.; BEITZ W. Engineering design: a systematic approach. 2.ed. London: Springer-Verlag, 1999.

PETERSON, C. D.; FILIATRAULT, C. L. Earned value vs. critical chain project management. In: Annual Project Management Institute / Seminar Symposium, Houston, 2000. Proceedings. [s.1.] : [s.n.], 2000.

PROJECT MANAGEMENT INSTITUTE. Practice standard for work breakdown structures, [ s.1.] : PMI, 2001.

RANDOLPH, W. A.; POSNER, B. Z. Getting the job done! Managing project teams and task forces for success. Englewood Cliffs : Prentice Hall, 1992.

RAZ, T.; GLOBERSON, S. Effective sizing and content definition of work packages. Project Management Journal, v. 29, n. 4, p.17-23, 1998.

STEYN, H. Project management applications of the theory of constraints beyond critical chain scheduling. International Journal of Project Management. v. 20, n.1. p.75-80, 2002.

TAYLOR, F. W. The principles of scientific management. New York: Harper \& Row, 1916. 
THE NATIONAL SHIPBUILDING RESEARCH PROGRAM. Quality function deployment: user's manual, [s.n.t.]

THOMSETT, M. C. The Little black book of project management. New York: Amacom Books, 1990.

THOREN, J. A. Application of earned value concepts to non-government contracts. In: Annual Project Management Institute / Seminar Symposium, Houston, 2000. Proceedings. [s.n.t.]

TURNER, J. R. Projects for shareholder value: the influence of project performance parameters at different financial ratios. Project Management, v. 4, n. 1, p. 70-73, 1988.

VÄLIMÄKI, J. True Project management is earned value based cost management. Project Management, v 3, p. 8-9, 1995.

VARGAS, R. V. Gerenciamento de projetos. 2. ed. Rio de Janeiro: Editora Brasport, 2000.

VARGAS, R. V. Análise de valor agregado em projetos. Rio de Janeiro: Editora Brasport, 2002.

VUOLO, J. H. Fundamentos da teoria de erros. 2.ed. São Paulo: Edgard Blucher, 1996.

WHITE, D.; FORTUNE, J. Current practice in project management: an empirical study. International Journal of Project Management. , v..20, n.1, p.1-11, 2002. 